\title{
Kinetic model framework for aerosol and cloud surface chemistry and gas-particle interactions - Part 1: General equations, parameters, and terminology
}

\author{
U. Pöschl ${ }^{1, *}$, Y. Rudich ${ }^{2}$, and M. Ammann ${ }^{3}$ \\ ${ }^{1}$ Technical University of Munich, Institute of Hydrochemistry, 81377 Munich, Germany \\ ${ }^{2}$ Department of Environmental Sciences, Weizmann Institute of Science, Rehovot 76100, Israel \\ ${ }^{3}$ Paul Scherrer Institute, 5232 Villigen PSI, Switzerland \\ *now at: Max Planck Institute for Chemistry, Biogeochemistry Department, 55128 Mainz, Germany
}

Received: 20 January 2005 - Published in Atmos. Chem. Phys. Discuss.: 11 April 2005

Revised: 4 October 2007 - Accepted: 11 November 2007 - Published: 10 December 2007

\begin{abstract}
Aerosols and clouds play central roles in atmospheric chemistry and physics, climate, air pollution, and public health. The mechanistic understanding and predictability of aerosol and cloud properties, interactions, transformations, and effects are, however, still very limited. This is due not only to the limited availability of measurement data, but also to the limited applicability and compatibility of model formalisms used for the analysis, interpretation, and description of heterogeneous and multiphase processes. To support the investigation and elucidation of atmospheric aerosol and cloud surface chemistry and gasparticle interactions, we present a comprehensive kinetic model framework with consistent and unambiguous terminology and universally applicable rate equations and parameters. It enables a detailed description of mass transport and chemical reactions at the gas-particle interface, and it allows linking aerosol and cloud surface processes with gas phase and particle bulk processes in systems with multiple chemical components and competing physicochemical processes.

The key elements and essential aspects of the presented framework are: a simple and descriptive double-layer surface model (sorption layer and quasi-static layer); straightforward flux-based mass balance and rate equations; clear separation of mass transport and chemical reactions; well-defined and consistent rate parameters (uptake and accommodation coefficients, reaction and transport rate coefficients); clear distinction between gas phase, gas-surface, and surfacebulk transport (gas phase diffusion, surface and bulk accommodation); clear distinction between gas-surface, surface layer, and surface-bulk reactions (Langmuir-Hinshelwood and Eley-Rideal mechanisms); mechanistic description of
\end{abstract}

Correspondence to: U. Pöschl

(poeschl@mpch-mainz.mpg.de) concentration and time dependences (transient and steadystate conditions); flexible addition of unlimited numbers of chemical species and physicochemical processes; optional aggregation or resolution of intermediate species, sequential processes, and surface layers; and full compatibility with traditional resistor model formulations.

The outlined double-layer surface concept and formalisms represent a minimum of model complexity required for a consistent description of the non-linear concentration and time dependences observed in experimental studies of atmospheric multiphase processes (competitive co-adsorption and surface saturation effects, etc.). Exemplary practical applications and model calculations illustrating the relevance of the above aspects are presented in a companion paper (Ammann and Pöschl, 2007).

We expect that the presented model framework will serve as a useful tool and basis for experimental and theoretical studies investigating and describing atmospheric aerosol and cloud surface chemistry and gas-particle interactions. It shall help to end the "Babylonian confusion" that seems to inhibit scientific progress in the understanding of heterogeneous chemical reactions and other multiphase processes in aerosols and clouds. In particular, it shall support the planning and design of laboratory experiments for the elucidation and determination of fundamental kinetic parameters; the establishment, evaluation, and quality assurance of comprehensive and self-consistent collections of rate parameters; and the development of detailed master mechanisms for process models and derivation of simplified but yet realistic parameterizations for atmospheric and climate models. 


\section{Introduction}

Aerosols and clouds play central roles in atmospheric chemistry and physics, climate, air pollution, and public health. They influence the Earth's energy budget by scattering and absorption of radiation, they regulate the hydrological cycle, and they affect the abundance of trace gases via heterogeneous chemical reactions and other multiphase processes (Andreae and Crutzen, 1997; Ravishankara, 1997; Seinfeld and Pandis, 1998; Waibel et al., 1999; Finlayson-Pitts and Pitts, 2000; Ramanathan et al., 2001; Ramaswamy et al., 2001; Rudich, 2003; Mikhailov et al., 2004; Kulmala et al., 2004; Kanakidou et al., 2005; Lohmann and Feichter, 2005; Pöschl, 2005; Fuzzi et al., 2006; Rudich et al., 2007; and references therein).

Moreover, aerosols can cause respiratory, cardiovascular, and allergic diseases when inhaled and deposited in the human respiratory tract (Finlayson-Pitts and Pitts, 1997; Finlayson-Pitts and Pitts, 2000; Katsouyanni et al., 2001; Pope et al., 2002; Pöschl, 2002a; Bömmel et al., 2003; Gauderman et al., 2004; Franze et al., 2005; Pöschl, 2005; Gruijthuijsen et al., 2006; and references therein).

The quantification of aerosol and cloud effects and the assessment of natural and anthropogenic influencing factors are among the key topics of current research on the environment and public health. The mechanistic understanding and predictability of aerosol and cloud properties, interactions, and transformation (chemical and physical aging) are, however, still very limited.

Atmospheric aerosols and clouds are complex multiphase systems consisting of a wide variety of organic and inorganic chemical compounds - multiple main components and hundreds of trace substances - in gaseous, liquid, and solid form (Seinfeld and Pandis, 1998; Finlayson-Pitts and Pitts, 2000; McMurry, 2000; Raes et al., 2000; Matta et al., 2003; Maßling et al., 2003; Pöschl, 2003; Sciare et al., 2003; Smolik et al., 2003; Schauer et al., 2003, 2004; Schneider et al., 2004; Putaud et al., 2004a, b; Pöschl, 2005; Fuzzi et al., 2006; Elbert et al., 2007; Rudich et al., 2007; and references therein).

Chemical reactions proceed both at the surface as well as in the bulk of solid and liquid particles, influencing atmospheric gas phase chemistry as well as the physicochemical properties and effects of the particles (Ravishankara, 1997; Atkinson et al., 1997; Seinfeld and Pandis, 1998; FinlaysonPitts and Pitts, 2000; Moise et al., 2000, 2001, 2002a, b, 2005; Pöschl et al., 2001; Sander et al., 2002; Ammann et al., 2003; Reid and Sayer, 2003; Rudich, 2003; Katrib et al., 2005; Laskin et al., 2005; Pöschl, 2005; Fuzzi et al., 2006; George et al., 2007; and references therein).

For example, they lead to the formation of reactive halogen species and depletion of ozone in the stratosphere and marine boundary layer (Austin et al., 2003; Sander et al., 2003; Pszenny et al., 2004; Coe et al., 2006; von Glasow, 2006; Pechtl et al., 2007), to the decomposition of $\mathrm{N}_{2} \mathrm{O}_{5}$ (Meilinger et al., 2002; Stewart et al., 2004; Seisel et al., 2005; Karagulian et al., 2006; McNeill et al., 2006), and have been extensively discussed as a source for HONO (Broske et al., 2004; Stemmler et al., 2007; and references therein).

On the other hand, chemical aging of aerosol particles generally decreases their reactivity, increases their hygroscopicity and cloud condensation activity (Pöschl et al., 2001; Kumar et al., 2003; Rudich, 2003; Asad et al., 2004; Broekhuizen et al., 2004; McFiggans et al., 2006; Dinar et al., 2006a, b, 2007; Rudich et al., 2007; and references therein), and can change their optical properties (Gelencser et al., 2003; Abo Riziq et al., 2007; Dinar et al., 2008; and references therein).

Heterogeneous oxidation and nitration reactions lead to the formation or degradation of hazardous aerosol components (Finlayson-Pitts and Pitts, 1997; Letzel et al., 2001; Pöschl, 2002a; Schauer et al., 2004; Franze et al., 2005; Pöschl, 2005; Gruijthuijsen et al., 2006; and references therein), they cause artifacts upon sampling and analysis of air particulate matter (Finlayson-Pitts and Pitts, 2000; Schauer et al., 2003; Pöschl, 2005; and references therein), and they play a major role in technical processes and devices for the control of combustion aerosol emissions ( $\mathrm{Su}$ et al., 2004; Messerer et al., 2004, 2006; Ivleva et al., 2007; and refernces therein).

Efficient investigation and description of these multiphase and multicomponent processes in laboratory, field, and model studies require consistent terminologies and universally applicable mathematical formalisms. Such formalisms have been presented and are widely applied for reactions occurring in the bulk of liquid atmospheric particles (Schwartz and Freiberg, 1981; Schwartz, 1986; Hanson et al., 1994; Kolb et al., 1995; Sander, 1999; Finlayson-Pitts and Pitts, 2000; Ervens et al., 2003; Sander et al., 2005; Sandu and Sander, 2006; Tost et al., 2007; and references therein).

The formalisms presented and applied for the description of particle surface reactions, however, generally have been limited to specific reaction systems and conditions: liquid water, water ice, acid hydrates, soot, or mineral dust; fresh or aged surfaces; low or high reactant concentrations; transient or (quasi-)steady-state conditions; limited numbers of chemical species and reactions; etc. (e.g. Jayne et al., 1990; Davidovits et al., 1991; Mozurkewich, 1993; Tabazadeh and Turco, 1993; Tabor et al., 1994; Davidovits et al., 1995; Kolb et al., 1995; Nathanson et al., 1996; Atkinson et al., 1997; Carslaw and Peter, 1997; Hanson, 1997; Jayne et al., 1997; Pöschl et al., 1998; Bertram et al., 2001; Clegg and Abbatt, 2001; Grassian, 2001; Katrib et al., 2001; Pöschl et al., 2001; Vesala et al., 2001; Adams et al., 2002; Hynes et al., 2002; Remorov et al., 2002; Sander et al., 2002; Smith et al., 2002; Worsnop et al., 2002; Ammann et al., 2003; da Rosa et al., 2003; Djikaev and Tabazadeh, 2003; Folkers et al., 2003; Reid and Sayer, 2003; Rudich, 2003; Strekowski et al., 2003; Frinak et al., 2004; Kwamena et al., 2004, 2006, 2007; Thornberry and Abbatt, 2004; Adams et al., 2005; Al- 
Hosney and Grassian, 2005; Gustafsson et al., 2005; Kleffmann and Wiesen, 2005; Pöschl, 2005; Remorov and Bardwell, 2005; Seisel et al., 2005; Garrett et al., 2006; Kahan et al., 2006; Li et al., 2006; Remorov and George, 2006; Vlasenko et al., 2006; Chan et al., 2007; Hatch et al., 2007; Rudich et al., 2007; Zahardis and Petrucci, 2007; and references therein).

The different and sometimes inconsistent rate equations, parameters, and terminologies make it hard to compare and to extrapolate the results of different studies over the wide range of reaction conditions relevant for the atmosphere on the one hand, and for laboratory experiments and technical processes on the other. Indeed, scientific progress in the understanding of heterogeneous chemical reactions and other multiphase processes in aerosols and clouds appears to be inhibited by a "Babylonian confusion" of terms and parameters (Pöschl, 2005; Pöschl et al., 2005a, b, c; Fuzzi et al., 2006; Garrett et al., 2006; Rudich et al., 2007).

To provide a basis for consistent description of chemical reactions and mass transport at the surface and in the bulk of liquid and solid atmospheric particles, we have developed a comprehensive model framework for aerosol and cloud surface chemistry and gas-particle interactions. In analogy to well-established formalisms of gas phase chemistry, it shall support the establishment and evaluation of comprehensive and self-consistent collections of rate parameters (Atkinson et al., 1997; Sander et al., 2002; Atkinson et al., 2004, 2006, 2007), the development of detailed master mechanisms and process models (Saunders et al., 2003; Jenkin et al., 2003; Bloss et al., 2005a, b; Aumont et al., 2005; Johnson et al., 2006), and the derivation of simplified but realistic mechanisms and parameterisations for large scale atmospheric and climate models (Pöschl et al., 2000; von Kuhlmann et al., 2004; Jöckel et al., 2005; Spracklen et al., 2005; Croft et al., 2005; Textor et al., 2006; Tost et al., 2007).

The presented model framework builds on the basic kinetic theories of gases, condensed phases, and interfaces, and it combines concepts, rate equations, and rate parameters developed and applied in physical chemistry, surface science and aerosol research (Masel, 1996; Seinfeld and Pandis, 1998; Berry et al., 2000; Finlayson-Pitts and Pitts, 2000). It is meant to be sufficiently general and flexible to allow efficient description of both simple and complex systems, to enable the inclusion of more elaborate concepts and formalisms of current and future atmospheric research and surface science, and to bridge the gaps between atmospheric and technical processes as well as between modeling and experimental studies. Most likely not all of the rate parameters introduced below will be available for all species and systems of atmospheric relevance, but in analogy to the development of detailed master mechanisms of atmospheric gas phase chemistry they can be determined for certain model species and systems and extrapolated for others. The presented terminology and formalisms shall help to develop a clear picture of the measurements, calculations, and assumptions which are required for a mechanistic description and prediction of aerosol surface chemistry and gas-particle interactions.

The general concept, terminology, and rate equations are outlined in the following sections of this manuscript: Sect. 2 deals with the basic concepts of gas kinetics and uptake coefficients and with the influence of gas phase diffusion. Section 3 introduces a double-layer surface model and the quasielementary steps of mass transport and chemical reaction at the surface, which represent a minimum of model complexity that is needed for mechanistic description of the concentration and time-dependent surface reaction kinetics observed in experimental studies of atmospheric multiphase chemistry. Section 4 addresses general aspects of model application such as the change of gas uptake coefficients and other rate parameters with composition, temperature, and time. Moreover, Sect. 4 shows how the general rate equations introduced in Sects. 2 and 3 are related to standard surface reaction mechanisms (Langmuir-Hinshelwood, Eley-Rideal) and how they can be simplified and applied under (quasi-)steadystate conditions (adsorption equilibrium, adsorption-reaction steady-state, equivalent resistor model formulations).

Exemplary practical applications including analytical and numerical solutions for different systems under transient and (quasi-)steady-state conditions are presented in a companion paper (Ammann and Pöschl, 2007).

\section{Gas phase composition and processes}

\subsection{Gas kinetic fluxes and uptake coefficients}

In atmospheric chemistry the net uptake of gases by aerosol and cloud particles is usually described by an uptake coefficient, which is defined as the number of gas molecules taken up by the particle divided by the number of gas molecules impinging onto the particle surface (here and below the term "molecule" includes atomic, ionic, and radical species). In terms of molecular fluxes, the uptake coefficient for a gas species $\mathrm{X}_{i}, \gamma_{\mathrm{X} i}$, can be expressed as the ratio between the net flux of $\mathrm{X}_{i}$ from the gas phase to the condensed phase, $J_{\text {net, }} \mathrm{X}_{i}$, and the gas kinetic flux of $\mathrm{X}_{i}$ colliding with the surface, $J_{\text {coll, } \mathrm{X} i}$ (number of molecules per unit area and unit time):

$\gamma_{\mathrm{X} i}=\frac{J_{\mathrm{net}, \mathrm{X} i}}{J_{\mathrm{coll}, \mathrm{X} i}}$

Equation (1) is fully compatible with traditional verbal definitions of the uptake coefficient, but $J_{\mathrm{net}, \mathrm{X} i}$ and $\gamma_{\mathrm{X} i}$ can assume negative values if the particle acts as a net source of $\mathrm{X}_{i}$, which will be discussed below. For a list of symbols and SI units see Appendix A.

Based on gas kinetic theory, the flux of collisions of gas species $X_{i}$ with a surface can be expressed as

$J_{\mathrm{coll}, \mathrm{X} i}=\left[\mathrm{X}_{i}\right]_{\mathrm{gs}} \frac{\omega_{\mathrm{X} i}}{4}$ 
$\left[\mathrm{X}_{i}\right]_{\mathrm{gs}}$ is the gas phase concentration of $\mathrm{X}_{i}$ close the surface, i.e. about one mean free path off the surface (see Sect. 2.2), and $\omega_{\mathrm{X} i}$ is its mean thermal velocity given by $\omega_{\mathrm{X} i}=\left(8 R T /\left(\pi M_{\mathrm{X} i}\right)\right)^{1 / 2}$, where $M_{\mathrm{X} i}$ is the molar mass of $\mathrm{X}_{i}, R$ is the gas constant, and $T$ is the absolute temperature.

Assuming that the gas phase concentration of $\mathrm{X}_{i}$ is homogeneous throughout the investigated system, the flux of surface collisions can be described by the average gas kinetic flux, $J_{\text {coll, avg, } \mathrm{X} i}=\left[\mathrm{X}_{i}\right]_{\mathrm{g}} \omega_{\mathrm{X} i} / 4$, where $\left[\mathrm{X}_{i}\right]_{\mathrm{g}}$ is the average gas phase concentration of $\mathrm{X}_{i}$, i.e. the concentration far from the particle. Under these conditions the net flux of $\mathrm{X}_{i}$ into the condensed phase can be described by $J_{\text {net, } \mathrm{X} i}=\gamma_{\mathrm{X} i}\left[\mathrm{X}_{i}\right]_{\mathrm{g}} \omega_{\mathrm{X} i} / 4$. Significant net uptake, however, will lead to local depletion of $\mathrm{X}_{i}$ close to the particle surface $\left(\left[\mathrm{X}_{i}\right]_{\mathrm{gs}}<\left[\mathrm{X}_{i}\right]_{\mathrm{g}}\right)$, and gas phase diffusion will influence further uptake $\left(J_{\text {coll, }, \mathrm{X} i}<J_{\text {coll, avg, } \mathrm{X} i}\right)$. Therefore it is useful to define an effective uptake coefficient $\gamma_{\mathrm{eff}, \mathrm{X} i}$ and a gas phase diffusion correction factor $C_{\mathrm{g}, \mathrm{X} i}$ :

$$
\begin{aligned}
J_{\mathrm{net}, \mathrm{X} i} & =\gamma_{\mathrm{eff}, \mathrm{X} i} J_{\mathrm{coll}, \mathrm{avg}, \mathrm{X} i}=\gamma_{\mathrm{eff}, \mathrm{X} i}\left[\mathrm{X}_{i}\right]_{\mathrm{g}} \frac{\omega_{\mathrm{X} i}}{4} \\
& =\gamma_{\mathrm{X} i}\left[\mathrm{X}_{i}\right]_{\mathrm{gg}} \frac{\omega_{\mathrm{X} i}}{4} \\
C_{\mathrm{g}, \mathrm{X} i} & =\frac{\gamma_{\mathrm{eff}, \mathrm{X} i}}{\gamma_{\mathrm{X} i}}=\frac{J_{\mathrm{coll}, \mathrm{X} i}}{J_{\mathrm{coll}, \mathrm{avg}, \mathrm{X} i}}=\frac{\left[\mathrm{X}_{i}\right]_{\mathrm{gs}}}{\left[\mathrm{X}_{i}\right]_{\mathrm{g}}}
\end{aligned}
$$

$\gamma_{\mathrm{eff}, \mathrm{X} i}$ relates the net uptake of species $\mathrm{X}_{i}$ directly to its average gas phase concentration, which is usually the major observable in laboratory studies and the most relevant variable in atmospheric models. It is sometimes also referred to as the "apparent", "measurable", or "net" uptake coefficient. Note, however, that the term "net uptake coefficient" is not well suited to distinguish $\gamma_{\mathrm{eff}, \mathrm{X} i}$ from $\gamma_{\mathrm{X} i}$, because both quantities describe the same net flux of species $\mathrm{X}_{i}$ from the gas phase to the condensed phase and are just normalized by different gas kinetic reference fluxes (average gas kinetic flux or actual surface collision flux). $C_{\mathrm{g}, \mathrm{X} i}$ describes the ratio between these fluxes, which is determined by the rates of uptake and gas phase diffusion and will be described in detail below (Sect. 2.2).

The net gas phase loss of $\mathrm{X}_{i}$ due to gas-particle interactions, $L_{\mathrm{g}, \mathrm{p}, \mathrm{X} i}-P_{\mathrm{g}, \mathrm{p}, \mathrm{X} i}$ (i.e. gross loss minus production; molecules per unit volume and unit time), can be conveniently calculated, when the particle surface concentration, $[\mathrm{PS}]_{\mathrm{g}}$ (area per unit volume), and the effective uptake coefficient are known:

$$
\begin{aligned}
& L_{\mathrm{g}, \mathrm{p}, \mathrm{X} i}-P_{\mathrm{g}, \mathrm{p}, \mathrm{X} i}=J_{\mathrm{net}, \mathrm{X} i}[\mathrm{PS}]_{\mathrm{g}}=\gamma_{\mathrm{eff}, \mathrm{X} i}[P S]_{\mathrm{g}}\left[\mathrm{X}_{i}\right]_{\mathrm{g}} \frac{\omega_{\mathrm{X} i}}{4} \\
& \quad=k_{\mathrm{g}, \mathrm{p}, \mathrm{X} i}\left[\mathrm{X}_{i}\right]_{\mathrm{g}}
\end{aligned}
$$

Equation (5) allows to use an apparent first-order rate coefficient, $k_{\mathrm{g}, \mathrm{p}, \mathrm{X} i}=\gamma_{\mathrm{eff}, \mathrm{X} i}[\mathrm{PS}]_{\mathrm{g}} \omega_{\mathrm{X} i} / 4$, to calculate the net gas phase loss as a (pseudo-)first-order process with respect to average gas phase composition, which is usually the preferred way to handle heterogeneous reactions in atmospheric models.
Uptake coefficients for different types of gases and aerosol particles are usually determined in laboratory studies covering a limited range of experimental conditions. For a reliable extrapolation and application of the experimentally determined uptake coefficients to atmospheric conditions and in numerical models of the atmosphere, the uptake coefficients have to be deconvoluted into basic physicochemical parameters, which describe the multiple steps (elementary processes) that are usually involved in aerosol surface reactions and gas-particle interactions and will be outlined in the following sections (transport and chemical reactions in and between gas phase, surface, and particle bulk).

For gas uptake by liquid droplets a widely used resistor model has been developed to deconvolute $\gamma_{\text {eff, } \mathrm{X} i}$ under (quasi-)steady-state conditions. In this model, gas phase diffusion to the particle surface, mass transfer from the gas phase into the liquid phase, and subsequent chemical reaction in the liquid are regarded as decoupled processes. These processes are described by individual resistance terms which can be added up to obtain $1 / \gamma_{\text {eff, }} \mathrm{X}$ as the overall resistance in analogy to an electrical circuit consisting of serial resistors (Schwartz and Freiberg, 1981; Schwartz, 1986; Hanson et al., 1994; Kolb et al., 1995; Finlayson-Pitts and Pitts, 2000; and references therein):

$$
\begin{aligned}
& \frac{1}{\gamma_{\mathrm{eff}, \mathrm{X} i}}=\frac{1}{\Gamma_{\mathrm{g}, \mathrm{X} i}}+\frac{1}{\gamma_{\mathrm{X} i}} \\
& \frac{1}{\gamma_{\mathrm{X} i}}=\frac{1}{\alpha_{\mathrm{X} i}}+\frac{1}{\Gamma_{\mathrm{b}, \mathrm{X} i}}
\end{aligned}
$$

$\alpha_{\mathrm{X} i}$ represents the probability or normalized rate of transfer of gas molecules across the surface (or gas-liquid interface) into the liquid and has usually been referred to as the "mass accommodation coefficient". The "conductances" (inverse resistances) $\Gamma_{\mathrm{g}, \mathrm{X} i}$ and $\Gamma_{\mathrm{b}, \mathrm{X} i}$ represent normalized rates of gas phase diffusion and bulk diffusion and reaction, respectively. The most common formulae used to calculate these conductances are $\Gamma_{\mathrm{g}, \mathrm{X} i} \approx 8 D_{\mathrm{g}, \mathrm{X} i} \omega_{\mathrm{X} i}^{-1} d_{p}^{-1}$ and $\Gamma_{\mathrm{b}, \mathrm{X} i} \approx 4 H_{\mathrm{cp}, \mathrm{X} i} R T \omega_{\mathrm{X} i}^{-1}\left(D_{\mathrm{b}, \mathrm{X} i} k_{\mathrm{b}, \mathrm{X} i}\right)^{\frac{1}{2}}$, where $D_{\mathrm{g}, \mathrm{X} i}$ is the gas phase diffusion coefficient of $\mathrm{X}_{i}, d_{p}$ is the particle diameter, $H_{\mathrm{cp}, \mathrm{X} i}$ is the solubility or Henry's law coefficient of $\mathrm{X}_{i}, D_{\mathrm{b}, \mathrm{X} i}$ is the diffusion coefficient of $\mathrm{X}_{i}$ in the liquid, and $k_{\mathrm{b}, \mathrm{X} i}$ is the first-order chemical loss rate coefficient of $\mathrm{X}_{i}$ in the liquid. The derivation and applicability of the resistor model equations and parameters will be addressed below (Sects. 2.2 and 4.3.2). Several studies have already set out to include surface reaction terms in the resistor model for gas uptake by liquid atmospheric particles and to extend it to solid particles. So far, however, the applicability of the published formalisms and terminologies was generally limited to specific types of aerosols and reaction conditions (e.g. Hanson, 1997; Smith et al., 2002; Worsnop et al., 2002; Ammann et al., 2003; Reid and Sayer, 2003; and references therein). 


\subsection{Gas phase diffusion}

Mass transport from the gas phase to the surface of an aerosol or cloud particle and the influence of molecular diffusion in the gas phase depend on the flow regime, which is characterized by the Knudsen number, $K n_{\mathrm{X} i}$, and determined by the mean free path of the investigated species $\mathrm{X}_{i}$ in the gas phase, $\lambda_{\mathrm{X} i}$, and by the particle radius, $r_{p}$, or diameter, $d_{p}$ : $K n_{\mathrm{X} i}=\lambda_{\mathrm{X} i} / r_{p}=2 \lambda_{\mathrm{X} i} / d_{p}$.

Based on simple gas kinetic theory and on earlier studies of gas-particle interaction, $\lambda_{\mathrm{X} i}$ and $K n_{\mathrm{X} i}$ can be approximated by (Fuchs, 1964; Fuchs and Sutugin, 1971; Seinfeld and Pandis, 1998; and references therein):

$\lambda_{\mathrm{X} i}=\frac{3 D_{\mathrm{g}, \mathrm{X} i}}{\omega_{\mathrm{X} i}}$

$K n_{\mathrm{X} i}=\frac{6 D_{\mathrm{g}, \mathrm{X} i}}{\omega_{\mathrm{X} i} d_{\mathrm{p}}}$

For air and most atmospheric gases the mean free path at standard temperature and pressure (STP, $0^{\circ} \mathrm{C}, 1 \mathrm{~atm}$ ) is on the order of $\sim 60 \mathrm{~nm}$, and the particle size dependence of the Knudsen number can be approximated by $K n_{\mathrm{X} i} \approx\left(10^{2} \mathrm{~nm}\right) / d_{p}$ with $d_{p}$ in nm or by $K n_{\mathrm{X} i} \approx(0.1 \mu \mathrm{m}) / d_{p}$ with $d_{p}$ in $\mu \mathrm{m}$, respectively.

In the gas kinetic or free-molecule regime $\left(d_{p} \ll \lambda_{\mathrm{X} i}\right.$, $\left.K n_{\mathrm{X} i} \gg 1\right)$ and whenever $K n_{\mathrm{X} i} / \gamma_{\mathrm{X} i} \gg 1$, the flow of $\mathrm{X}_{i}$ from the gas phase to the condensed phase is limited only by surface kinetics and independent of the gas phase diffusion coefficient. Under these conditions the gas phase concentration of $\mathrm{X}_{i}$ is homogeneous $\left(\left[\mathrm{X}_{i}\right]_{\mathrm{gs}} \approx\left[\mathrm{X}_{i}\right]_{\mathrm{g}}\right)$, and the net flow, $F_{\text {net,Xi }}$ (molecules per unit time), is simply given by multiplication of $J_{\text {net,Xi }}$ as defined in Eq. (3) with the particle surface area $\left(d_{\mathrm{p}}^{2} \pi\right.$ for spherical geometry): $F_{\text {net,Xi }}=d_{\mathrm{p}}^{2} \pi \gamma_{\mathrm{X} i}\left[\mathrm{X}_{i}\right]_{\mathrm{g}}$ $\omega_{\mathrm{X} i} / 4$.

In the continuum regime $\left(d_{p} \gg \lambda_{\mathrm{X} i}, K n_{\mathrm{X} i} \ll 1\right)$, the flow of $\mathrm{X}_{i}$ is limited only by gas phase diffusion when $K n_{\mathrm{X} i} / \gamma_{\mathrm{X} i} \ll 1$. Under these conditions, the flow is directly proportional to the gas phase diffusion coefficient and particle diameter, and it is independent of the uptake coefficient (Seinfeld and Pandis, 1998; and references therein).

In the transition regime $\left(d_{p} \approx \lambda_{\mathrm{X} i}, K n_{\mathrm{X} i} \approx 1\right)$ when $\gamma_{\mathrm{X} i} \approx 1$ and also in the continuum regime when $K n_{\mathrm{X} i} / \gamma_{\mathrm{X} i} \approx 1$, the flow of $\mathrm{X}_{i}$ is influenced by both gas phase diffusion and surface kinetics, which can be described by correction terms in the continuum and gas kinetic flow equations as detailed below.

Whenever $K n_{\mathrm{X} i} / \gamma_{\mathrm{X} i}<\approx 1$ (continuum or transition regime), the gas concentration of $X_{i}$ far from the surface $\left(\left[\mathrm{X}_{i}\right]_{\mathrm{g}}\right)$, which drives gas phase diffusion, is different from the near-surface concentration $\left(\left[\mathrm{X}_{i}\right]_{\mathrm{gs}}\right)$, which drives surface uptake kinetics. A relation between $\left[\mathrm{X}_{i}\right]_{\mathrm{g}}$ and $\left[\mathrm{X}_{i}\right]_{\mathrm{gs}}$ can be obtained by matching the flow of gas phase diffusion to the surface with the flow of uptake at the surface.
For the uptake of $\mathrm{X}_{i}$ by a "perfectly absorbing sphere" $\left(\gamma_{\mathrm{X} i}=1\right)$ under steady-state conditions in the continuum regime $\left(K n_{\mathrm{X} i} \ll 1\right)$, the net flow from the gas phase into the particle (number of molecules per unit time) can be described by the following continuum and gas kinetic expressions (Fuchs, 1964; Fuchs and Sutugin, 1971; Seinfeld and Pandis, 1998):

$F_{\text {net }, \mathrm{X} i}=2 \pi d_{\mathrm{p}} D_{\mathrm{g}, \mathrm{X} i}\left[\mathrm{X}_{i}\right]_{\mathrm{g}}=d_{\mathrm{p}}^{2} \pi \frac{\omega_{\mathrm{X} i}}{4}\left[\mathrm{X}_{i}\right]_{\mathrm{gs}}$

In this case, the relation between the near-surface and average (distant) gas phase concentrations of $\mathrm{X}_{i}$ is given by: $\left[\mathrm{X}_{i}\right]_{\mathrm{gs}} /\left[\mathrm{X}_{i}\right]_{\mathrm{g}}=8 \mathrm{D}_{\mathrm{g}, \mathrm{X} i} /\left(\omega_{\mathrm{X} i} d_{\mathrm{p}}\right)=4 / 3 K n_{\mathrm{X} i}$.

For lower values of $\gamma_{\mathrm{X} i}$ and for the transition regime, the flow matching approach of Fuchs (1964) can be applied to obtain a relation between $\left[\mathrm{X}_{i}\right]_{\mathrm{gs}}$ and $\left[\mathrm{X}_{i}\right]_{\mathrm{g}}$. It had been developed for the coagulation of aerosol particles and is adopted here for the special case where one particle (molecule) is very small and moving much faster than the other one (quasi-static aerosol particle). Under these conditions, the average distance from which the molecule has a straight trajectory to the particle surface, $\Delta_{\mathrm{X} i}$, can be approximated by $\lambda_{\mathrm{X} i}$ for $K n_{\mathrm{X} i} \gg 1, \lambda_{\mathrm{X} i} / 2$ for $K n_{\mathrm{X} i} \ll 1$, and values in between for $K n_{\mathrm{X} i} \approx 1$ :

$\Delta_{\mathrm{X} i}=\frac{2}{3 d_{\mathrm{p}} \lambda_{\mathrm{X} i}}\left\{\left(\frac{d_{\mathrm{p}}}{2}+\lambda_{\mathrm{X} i}\right)^{3}-\left(\left(\frac{d_{\mathrm{p}}}{2}\right)^{2}+\lambda_{\mathrm{X} i}^{2}\right)^{\frac{3}{2}}\right\}-\frac{d_{\mathrm{p}}}{2}$

By defining the gas phase concentration of $\mathrm{X}_{i}$ at the distance $\Delta_{\mathrm{X} i}$ from the surface as $\left[\mathrm{X}_{i}\right]_{\mathrm{gs}}$, the net flow of gas phase diffusion through a virtual particle envelope with the diameter $\left(d_{\mathrm{p}}+2 \Delta_{\mathrm{X} i}\right)$ can be expressed as

$F_{\text {net }, \mathrm{X} i}=2 \pi\left(d_{\mathrm{p}}+2 \Delta_{\mathrm{X} i}\right) D_{\mathrm{g}, \mathrm{X} i}\left(\left[\mathrm{X}_{i}\right]_{\mathrm{g}}-\left[\mathrm{X}_{i}\right]_{\mathrm{gs}}\right)$

For mass conservation, the above continuum expression for the flow of gas phase diffusion to the surface has to equal the gas kinetic expression for the flow of uptake at the surface $\left(F_{\text {net }, \mathrm{X} i}=d_{\mathrm{p}}^{2} \pi J_{\text {net }, \mathrm{X} i}\right)$ :

$$
\begin{gathered}
2 \pi\left(d_{\mathrm{p}}+2 \Delta_{\mathrm{X} i}\right) D_{\mathrm{g}, \mathrm{X} i}\left(\left[\mathrm{X}_{i}\right]_{\mathrm{g}}-\left[\mathrm{X}_{i}\right]_{\mathrm{gs}}\right) \\
=d_{\mathrm{p}}^{2} \pi \gamma_{\mathrm{X} i} \frac{\omega_{\mathrm{X} i}}{4}\left[\mathrm{X}_{i}\right]_{\mathrm{gs}}
\end{gathered}
$$

Rearrangement using the above definitions of $C_{\mathrm{g}, \mathrm{X} i}, \lambda_{\mathrm{X} i}$, $K n_{\mathrm{X} i}$, and $\Delta_{\mathrm{X} i}$ leads to

$$
\begin{aligned}
C_{\mathrm{g}, \mathrm{X} i} & =\frac{\left[\mathrm{X}_{i}\right]_{\mathrm{gs}}}{\left[\mathrm{X}_{i}\right]_{\mathrm{g}}}=\frac{d_{\mathrm{p}}+2 \Delta_{\mathrm{X} i}}{\frac{3 \gamma_{\mathrm{X} i} d_{\mathrm{p}}^{2}}{8 \lambda_{\mathrm{X} i}}+d_{\mathrm{p}}+2 \Delta_{\mathrm{X} i}} \\
= & \frac{1}{1+\gamma_{\mathrm{X} i} \frac{0.75}{K n_{\mathrm{X} i}\left(1+K n_{\mathrm{X} i} \frac{\Delta_{\mathrm{X} i}}{{ }_{\mathrm{X} i}}\right)}}
\end{aligned}
$$

Equation (14) can be further simplified by neglecting the size dependence of $\Delta_{\mathrm{X} i}$ and assuming $\Delta_{\mathrm{X} i}=\lambda_{\mathrm{X} i}$ as will be discussed and illustrated below (Fig. 1). 


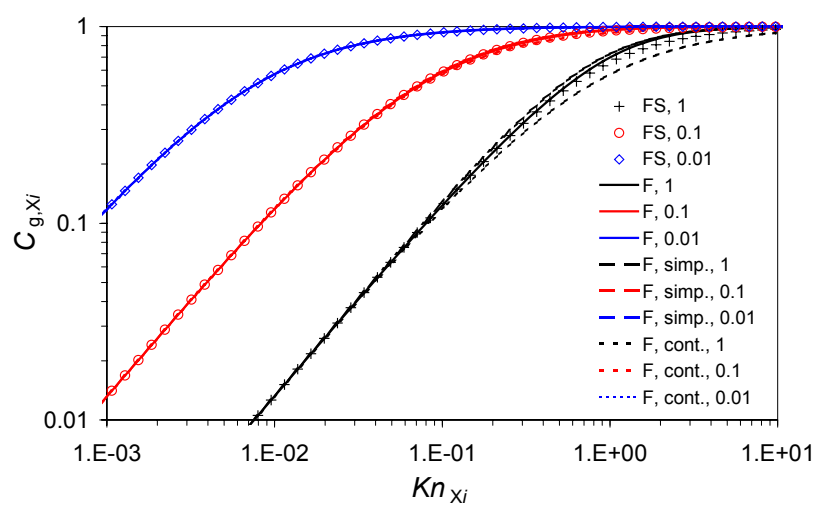

Fig. 1. Gas phase diffusion correction factor $C_{\mathrm{g}, \mathrm{X} i}$ plotted against Knudsen number $K n_{\mathrm{X} i}$ for different uptake coefficients and transition regime flux matching approaches: $\gamma_{\mathrm{X} i}=1$ for black lines and symbols; $\gamma_{X_{i}}=0.1$ for red lines and symbols; $\gamma_{X_{i}}=0.01$ for blue lines and symbols; FS (symbols): Eq. (19) based on Fuchs and Sutugin (1971); F (solid lines): Eq. (14) based on Fuchs (1964); $\mathrm{F}$, simp. (dashed lines): Eq. (14) with $\Delta_{\mathrm{X} i}=\lambda_{\mathrm{X} i} ; \mathrm{F}$, cont. (dotted lines): Eq. (20).

Fuchs (1964) expressed the result of flux matching as a correction factor $\beta_{F}$ for the flow of a trace gas species $\mathrm{X}_{i}$ into a "perfectly absorbing sphere" under continuum conditions:

$F_{\text {net }, \mathrm{X} i}=\beta_{F} 2 \pi d_{\mathrm{p}} D_{\mathrm{g}, \mathrm{X} i}\left[\mathrm{X}_{i}\right]_{\mathrm{g}}$

$\beta_{\mathrm{F}}=\frac{\gamma_{\mathrm{X} i}\left(1+K n_{\mathrm{X} i} \frac{\Delta \mathrm{X} i}{\lambda_{\mathrm{X}} i}\right)}{\gamma_{\mathrm{X} i}+\frac{4}{3} K n_{\mathrm{X} i}\left(1+K n_{\mathrm{X} i} \frac{\Delta \mathrm{X} i}{\lambda_{\mathrm{X} i}}\right)}$

Fuchs and Sutugin (1971) proposed an alternative correction factor $\beta_{\mathrm{FS}}$, which was derived from a numerical solution of the Boltzmann diffusion equation for neutron transfer to a black sphere and is thus characteristic for light molecules in a heavy background gas:

$\beta_{\mathrm{FS}}=\frac{\gamma_{\mathrm{X} i}\left(1+K n_{\mathrm{X} i}\right)}{\gamma_{\mathrm{X} i}+\frac{4}{3} K n_{\mathrm{X} i}\left(K n_{\mathrm{X} i}+1+0.28 \gamma_{\mathrm{X} i}\right)}$

The applicability of $\beta_{\mathrm{FS}}$ for trace gases in air (including species with higher molecular mass) has been confirmed by good agreement with experimental data (Li and Davis, 1996; Widmann and Davis, 1997; Seinfeld and Pandis, 1998; Shi et al., 1999; Swartz et al., 1999; Qu and Davis, 2001; Worsnop et al., 2001).

By inserting $\beta_{\mathrm{FS}}$ instead of $\beta_{\mathrm{F}}$ in Eq. (15) and rearrangement using $J_{\text {net, } \mathrm{X} i}=F_{\text {net, } \mathrm{X} i} /\left(d_{\mathrm{p}}^{2} \pi\right)$ and Eq. (9), $C_{\mathrm{g}, \mathrm{X} i}$ can be flexibly adapted to the approach of Fuchs and Sutugin (1971):

$$
\begin{aligned}
& J_{\mathrm{net}, \mathrm{X} i}=\beta_{\mathrm{FS}} \frac{\omega_{\mathrm{X} i}}{3} K n_{\mathrm{X} i}\left[\mathrm{X}_{i}\right]_{\mathrm{g}}= \\
& =\frac{K n_{\mathrm{X} i}^{2}+K n_{\mathrm{X} i}}{K n_{\mathrm{X} i}^{2}+K n_{\mathrm{X} i}+0.28 K n_{\mathrm{X} i} \gamma_{\mathrm{X} i}+0.75 \gamma_{\mathrm{X} i}} \gamma_{\mathrm{X} i} \frac{\omega_{\mathrm{X} i}}{4}\left[\mathrm{X}_{i}\right]_{\mathrm{g}} \\
& =C_{\mathrm{g}, \mathrm{X} i} \gamma_{\mathrm{X} i} \frac{\omega_{\mathrm{X} i}}{4}\left[\mathrm{X}_{i}\right]_{\mathrm{g}}
\end{aligned}
$$

$$
C_{\mathrm{g}, \mathrm{X} i}=\frac{1}{1+\gamma_{\mathrm{X} i} \frac{0.75+0.28 K n_{\mathrm{X} i}}{K n_{\mathrm{X} i}\left(1+K n_{\mathrm{X} i}\right)}}
$$

In the gas kinetic or free-molecule regime $\left(K n_{X i} \gg 1\right), C_{\mathrm{g}, \mathrm{X} i}$ is close to unity $\left(\left[\mathrm{X}_{i}\right]_{\mathrm{gs}} \approx\left[\mathrm{X}_{i}\right]_{\mathrm{g}}\right)$, and in the continuum regime $\left(K n_{\mathrm{X} i} \ll 1\right)$, Eqs. (14) and (19) both can be reduced to:

$$
C_{\mathrm{g}, \mathrm{X} i}=\frac{1}{1+\gamma_{\mathrm{X} i} \frac{0.75}{K_{\mathrm{X} i}}}
$$

Figure 1 displays $C_{\mathrm{g}, \mathrm{X} i}$ calculated as a function of $K n_{\mathrm{X} i}$ for $\gamma_{\mathrm{X} i}=0.01,0.1$, and 1 , respectively. The calculations have been performed with Eqs. (20), (19), (14), and with a simplified version of Eq. (14) assuming $\Delta_{\mathrm{X} i}=\lambda_{\mathrm{X} i}$. For $\gamma_{\mathrm{X} i} \leq 0.01$ the results of the different formalisms are essentially identical. For $\gamma_{\mathrm{X} i} \approx 0.1$ small differences occur in the transition regime but the relative deviations are less than $5 \%$. Substantial deviations between the different formalisms occur only for $\gamma_{\mathrm{X} i} \approx 1$ and $K n_{\mathrm{X} i} \approx 1$. Even under these conditions, however, the differences relative to Eq. (19) do not exceed $+7 \%$ for Eq. (14), $+10 \%$ for Eq. (14) with $\Delta_{\mathrm{X} i}=\lambda_{\mathrm{X} i}$, and $-13 \%$ for Eq. (20), respectively. For many atmospheric process studies, these differences are well within the general uncertainties. They should, however, not be neglected in highprecision measurements and model calculations of processes with $\gamma_{\mathrm{X} i} \approx 1$ and $K n_{\mathrm{X} i} \approx 1$. The results of earlier studies suggest that Eq. (19) based on Fuchs and Sutugin (1971) is most appropriate under isothermal conditions (Li and Davis, 1996; Widmann and Davis, 1997; Seinfeld and Pandis, 1998; Shi et al., 1999; Swartz et al., 1999; Qu and Davis, 2001; Worsnop et al., 2001). More elaborate formalisms may be required for non-isothermal processes (Qu et al., 2001), but several studies have shown that the formulation of Fuchs and Sutugin (1971) works well also under non-isothermal conditions (Kulmala and Vesala, 1991; Vesala et al., 1997; Kulmala and Wagner, 2001; Winkler et al., 2004).

To our knowledge, a gas phase diffusion correction factor similar to $C_{g, X i}$ as defined in Eq. (4) and calculated in Eqs. (14), (19), and (20) has not been explicitly defined and introduced for the description of atmospheric gas-particle interactions before. At least within the kinetic model presented in the following sections, however, it appears to be the most useful, convenient, and descriptive way of representing the influence of gas phase diffusion on mass transport and chemical reaction at the surface of aerosol particles. In particular, it allows the flexible implementation of different models and corrections for gas phase diffusion effects without changing the remainder of the kinetic model formalism.

The relation of $C_{\mathrm{g}, \mathrm{X} i}$ with the gas phase diffusion conductance, $\Gamma_{\mathrm{g}, \mathrm{X} i}$, of the traditional resistor model outlined above follows from Eqs. (4) and (6):

$C_{\mathrm{g}, \mathrm{X} i}=\frac{\gamma_{\mathrm{eff}, \mathrm{X} i}}{\gamma_{\mathrm{X} i}}=\frac{1}{1+\gamma_{\mathrm{X} i} \frac{1}{\Gamma_{\mathrm{g}, \mathrm{X} i}}}$ 
with

$\Gamma_{\mathrm{g}, \mathrm{X} i}=\gamma_{\mathrm{X} i} \frac{C_{\mathrm{g}, \mathrm{X} i}}{1-C_{\mathrm{g}, \mathrm{X} i}}=\frac{4}{3} K n_{\mathrm{X} i}\left(1+K n_{\mathrm{X} i} \frac{\Delta_{\mathrm{X} i}}{\lambda_{\mathrm{X} i}}\right)$

for the approach of Fuchs (1964), and

$$
\Gamma_{\mathrm{g}, \mathrm{X} i}=\frac{K n_{\mathrm{X} i}\left(1+K n_{\mathrm{X} i}\right)}{0.75+0.28 K n_{\mathrm{X} i}}
$$

for the interpolation of Fuchs and Sutugin (1971), respectively.

For the calculation of gas phase diffusion resistances in the continuum regime $\left(K n_{\mathrm{X} i} \ll 1\right)$ the above equations can be rearranged by inversion, multiplication with $\left(1-K n_{\mathrm{X} i}\right)$, and omission of quadratic terms of $K n_{\mathrm{X} i}$, which leads to

$$
\frac{1}{\Gamma_{\mathrm{g}, \mathrm{X} i}} \approx \frac{\omega_{\mathrm{X} i} d_{\mathrm{p}}}{8 D_{\mathrm{g}, \mathrm{X} i}}-0.38
$$

for the gas phase diffusion resistance term based on Fuchs (1964), and

$$
\frac{1}{\Gamma_{\mathrm{g}, \mathrm{X} i}} \approx \frac{\omega_{\mathrm{X} i} d_{\mathrm{p}}}{8 D_{\mathrm{g}, \mathrm{X} i}}-0.47
$$

for the resistance term based on Fuchs and Sutugin (1971), respectively.

The additive constants -0.38 and -0.47 on the right hand side of Eqs. (24) and (25), respectively, correspond to the correction term $-1 / 2$ in traditional resistor model formulations for the effect of gas phase diffusion in the continuum regime (Danckwerts, 1951; Finlayson-Pitts and Pitts, 2000; and references therein), which have been attributed to an effective doubling of the mean molecular velocity component directed towards the surface in case of high net uptake (distortion of Maxwellian flow; Motz and Wise, 1960). If, however, $K n_{\mathrm{X} i}$ is indeed more than an order of magnitude below unity, the additive constants contribute less than $\sim 5 \%$ to the gas phase diffusion resistances and can be omitted from Eqs. (24) and (25), which become equivalent to Eq. (20).

\section{Particle surface and bulk composition and processes}

\subsection{Double-layer surface model and surface mass balance}

To describe the physicochemical processes at the gas-particle interface, we apply a simple double-layer surface model which comprises two monomolecular layers: a quasi-static surface layer consisting of (quasi-)non-volatile particle components $\mathrm{Y}_{j}$ (molecules, ions, or functional groups), and a sorption layer consisting of adsorbed volatile molecules $\mathrm{X}_{i}$ (Fig. 2). Both the non-volatile particle components $Y_{j}$ and the volatile molecules $\mathrm{X}_{i}$ can be reversibly transferred between the double-layer surface and the underlying particle bulk, in which they can undergo diffusion and reaction. The

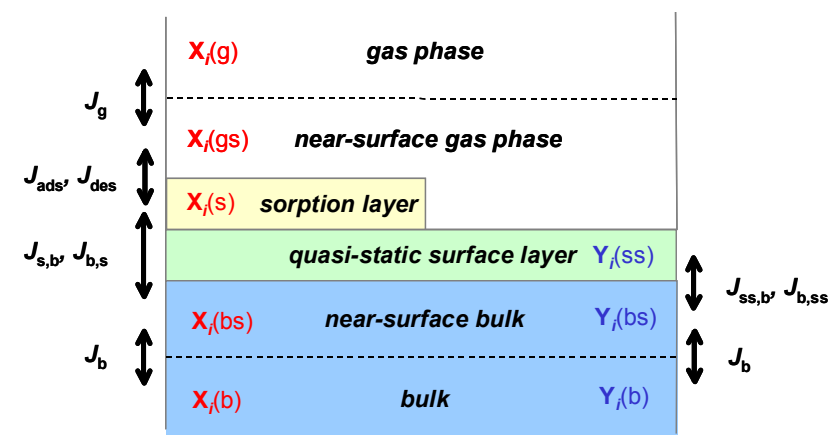

Fig. 2. Double-layer surface model compartments and transport fluxes for volatile species $\mathrm{X}_{i}$ (left) and non-volatile species $\mathrm{Y}_{j}$ (right).

contribution of $\mathrm{X}_{i}$ to the chemical composition and physicochemical properties of the quasi-static surface layer, however, is assumed to be negligible. The description and effects of semivolatile species that can significantly contribute to the composition of all model compartments (gas phase, sorption layer, quasi-static surface, particle bulk) will be addressed below (Sect. 3.7). Note that a double-layer surface model as outlined above represents a minimum of model complexity required for consistent description of competitive co-adsorption and surface saturation effects as detailed and discussed in Sects. 4 and 5.

To describe surface-bulk mass transport and the potential influence of bulk composition on surface processes, it is useful to define the condensed phase directly adjacent to the quasi-static surface layer as the "near-surface particle bulk". Depending on the chemical composition and physical state of the investigated particles, the near-surface bulk region can be pictured to extend one or a few molecular diameters or chemical bonds $(\sim 1 \mathrm{~nm})$ from the quasi-static surface into the particle bulk. The chemical species present in the near-surface particle bulk are not directly exposed to the gas phase or sorption layer species, but they interact with the quasi-static surface layer and can influence its physicochemical properties: e.g. electron donor-acceptor and charge-transfer interactions; hydrogen bonding networks (O'Hanlon and Forster, 2000); quasi-liquid or structurally disordered surface layers on ice (Delzeit et al., 1996; Girardet and Toubin, 2001). With respect to mass transport, the near-surface particle bulk is analogous to the near-surface gas-phase, i.e. the gas phase about one mean free path off the surface as discussed in the preceding section on gas phase diffusion. Both can be pictured as the region from which a molecule of the investigated species can directly interact and undergo exchange with the molecules in the double-layer surface.

Mass transport of the volatile species $\mathrm{X}_{i}$ and non-volatile species $\mathrm{Y}_{j}$ between the near-surface gas phase (gs), the sorption layer (s), the quasi-static surface layer (ss), and the near- 


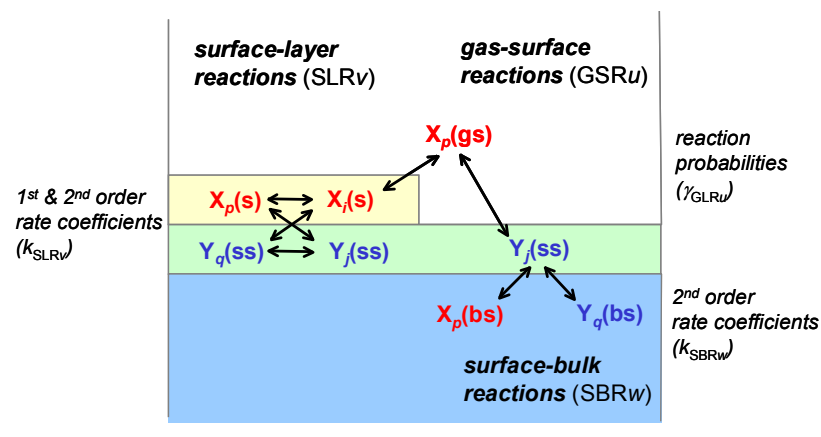

Fig. 3. Classification of chemical reactions between volatile and non-volatile species at the surface.

surface particle bulk (bs) can be summarized by:

$\mathrm{X}_{i}(\mathrm{gs}) \underset{J_{\mathrm{des}, \mathrm{X} i}}{\stackrel{J_{\mathrm{ads}, \mathrm{X} i}}{\longrightarrow}} \mathrm{X}_{i}(\mathrm{~s}) \underset{J_{\mathrm{b}, \mathrm{s}, \mathrm{X} i}}{\stackrel{J_{\mathrm{s}, \mathrm{b}, \mathrm{X} i}}{\longrightarrow}} \mathrm{X}_{i}(\mathrm{bs})$
$\mathrm{Y}_{j}(\mathrm{ss}) \underset{J_{\mathrm{b}, \mathrm{ss}, \mathrm{Y} j}}{\stackrel{J_{\mathrm{ss}, \mathrm{b}, \mathrm{Y} j}}{\rightleftarrows}} \mathrm{Y}_{j}(\mathrm{bs})$

Compartments and transport fluxes in the double-layer surface model considering only volatile and non-volatile species are illustrated in Fig. 2. Combination of transport with chemical production and loss at the surface leads to the following surface mass balance equations for $\mathrm{X}_{i}$ and $\mathrm{Y}_{j}$ :

$$
\begin{aligned}
d\left[\mathrm{X}_{i}\right]_{\mathrm{s}} / \mathrm{d} t & =J_{\mathrm{ads}, \mathrm{X} i}-J_{\mathrm{des}, \mathrm{X} i}+P_{\mathrm{s}, \mathrm{X} i}-L_{\mathrm{s}, \mathrm{X} i} \\
& +J_{\mathrm{b}, \mathrm{s}, \mathrm{X} i}-J_{\mathrm{s}, \mathrm{b}, \mathrm{X} i} \\
d\left[\mathrm{Y}_{j}\right]_{\mathrm{ss}} / \mathrm{d} t & =P_{\mathrm{ss}, \mathrm{Y} j}-L_{\mathrm{ss}, \mathrm{Y} j}+J_{\mathrm{b}, \mathrm{ss}, \mathrm{Y} j}-J_{\mathrm{ss}, \mathrm{b}, \mathrm{Y} j}
\end{aligned}
$$

$\left[\mathrm{X}_{i}\right]_{\mathrm{S}}$ is the concentration of $\mathrm{X}_{i}$ in the sorption layer (number per unit area), and $\left[Y_{j}\right]_{s s}$ is the concentration of $Y_{j}$ in the quasi-static surface layer (number per unit area). All terms on the right hand side of Eqs. (28) and (29) are flux densities (number per unit area and unit time): $J_{\mathrm{ads}, \mathrm{X} i}$ and $J_{\mathrm{des}, \mathrm{X} i}$ stand for adsorption and desorption, i.e. reversible mass transport from the near-surface gas phase to the sorption layer; $J_{\mathrm{b}, \mathrm{s}, \mathrm{X} i}$ and $J_{\mathrm{s}, \mathrm{b}, \mathrm{X} i}$ for mass transport from the near-surface bulk to the sorption layer and vice versa; $P_{\mathrm{s}, \mathrm{X} i}$ and $L_{\mathrm{s}, \mathrm{X} i}$ for production and loss of adsorbed $\mathrm{X}_{i}$ by chemical reaction at the surface; $J_{\mathrm{b}, \mathrm{ss}, \mathrm{Y} j}$ and $J_{\mathrm{ss}, \mathrm{b}, \mathrm{Y} j}$ for mass transport from the bulk to the quasi-static surface layer and vice versa; $P_{\mathrm{ss}, \mathrm{Y} j}$ and $L_{\mathrm{ss}, \mathrm{Y} j}$ for chemical production and loss of $Y_{j}$ in the quasi-static surface layer. The mass transport flux densities, $J_{\mathrm{ads}, \mathrm{X} i}, J_{\mathrm{des}, \mathrm{X} i}, J_{\mathrm{b}, \mathrm{s}, \mathrm{X} i}, J_{\mathrm{s}, \mathrm{b}, \mathrm{X} i}, J_{\mathrm{b}, \mathrm{ss}, \mathrm{Y} j}$, and $J_{\mathrm{ss}, \mathrm{b}, \mathrm{Y} j}$, are determined by the chemical composition and physicochemical properties of the surface (sorption layer and quasi-static layer), the near-surface gas phase, and the nearsurface particle bulk. Molecular mechanisms and rate equations for the mass transport processes will be outlined below (Sects. 3.2 and 3.4). For chemical production and loss of $\mathrm{X}_{i}$ in the sorption layer $\left(P_{\mathrm{s}, \mathrm{X} i}-L_{\mathrm{s}, \mathrm{X} i}\right)$ and of $\mathrm{Y}_{j}$ in the quasi-static surface layer $\left(P_{\mathrm{Ss}, \mathrm{Y} j}-L_{\mathrm{ss}, \mathrm{Y} j}\right)$, respectively, different reaction mechanisms have to be taken into account. Depending on the involved model compartments we distinguish between gas-surface reactions, surface layer reactions and surface-bulk reactions. The different types of chemical reactions and rate parameters are illustrated in Fig. 3 and will be described in detail below (Sect. 3.3).

\subsection{Adsorption and desorption (gas-surface mass transport)}

We define adsorption as the accommodation of gas molecules on the quasi-static particle surface, i.e. transport from the gas phase into the sorption layer on the quasi-static surface, and desorption as the reverse process. As indicated by the surface mass balance equations outlined above, the presented model framework aims at a clear distinction of transport processes (adsorption and desorption) from chemical reactions at the surface. We speak of adsorption or surface accommodation when the gas molecule colliding with the surface neither reacts nor bounces off immediately but stays within a distance on the order of a chemical bond $\left(\sim 10^{-10} \mathrm{~m}\right)$ for a duration longer than the average duration of a (quasi-)elastic gas-surface collision or molecular scattering process. From gas kinetic theory this duration can be approximated by the ratio of the typical length of a chemical bond and the mean thermal velocity of the gas molecule $\left(\sim 10^{2} \mathrm{~m} \mathrm{~s}^{-1}\right)$, which is generally on the order of $\sim 10^{-12}$ s under ambient conditions in the lower atmosphere.

The processes of adsorption and desorption are considered to include intermolecular interactions between molecules in the sorption layer and in the quasi-static surface layer (van der Waals interactions, hydrogen bonding, and similar electron donor-acceptor interactions; Goss, 2004) but no formation or cleavage of stable chemical bonds. Gas-surface interactions which lead to the formation or cleavage of stable chemical bonds (including so-called dissociative adsorption or desorption) are regarded either as (quasi-)elementary "gas-surface reactions" (Sect. 3.3.1) or as two-step processes of gas-surface mass transport and subsequent chemical reaction within the surface double-layer ("surface layer reactions", Sect. 3.3.2). The conceptual distinction between adsorption, scattering (bounce), and immediate reaction of gas molecules colliding with a liquid or solid surface is supported by the results of molecular beam experiments and other advanced surface science studies revealing further details of gas-surface interactions on a molecular level (e.g. Masel, 1996; Nathanson et al., 1996; Rettner et al., 1996; BartelsRausch et al., 2002, 2005; and references therein).

In surface science the terms "physisorption" and "trapping" are frequently used to describe loose binding of adsorbed molecules to a surface (negative adsorption enthalpies typically $<50 \mathrm{~kJ} \mathrm{~mol}^{-1}$ ), whereas "chemisorption" and "sticking" are used to describe strong binding (negative adsorption enthalpies typically $>50 \mathrm{~kJ} \mathrm{~mol}^{-1}$; Masel, 
1996). Within the kinetic model framework outlined in this manuscript, however, all of these terms are sub-summarized under the umbrella terms adsorption or surface accommodation, which comprise the full range from rather loose to relatively strong binding of molecules to the quasi-static surface, as long as no formation or cleavage of stable chemical bonds is involved. This definition is in line with Langmuir's understanding of adsorption (Langmuir, 1916) and aims at making the presented kinetic model framework with a limited number of rate equations and parameters consistently applicable for the wide variety of particles and trace gases interacting in the atmosphere. It is, however, not meant to constrain the distinction and application of different mechanisms and traditional categories of adsorption for detailed investigation and characterization of specific systems, from which the generalized rate parameters defined below can be determined and extrapolated to atmospheric conditions.

The flux of adsorption of gas molecules $\mathrm{X}_{i}$ can be described by multiplication of the flux of surface collisions, $J_{\text {coll, } \mathrm{X} i}$, with a surface accommodation coefficient or adsorption probability, $\alpha_{\mathrm{s}, \mathrm{X} i}$ :

$J_{\mathrm{ads}, \mathrm{X} i}=\alpha_{\mathrm{s}, \mathrm{X} i} J_{\mathrm{coll}, \mathrm{X} i}$

$\alpha_{\mathrm{s}, \mathrm{X} i}$ is defined as the probability that $\mathrm{X}_{i}$ undergoes neither scattering nor immediate chemical reaction upon collision with the particle but is accommodated in the sorption layer of the particle $\left(0 \leq \alpha_{\mathrm{s}, \mathrm{X} i} \leq 1\right)$. In the scientific literature similarly defined parameters have been called adsorption coefficient (Shi et al., 1999; Turco et al., 1989; Worsnop et al., 2002), condensation coefficient (Pruppacher and Klett, 1997), sticking coefficient (Hanson, 1997), sticking probability (Clement et al., 1996; Garrett et al., 2006), trapping probability (Masel, 1996), adsorptive mass accommodation coefficient (Elliott et al., 1991), (mass) accommodation coefficient (Jayne et al., 1990; Tabazadeh and Turco, 1993; Pruppacher and Klett, 1997; Kulmala and Wagner, 2001; Huthwelker et al., 2006), and thermal accommodation coefficient (Li et al., 2001; Worsnop et al., 2002). For clarity and unambiguous distinction of the gas-to-surface mass transfer process specified above from mass transfer into the bulk, from chemical reactions, and from heat transfer (Sect. 4.2), however, we propose to use the term surface accommodation coefficient.

Inserting Eq. (2) in (30) leads to

$J_{\mathrm{ads}, \mathrm{X} i}=k_{\mathrm{a}, \mathrm{X} i}\left[\mathrm{X}_{i}\right]_{\mathrm{gs}}$

with a first-order adsorption rate coefficient $k_{\mathrm{a}, \mathrm{X} i}=$ $\alpha_{\mathrm{s}, \mathrm{X} i} \omega_{\mathrm{X} i} / 4$, which has the dimensions of unit length per unit time and can be regarded as a deposition velocity.

In Eqs. (30) and (31) all surface-specific parameters are lumped in the surface accommodation coefficient $\alpha_{\mathrm{s}, \mathrm{X} i}$, without making any a priori assumptions about the number and nature of sorption sites, surface coverage by competing adsorbate molecules, surface mobility and residence of adsorbate molecules, etc. The simplest way to estimate $\alpha_{\mathrm{s}, \mathrm{X} i}$ is a Langmuir adsorption model in which all adsorbate species compete for a single type of non-interfering sorption sites with an overall concentration $[\mathrm{SS}]_{\mathrm{ss}}$ (number per unit area) on the quasi-static surface. In this case $\alpha_{\mathrm{s}, \mathrm{X} i}$ is determined by the surface accommodation coefficient on a clean, i.e. adsorbate-free surface, $\alpha_{\mathrm{s}, 0, \mathrm{X} i}$, and the sorption layer surface coverage, $\theta_{\mathrm{s}}$, which is given by the sum of the fractional surface coverages of all competing adsorbate species, $\theta_{\mathrm{s}, \mathrm{X} p}$ :

$\alpha_{\mathrm{s}, \mathrm{X} i}=\alpha_{\mathrm{s}, 0, \mathrm{X} i}\left(1-\theta_{\mathrm{s}}\right)$

$\theta_{\mathrm{s}}=\sum_{p} \theta_{\mathrm{s}, \mathrm{X} p}$

Under the assumption of a single type and surface concentration of sorption sites for all adsorbate species, the fractional surface coverage of an individual species $\mathrm{X}_{p}$ is given by $\theta_{\mathrm{s}, \mathrm{Xp}}=\left[\mathrm{X}_{p}\right]_{\mathrm{s}} /[\mathrm{SS}]_{\mathrm{ss}}$.

In practice the nature of sorption sites at the surface of an aerosol particle is determined by its chemical composition, and the interaction between different adsorbates and specific surface sites (molecules, functional groups, atoms, or ions) may be highly variable. For such complex systems different types of sorption sites can be defined for different types of phase species interacting with the surface. For example, dual-site Langmuir formalisms have been applied to describe the interaction of carbonaceous particles with nitrogen oxides (Gray and Do, 1992). In principle, such formalisms are compatible with the model framework outlined in this manuscript, but they seem to be hard to generalize for atmospheric applications with a large number of interacting trace gases and their elaboration goes beyond the scope of this paper. Here we apply a simple approach assuming that the competition of different adsorbate species for different adsorption sites on the quasi-static particle surface can be described by assigning effective molecular cross sections to the adsorbate species and letting them compete for surface area rather than specific sites. In this case, the fractional surface coverage of individual species $\mathrm{X}_{p}$ can be calculated by

$\theta_{\mathrm{s}, \mathrm{X} p}=\left[\mathrm{X}_{p}\right]_{\mathrm{s}} /\left[\mathrm{X}_{p}\right]_{\mathrm{s}, \max }=\sigma_{\mathrm{s}, \mathrm{X} p}\left[\mathrm{X}_{p}\right]_{\mathrm{s}}$

where $\sigma_{\mathrm{s}, \mathrm{X} p}$ is the effective molecular cross section of $\mathrm{X}_{p}$ in the sorption layer, and the inverse of $\sigma_{\mathrm{s}, \mathrm{X} p}$ is the maximum surface concentration of $\mathrm{X}_{p},\left[\mathrm{X}_{p}\right]_{\mathrm{s}, \max }$.

Equations (31)-(34) describe a Langmuir-type adsorption process accounting for different competing adsorbate species. The influence of the (potentially changing) chemical composition of the quasi-static particle surface on adsorbatesurface interactions and thus on the surface accommodation coefficient can be taken into account by describing $\alpha_{\mathrm{s}, 0, \mathrm{X} i}$ as a linear combination of the initial surface accommodation coefficients that would be observed on pure substrates made up by the different surface components $\mathrm{Y}_{q}$ weighted by their fractional surface area $\theta_{\mathrm{ss}, \mathrm{Y} q}$, i.e. their surface concentration 
$\left[\mathrm{Y}_{q}\right]_{\mathrm{ss}}$ multiplied by their effective molecular cross section

$\sigma_{\mathrm{ss}, \mathrm{Y} q}$

$\alpha_{\mathrm{s}, 0, \mathrm{X} i}=\sum_{q} \alpha_{\mathrm{s}, 0, \mathrm{X} i, \mathrm{Y} q} \theta_{\mathrm{ss}, \mathrm{Y} q}$

$\theta_{\mathrm{ss}, \mathrm{Y} q}=\left[\mathrm{Y}_{q}\right]_{\mathrm{ss}} \sigma_{\mathrm{ss}, \mathrm{Y} q}$

with $\sum_{q} \theta_{\mathrm{ss}, \mathrm{Y} q}=1$.

If the surface accommodation process were significantly influenced not only by the quasi-static surface layer but also by the underlying condensed phase (e.g. by hydrogen bonding or other electron donor-acceptor interactions), the composition of the near-surface particle would also have to be taken into account. This could be achieved by expressing $\alpha_{\mathrm{s}, 0, \mathrm{X} i, \mathrm{Y} p}$ as a linear combination of the adsorption probabilities $\alpha_{\mathrm{s}, 0, \mathrm{X} i, \mathrm{Y} p, \mathrm{Y} q}$ which would be observed for $\mathrm{X}_{i}$ colliding with an adsorbate-free surface made up of pure $\mathrm{Y}_{p}$ on an underlying bulk of pure $\mathrm{Y}_{q}$ :

$\alpha_{\mathrm{s}, 0, \mathrm{X} i, \mathrm{Y} p}=\sum_{q} \alpha_{\mathrm{s}, 0, \mathrm{X} i, \mathrm{Y} p, \mathrm{Y} q} \phi_{\mathrm{Y} q}$

The weighting factor $\phi_{\mathrm{Y} q}$ could be the mole, mass, or volume fraction of $\mathrm{Y}_{q}$ in the near-surface particle bulk. The latter appear to be more suitable for the representation of macromolecular particle components.

In this approach surface heterogeneities and interferences between adsorbate molecules which may lead to non-linear dependence of $\alpha_{\mathrm{s}, \mathrm{X} i}$ on particle composition and sorption layer coverage, are assumed to be negligible or cancel out statistically. If this is not the case, appropriate corrections or alternative mathematical formalisms have to be applied. The investigated surfaces and underlying molecular layers have to be resolved into quasi-homogenous areas, or Monte-Carlotype simulations have to be performed. Such approaches could be included in the presented model framework, but they would have to be designed specifically for different aerosol systems and are beyond the scope of this paper.

Combining Eqs. (31) and (32) leads to

$J_{\mathrm{ads}, \mathrm{X} i}=k_{\mathrm{a}, 0, \mathrm{X} i}\left[\mathrm{X}_{i}\right]_{\mathrm{gs}}\left(1-\theta_{\mathrm{s}}\right)$

with

$k_{\mathrm{a}, 0, \mathrm{X} i}=\alpha_{\mathrm{s}, 0, \mathrm{X} i} \frac{\omega_{\mathrm{X} i}}{4}$

Equation (38) is consistent with standard textbook formulations for the flux of Langmuir adsorption (Langmuir, 1916; Laidler et al., 1940). The dependence of $\alpha_{\mathrm{s}, 0, \mathrm{X} i}$ and thus of $k_{\mathrm{a}, 0, \mathrm{X} i}$ on the composition of the quasi-static surface layer and near-surface particle bulk described in Eqs. (35)-(37), however, implies that even in the simple model of adsorption outlined above, the surface accommodation and adsorption rate coefficients may change over time if the particle components are transformed by chemical reactions (chemical aging).
In the Langmuir model of reversible adsorption, also the desorption process can be described by a first-order rate coefficient, $k_{\mathrm{d}, \mathrm{X} i}$, which is assumed not to depend on $\theta_{\mathrm{s}}$ and can be regarded as the inverse of the desorption lifetime, $\tau_{\mathrm{d}, \mathrm{X} i}$, i.e. the mean residence time of the investigated species on the surface in the absence of chemical reaction and surfacebulk mass transport (Laidler et al., 1940):

$J_{\mathrm{des}, \mathrm{X} i}=k_{\mathrm{d}, \mathrm{X} i}\left[\mathrm{X}_{i}\right]_{\mathrm{s}}=\tau_{\mathrm{d}, \mathrm{X} i}^{-1}\left[\mathrm{X}_{i}\right]_{\mathrm{s}}=\tau_{\mathrm{d}, \mathrm{X} i}^{-1} \sigma_{\mathrm{X} i}^{-1} \theta_{\mathrm{s}, \mathrm{X} i}$

Under adsorption equilibrium conditions it is useful to combine the rate coefficients of adsorption and desorption into a Langmuir adsorption equilibrium constant $K_{\text {ads, } \mathrm{X} i}$ (Sect. 4.4). In case of rapid chemical reaction or surface-bulk exchange, however, the actual mean residence time of $\mathrm{X}_{i}$ on the surface is shorter than its desorption lifetime, which can be taken into account in an effective adsorption equilibrium constant $K_{\mathrm{ads}, \mathrm{X} i}^{\prime}$ for the description of adsorption-reaction steady-state conditions (Sect. 4.5). These special cases of equilibrium and steady-state conditions will be described and discussed in more detail below (Sect. 4) and illustrated by exemplary model calculations in a companion paper (Ammann and Pöschl, 2007).

In analogy to Eqs. (35)-(37) for $\alpha_{\mathrm{s}, 0, \mathrm{X} i}$, the influence of the chemical composition of the quasi-static surface layer and near-surface particle bulk can be taken into account by describing $\tau_{\mathrm{d}, \mathrm{X} i}$ as a linear combination of the desorption lifetimes which would be observed on pure substrates made up by the different chemical components of the actual surface, $\tau_{\mathrm{d}, \mathrm{X} i, \mathrm{Y} p}$, or on surfaces made up by pure $\mathrm{Y}_{p}$ on an underlying bulk of pure $\mathrm{Y}_{q}, \tau_{\mathrm{d}, \mathrm{X} i, \mathrm{Y} p, \mathrm{Y} q}$.

Since desorption is driven by thermal motion, the mean residence times and desorption rate coefficients are expected to exhibit a strong temperature dependence, which can usually be described by an Arrhenius equation involving the heat of adsorption and a pre-exponential factor on the order of the vibration frequency of the involved molecules and chemical bonds (Laidler et al., 1940; Baetzold and Somorjai, 1976; Pöschl et al., 2001; and references therein). Of course the other rate coefficients of mass transport and chemical reaction introduced above and in the remainder of this manuscript can also exhibit more or less pronounced temperature dependences, as will be discussed below (Sect. 4.2).

From heterogeneous catalysis it is known that almost all technically relevant surface reactions (except for single crystal surfaces) can be described by Langmuir-Hinshelwood or Eley-Rideal rate equations derived on the basis of a simple Langmuir adsorption model; even in systems where the actual adsorption process does not follow a simple Langmuir isotherm, reaction rates can often be described by LangmuirHinshelwood rate equations based on the assumption of Langmuir adsorption (Sect. 4; Masel, 1996; Ammann et al., 2003; and references therein). Thus we expect that the above rate equations of adsorption and desorption will be suitable for the description of most relevant surface reactions on atmospheric particles, as indicated by multiple recent studies 
(Arens et al., 2001; Pöschl et al., 2001; Ammann et al., 2003; Rudich, 2003; Dubowski et al., 2004; Mmereki et al., 2004; Sullivan et al., 2004; Ammann and Pöschl, 2007; and references therein).

\subsection{Chemical reactions at the surface}

\subsubsection{Gas-Surface Reactions (GSR)}

We reserve the term gas-surface reactions exclusively for reactions which can be described by a single kinetic step of collision and reaction between gas phase and surface molecules, i.e. heterogenous elementary reactions in which one of the reactants comes directly from the gas phase without a separate step of surface accommodation prior to reaction. According to the above definition of surface accommodation, gassurface reactions in the lower troposphere would have to occur within $\sim 10^{-12}$ s upon collision of the gas molecule with the surface. In the chemical engineering literature, processes involving gas-surface reactions are commonly referred to as Eley-Rideal mechanisms.

In principle, sorption layer and quasi-static surface layer components $\mathrm{X}_{i}$ and $\mathrm{Y}_{j}$ can be formed upon reaction of any gas phase species $\mathrm{X}_{p}$ with any surface species $\mathrm{X}_{q}$ or $\mathrm{Y}_{q}$, respectively. Net chemical production (i.e. gross production minus loss) of $\mathrm{X}_{i}$ and $\mathrm{Y}_{j}$ by elementary second-order gassurface reactions can be described by the following generalized rate equations:

$$
\begin{array}{r}
P_{\mathrm{s}, \mathrm{g}, \mathrm{X} i}-L_{\mathrm{s}, \mathrm{g}, \mathrm{X} i}=\sum_{u} \sum_{p} \sum_{q} c_{\mathrm{GSR} u, \mathrm{~s}, \mathrm{X} i} J_{\mathrm{coll}, \mathrm{X} p} \\
\left(\gamma_{\mathrm{GSR} u, \mathrm{X} p, \mathrm{X} q} \theta_{\mathrm{s}, \mathrm{X} q}+\gamma_{\mathrm{GSR} u, \mathrm{X} p, \mathrm{Y} q} \theta_{\mathrm{ss}, \mathrm{Y} q}\left(1-\theta_{\mathrm{s}}\right)\right) \\
P_{\mathrm{Ss}, \mathrm{g}, \mathrm{Y} j}-L_{\mathrm{ss}, \mathrm{g}, \mathrm{Y} j}=\sum_{u} \sum_{p} \sum_{q} c_{\mathrm{GSR} u, \mathrm{ss}, \mathrm{Y} j} J_{\mathrm{coll}, \mathrm{X} p} \\
\left(\gamma_{\mathrm{GSR} u, \mathrm{X} p, \mathrm{X} q} \theta_{\mathrm{s}, \mathrm{X} q}+\gamma_{\mathrm{GSR} u, \mathrm{X} p, \mathrm{Y} q} \theta_{\mathrm{ss}, \mathrm{Y} q}\left(1-\theta_{\mathrm{s}}\right)\right)
\end{array}
$$

$c_{\mathrm{GSR} u, \mathrm{~s}, \mathrm{X} i}$ and $c_{\mathrm{GSR} u, \mathrm{ss}, \mathrm{Y} j}$ stand for the stoichiometric coefficients (negative for starting substances and positive for reaction products) of surface species $X_{i}$ and $Y_{j}$ involved in the elementary gas-surface reaction $\operatorname{GSR} u ; u=1, \ldots, u_{\max }$ for a total number of $u_{\max }$ elementary gas-surface reactions. $\gamma_{\mathrm{GSR} u, \mathrm{X} p, \mathrm{X} q}$ or $\gamma_{\mathrm{GSR} u, \mathrm{X} p, \mathrm{Y} q}$ are defined as elementary gassurface reaction probabilities, i.e. the probabilities that gas phase molecules $\mathrm{X}_{p}$ undergo an elementary gas-surface reaction GSR $u$ when colliding with an adsorbed volatile species $\mathrm{X}_{i}$ in the sorption layer or with a non-volatile species $\mathrm{Y}_{j}$ in the quasi-static surface layer, respectively.

Production and loss of $X_{i}$ by elementary gas-surface reactions can involve volatile species in the sorption layer as well as non-volatile species in the uncovered fraction, $\left(1-\theta_{\mathrm{s}}\right)$, of the quasi-static surface layer:

$$
\begin{array}{r}
P_{\mathrm{g}, \mathrm{gsr}, \mathrm{X} i}-L_{\mathrm{g}, \mathrm{gsr}, \mathrm{X} i}=\sum_{u} \sum_{p} \sum_{q} c_{\mathrm{GSR} u, \mathrm{~g}, \mathrm{X} i} J_{\mathrm{coll}, \mathrm{X} p} \\
\left(\gamma_{\mathrm{GSR} u, \mathrm{X} p, \mathrm{X} q} \theta_{\mathrm{s}, \mathrm{X} q}+\gamma_{\mathrm{GSR} u, \mathrm{X} p, \mathrm{Y} q} \theta_{\mathrm{ss}, \mathrm{Y} q}\left(1-\theta_{\mathrm{s}}\right)\right)
\end{array}
$$

$c_{\mathrm{GSR} u, \mathrm{~g}, \mathrm{X} i}$ stands for the stoichiometric coefficient of gas molecules $\mathrm{X}_{i}$ involved in the elementary gas-surface reaction GSRu.

Due to chemical interferences (activation or passivation by neighboring species, etc.), the reaction probabilities $\gamma_{\mathrm{GSR} u, \mathrm{X} p, \mathrm{X} q}$ and $\gamma_{\mathrm{GSR} u, \mathrm{X} p, \mathrm{Y} q}$ may depend on surface composition and adsorbate coverage. As discussed in the above Langmuir adsorption model, non-linear interferences cannot be easily taken into account, but linear dependences on surface and near-surface bulk composition could be accounted for by linear combination of the reaction probabilities that would be observed on pure substrates made up by the chemical components of the actual surface and near-surface particle bulk (in analogy to Eqs. 35-37). The same applies for the rate coefficients of surface layer reactions and surface-bulk reactions defined in the following sections.

\subsubsection{Surface Layer Reactions (SLR)}

The term surface layer reaction is reserved for reactions which proceed within the surface double layer and involve only adsorbed species or components of the quasi-static surface layer. Such reactions can be influenced by surface heterogeneities and chemical interferences (local depletion or enrichment, activation or passivation by neighboring species, etc.), but for simplicity we assume that they exhibit a straightforward rate-dependence on the average surface concentration of the reactants and that deviations cancel out statistically. The same approach has been taken in early surface science (Laidler et al., 1940; Hinshelwood, 1940) and is widely applied in heterogeneous catalysis (Masel, 1996). In the chemical engineering literature processes involving surface layer reactions are commonly referred to as LangmuirHinshelwood mechanisms.

Assuming that all relevant surface layer reactions can be described by quasi-elementary steps following first- or second-order kinetics, the following generalized expressions can be used to describe net chemical production (i.e. production minus loss) of surface species $\mathrm{X}_{i}$ or $\mathrm{Y}_{j}$ by reactions within the sorption layer $\left(P_{\mathrm{s}, \mathrm{s}, \mathrm{X} i}-L_{\mathrm{s}, \mathrm{s}, \mathrm{X} i}\right)$, between sorption layer and quasi-static surface layer $\left(P_{\mathrm{s}, \mathrm{ss}, \mathrm{X} i}-L_{\mathrm{s}, \mathrm{ss}, \mathrm{X} i}\right.$, $\left.P_{\mathrm{ss}, \mathrm{s}, \mathrm{Y} j}-L_{\mathrm{ss}, \mathrm{s}, \mathrm{Y} j}\right)$, and within the quasi-static surface layer $\left(P_{\mathrm{ss}, \mathrm{ss}, \mathrm{Y} j}-L_{\mathrm{ss}, \mathrm{ss}, \mathrm{Y} j}\right)$.

$$
\begin{gathered}
P_{\mathrm{S}, \mathrm{s}, \mathrm{X} i}-L_{\mathrm{S}, \mathrm{s}, \mathrm{X} i}=\sum_{v} \sum_{p} c_{\mathrm{SLR} v, \mathrm{~s}, \mathrm{X} i}\left[\mathrm{X}_{p}\right]_{\mathrm{s}} \\
\left(k_{\mathrm{SLR} v, \mathrm{X} p}+\sum_{q} k_{\mathrm{SLR} v, \mathrm{X} p, \mathrm{X} q}\left[\mathrm{X}_{q}\right]_{\mathrm{s}}\right)
\end{gathered}
$$

$$
P_{\mathrm{s}, \mathrm{ss}, \mathrm{X} i}-L_{\mathrm{s}, \mathrm{ss}, \mathrm{X} i}=\sum_{v} \sum_{p} \sum_{q} c_{\mathrm{SLR} v, \mathrm{~s}, \mathrm{X} i} k_{\mathrm{SLR} v, \mathrm{X} p, \mathrm{Y} q}
$$$$
\left[\mathrm{X}_{p}\right]_{\mathrm{s}}\left[\mathrm{Y}_{q}\right]_{\mathrm{ss}}
$$

$$
P_{\mathrm{ss}, \mathrm{ss}, \mathrm{Y} j}-L_{\mathrm{ss}, \mathrm{ss}, \mathrm{Y} j}=\sum_{v} \sum_{p} c_{\mathrm{SLR} v, \mathrm{ss}, \mathrm{Y} j}\left[\mathrm{Y}_{p}\right]_{\mathrm{ss}}
$$




$$
\begin{gathered}
\left(k_{\mathrm{SLR} v, \mathrm{Y} p}+\sum_{q} k_{\mathrm{SLR} v, \mathrm{Y} p, \mathrm{Y} q}\left[\mathrm{Y}_{q}\right]_{\mathrm{ss}}\right) \\
P_{\mathrm{ss}, \mathrm{s}, \mathrm{Y} j}-L_{\mathrm{ss}, \mathrm{s}, \mathrm{Y} j}=\sum_{v} \sum_{p} \sum_{q} c_{\mathrm{SLR} v, \mathrm{ss}, \mathrm{Y} j} k_{\mathrm{SLR} v, \mathrm{X} p, \mathrm{Y} q} \\
{\left[\mathrm{X}_{p}\right]_{\mathrm{s}}\left[\mathrm{Y}_{q}\right]_{\mathrm{ss}}}
\end{gathered}
$$

Here $c_{\mathrm{SLR} v, \mathrm{~s}, \mathrm{X} i}$ and $c_{\mathrm{SLR} v, \mathrm{ss}, \mathrm{Y} j}$ stand for the stoichiometric coefficients (negative for starting materials and positive for reaction products) of species $\mathrm{X}_{i}$ and $\mathrm{Y}_{j}$ in reaction $\operatorname{SLR} v ; v=1, \ldots, v_{\max }$ in a system with a total number of $v_{\max }$ (photo-)chemical reactions occurring on the surface of

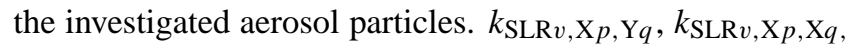
and $k_{\mathrm{SLR} v}, \mathrm{Y} p, \mathrm{Y} q$ are second-order reaction rate coefficients; $k_{\mathrm{SLR} v, \mathrm{X} p}$ and $k_{\mathrm{SLR} v, \mathrm{Y} q}$ are first-order reaction rate coefficients, including photolysis frequencies ( $j$-values).

In principle, higher-order reactions might also occur in real systems and could be flexibly included in Eqs. (44)-(47). In analogy to the description of complex gas phase reactions in atmospheric chemistry, however, it should be possible to avoid excessive complexity and diversity of rate equations and to describe such reactions by formal first- or secondorder rate equations with appropriate rate coefficients reflecting the influence of additional species (third-body reactions; Atkinson et al., 2004).

\subsubsection{Surface-bulk reactions}

The term surface-bulk reaction is reserved for elementary reactions between species in the quasi-static surface layer and in the near-surface particle bulk. For simplicity we assume that potential surface-bulk reactions proceed via quasielementary steps with straightforward second-order ratedependence on the surface concentration of the reactant in the quasi-static surface layer and on the volume concentration of the involved species in the near-surface particle bulk.

Under these conditions the following generalized expression can be used to describe net chemical production of quasi-static surface layer species $\mathrm{Y}_{j}$ by surface-bulk reactions $\left(P_{\mathrm{ss}, \mathrm{b}, \mathrm{Y} j}-L_{\mathrm{ss}, \mathrm{b}, \mathrm{Y} j}\right)$ :

$$
\begin{aligned}
& P_{\mathrm{Ss}, \mathrm{b}, \mathrm{Y} j}-L_{\mathrm{ss}, \mathrm{b}, \mathrm{Y} j}=\sum_{w} \sum_{p} c_{\mathrm{SBR} w, \mathrm{ss}, \mathrm{Y} j}\left[\mathrm{Y}_{p}\right]_{\mathrm{ss}} \\
& \left(\sum_{q} k_{\mathrm{SBR} w, \mathrm{Y} p, \mathrm{Y} q}\left[\mathrm{Y}_{q}\right]_{\mathrm{bs}}+\sum_{r} k_{\mathrm{SBR} w, \mathrm{Y} p, \mathrm{X} r}\left[\mathrm{X}_{r}\right]_{\mathrm{bs}}\right)
\end{aligned}
$$

$c_{\mathrm{SBR} w, \mathrm{~s}, \mathrm{Y} j}$ stands for the stoichiometric coefficient (negative for starting materials and positive for reaction products) of surface species $\mathrm{Y}_{j}$ in the surface bulk reaction $\operatorname{SBR} w$; $w=1, \ldots, w_{\max }$ in a system with a total number of $w_{\max }$ chemical reactions occurring between surface species and underlying condensed phase species on the surface of the investigated aerosol particles. $\left[\mathrm{Y}_{j}\right]_{\mathrm{b}, \mathrm{s}}$ or $\left[\mathrm{X}_{i}\right]_{\mathrm{b}, \mathrm{s}}$ are the volume concentrations of $\mathrm{Y}_{j}$ and $\mathrm{X}_{i}$ in the near-surface particle bulk (number per unit volume), and $k_{\mathrm{SBR} w, \mathrm{Y} p, \mathrm{Y} q}$ and $k_{\mathrm{SBR} w, \mathrm{Y} p, \mathrm{X} r}$ are the second-order rate coefficients.

On the other hand, the net chemical production of $\mathrm{X}_{i}$ and $\mathrm{Y}_{j}$ in the near-surface particle bulk due to surface-bulk reactions can be described by

$$
\begin{aligned}
& P_{\mathrm{b}, \mathrm{ss}, \mathrm{Y} j}-L_{\mathrm{b}, \mathrm{ss}, \mathrm{Y} j}=\sum_{w} \sum_{p} c_{\mathrm{SBR} w, \mathrm{~b}, \mathrm{Y} j}\left[\mathrm{Y}_{p}\right]_{\mathrm{ss}} \\
& \left(\sum_{q} k_{\mathrm{SBR} w, \mathrm{Y} p, \mathrm{Y} q}\left[\mathrm{Y}_{q}\right]_{\mathrm{bs}}+\sum_{r} k_{\mathrm{SBR} w, \mathrm{Y} p, \mathrm{X} r}\left[\mathrm{X}_{r}\right]_{\mathrm{bs}}\right) \\
& P_{\mathrm{b}, \mathrm{ss}, \mathrm{X} i}-L_{\mathrm{b}, \mathrm{ss}, \mathrm{X} i}=\sum_{w} \sum_{p} c_{\mathrm{SBR} w, \mathrm{~b}, \mathrm{X} i}\left[\mathrm{Y}_{p}\right]_{\mathrm{ss}} \\
& \left(\sum_{q} k_{\mathrm{SBR} w, \mathrm{Y} p, \mathrm{Y} q}\left[\mathrm{Y}_{q}\right]_{\mathrm{bs}}+\sum_{r} k_{\mathrm{SBR} w, \mathrm{Y} p, \mathrm{X} r}\left[\mathrm{X}_{r}\right]_{\mathrm{bs}}\right)
\end{aligned}
$$

$c_{\mathrm{SBR} w, \mathrm{~b}, \mathrm{X} i}$ and $c_{\mathrm{SBR} w, \mathrm{~b}, \mathrm{Y} j}$ stand for the stoichiometric coefficients (negative for starting materials and positive for reaction products) of near-surface bulk species $\mathrm{X}_{i}$ and $\mathrm{Y}_{j}$ in the surface-bulk reaction SBR $w$. For highly dynamic surfaces with rapid surface-bulk mass transport (low-viscosity liquid droplets with high molecular diffusivity and/or turbulent mixing), surface-bulk reactions can probably be neglected under most conditions. For non-volatile solid particles, however, they may play a significant role in the chemical aging of the surface and near-surface particle bulk.

\subsubsection{Overall chemical production and loss of surface layer components}

For conciseness, gross production and loss have not been separated in the above generalized rate equations for gassurface, surface layer and surface-bulk reactions. For some considerations, however, this separation may be useful and it is easy to achieve by separate summation of the reaction rate terms with positive stoichiometric coefficients (production) and with negative stoichiometric coefficients (loss). Accordingly, the overall flux densities of gross chemical production and loss of adsorbed molecules $\mathrm{X}_{i}$ in the sorption layer and of non-volatile particle components $\mathrm{Y}_{j}$ in the quasi-static surface layer, respectively, can be expressed as follows:

$$
\begin{aligned}
& P_{\mathrm{s}, \mathrm{X} i}=P_{\mathrm{s}, \mathrm{g}, \mathrm{X} i}+P_{\mathrm{s}, \mathrm{s}, \mathrm{X} i}+P_{\mathrm{s}, \mathrm{ss}, \mathrm{X} i} \\
& L_{\mathrm{s}, \mathrm{X} i}=L_{\mathrm{s}, \mathrm{g}, \mathrm{X} i}+L_{\mathrm{s}, \mathrm{s}, \mathrm{X} i}+L_{\mathrm{s}, \mathrm{ss}, \mathrm{X} i} \\
& P_{\mathrm{ss}, \mathrm{Y} j}=P_{\mathrm{ss}, \mathrm{g}, \mathrm{Y} j}+P_{\mathrm{ss}, \mathrm{s}, \mathrm{Y} j}+P_{\mathrm{ss}, \mathrm{ss}, \mathrm{Y} j}+P_{\mathrm{ss}, \mathrm{b}, \mathrm{Y} j} \\
& L_{\mathrm{ss}, \mathrm{Y} j}=L_{\mathrm{ss}, \mathrm{g}, \mathrm{Y} j}+L_{\mathrm{ss}, \mathrm{s}, \mathrm{Y} j}+L_{\mathrm{ss}, \mathrm{ss}, \mathrm{Y} j}+L_{\mathrm{ss}, \mathrm{b}, \mathrm{Y} j}
\end{aligned}
$$

To describe the influence of chemical reactions at the surface on the composition and mass balance of an aerosol particle surface, Eqs. (51)-(54) have to be inserted in Eqs. (28) and (29). Some of the reaction pathways and flux densities, however, which have been included for completeness and consistency of the above generalized rate expressions, are expected to be negligible under most atmospherically relevant 
conditions and will not be taken into account in the remainder of this manuscript (e.g. $P_{\mathrm{ss}, \mathrm{ss}, \mathrm{Y}} j, P_{\mathrm{b}, \mathrm{ss}, \mathrm{Y} j}, L_{\mathrm{b}, \mathrm{ss}, \mathrm{Y} j}, P_{\mathrm{b}, \mathrm{ss}, \mathrm{X}}$, $\left.L_{\mathrm{b}, \mathrm{ss}, \mathrm{X} i}\right)$.

\subsection{Surface-bulk mass transport}

3.4.1 Transfer of volatile species between sorption layer and near-surface particle bulk

For the mass transport of volatile species $\mathrm{X}_{i}$ between the sorption layer and near-surface particle bulk (solvation and desolvation, respectively), we assume a first-order dependence on sorption layer and near-surface bulk concentration, respectively:

$J_{\mathrm{s}, \mathrm{b}, \mathrm{X} i}=k_{\mathrm{s}, \mathrm{b}, \mathrm{X} i}\left[\mathrm{X}_{i}\right]_{\mathrm{s}}$

$J_{\mathrm{b}, \mathrm{s}, \mathrm{X} i}=k_{\mathrm{b}, \mathrm{s}, \mathrm{X} i}\left[\mathrm{X}_{i}\right]_{\mathrm{bs}}$

The surface-to-bulk transfer rate coefficient $k_{\mathrm{s}, \mathrm{b}, \mathrm{X} i}$ can be regarded as the inverse of the surface-bulk exchange lifetime, $\tau_{\mathrm{s}, \mathrm{b}, \mathrm{X} i}$, i.e. the mean residence time of the investigated species at the surface in the absence of chemical reaction and desorption. $\tau_{\mathrm{s}, \mathrm{b}, \mathrm{X} i}$ is expected to decrease with increasing dynamic variability of the quasi-static surface and with decreasing viscosity of the near-surface particle bulk. In analogy to the desorption lifetime, the influence of the chemical composition of the quasi-static surface and near-surface particle bulk on the surface-bulk exchange lifetime could be taken into account by describing $\tau_{\mathrm{s}, \mathrm{b}, \mathrm{X} i}$ as a linear combination of the residence times that would be observed on pure substrates made up by the chemical components of the actual surface and near-surface particle bulk (in analogy to Eqs. 3537). Moreover, the cluster-nucleation model proposed by Davidovits et al. (1991) and similar approaches of describing surface-to-bulk transfer could be used to determine and parameterize $k_{\mathrm{s}, \mathrm{b}, \mathrm{X} i}$ (Remorov and Bardwell, 2005; Remorov and George, 2006).

The bulk-to-surface transfer rate coefficient $k_{\mathrm{b}, \mathrm{s}, \mathrm{X} i}$ has dimensions of unit length per unit time and can be regarded as a transfer velocity, analogous to the deposition velocity (adsorption rate coefficient $k_{\mathrm{a}, \mathrm{X} i}$ ) on the gas phase side. It is expected to be negligibly small for solid non-volatile materials and to increase with increasing mobility of $\mathrm{X}_{i}$ in the condensed phase. Based on kinetic theory of condensed phases and on the diffusion coefficient of $\mathrm{X}_{i}$ in the near-surface particle bulk, it should be possible to estimate the magnitude of $k_{\mathrm{b}, \mathrm{s}, \mathrm{X} i}$ for different types of particles. A detailed discussion of this aspect, however, is beyond the scope of this paper, which is focused on surface reactivity rather than surface-bulk mass transport. As for the rate coefficients defined above, linear dependences on surface and near-surface bulk composition could be accounted for by linear combination of the inverse rate coefficients that would be observed on pure substrates made up by the chemical components of the actual surface and near-surface particle bulk (in analogy to Eqs. 35-37).
3.4.2 Mass transport of non-volatile particle components between quasi-static surface layer and near-surface particle bulk

Mass transport of chemical species between the quasi-static surface layer and the near-surface particle bulk, i.e. conversion of surface species into near-surface particle bulk species and vice versa, can proceed via two mechanisms: (a) coverage or exposure of near-surface bulk species by reactive transformation and size changes of the overlying quasi-static surface layer species (e.g. addition or loss of functional groups, partial volatilization); and (b) mutual exchange between surface and near-surface bulk species by thermal motion. We denote the transfer fluxes corresponding to the different mechanisms by $J_{\mathrm{ss}, \mathrm{b}, \mathrm{rx}, \mathrm{Y} j}$ and $J_{\mathrm{b}, \mathrm{ss}, \mathrm{rx}, \mathrm{Y} j}$ (reactive transformation) and by $J_{\mathrm{ss}, \mathrm{b}, \mathrm{ex}, \mathrm{Y} j}$ and $J_{\mathrm{b}, \mathrm{ss}, \mathrm{ex}, \mathrm{Y} j}$ (exchange), respectively.

\section{a) Reactive transformation}

Chemical transformations changing the molecular size of particle components in the quasi-static surface layer (e.g. addition or loss of functional groups, volatilization) will generally lead to the coverage of neighboring surface species or to the exposure of previously underlying near-surface bulk species. The overall process can be described by a pseudo-first-order "quasi-static surface transformation rate coefficient" $k_{\mathrm{ss}, \mathrm{rx}}$ calculated from the net production and effective cross section of all quasi-static surface species $\mathrm{Y}_{p}$ :

$k_{\mathrm{ss}, \mathrm{rx}}=\sum_{p}\left(P_{\mathrm{ss}, \mathrm{Y} p}-L_{\mathrm{ss}, \mathrm{Y} p}\right) \sigma_{\mathrm{Y} p}$

Negative values of $k_{\mathrm{s}, \mathrm{rx}}$ describe the exposure of nearsurface bulk species to the gas phase or sorption layer, which implies their transfer from the near-surface bulk to the quasistatic surface, $J_{\mathrm{ss}, \mathrm{b}, \mathrm{rx}, \mathrm{Y} j}$. Positive values of $k_{\mathrm{ss}, \mathrm{rx}}$, on the other hand, describe the coverage of surface species which implies their transfer from the quasi-static surface to the nearsurface particle bulk, $J_{\mathrm{b}, \mathrm{ss}, \mathrm{rx}, \mathrm{Y} j}$.

By multiplication of the surface transformation rate coefficient with the surface concentration $\left[\mathrm{Y}_{j}\right]_{\mathrm{ss}}$ or with the nearsurface bulk mole fraction and effective cross section of a non-volatile particle component $\mathrm{Y}_{j}$, respectively, the corresponding surface-bulk mass transport fluxes can be approximated as follows:

$$
\begin{aligned}
& J_{\mathrm{ss}, \mathrm{b}, \mathrm{rx}, \mathrm{Y} j}=\frac{k_{\mathrm{ss}, \mathrm{rx}}+\left|k_{\mathrm{ss}, \mathrm{rx}}\right|}{2}\left[\mathrm{Y}_{j}\right]_{\mathrm{ss}}=k_{\mathrm{ss}, \mathrm{b}, \mathrm{rx}, \mathrm{Y} j}\left[\mathrm{Y}_{j}\right]_{\mathrm{ss}} \\
& J_{\mathrm{b}, \mathrm{ss}, \mathrm{rx}, \mathrm{Y} j}=\frac{\left|k_{\mathrm{ss}, \mathrm{rx}}\right|-k_{\mathrm{ss}, \mathrm{rx}}}{2} \frac{\phi_{\mathrm{Y} j} / \sigma_{\mathrm{Y} j}}{\sum_{p} \phi_{\mathrm{Y} p} / \sigma_{\mathrm{Y} p}} \sigma_{\mathrm{Y} j}^{-1} \\
& =\frac{\left|k_{\mathrm{ss}, \mathrm{rx}}\right|-k_{\mathrm{ss}, \mathrm{rx}}}{2} \frac{1}{\sigma_{\mathrm{Y} j}^{2} \sum_{p}\left[\mathrm{Y}_{p}\right]_{\mathrm{bs}} \sum_{p} \phi_{\mathrm{Y} p} / \sigma_{\mathrm{Y} p}}\left[\mathrm{Y}_{j}\right]_{\mathrm{bs}} \\
& =k_{\mathrm{b}, \mathrm{ss}, \mathrm{rx}, \mathrm{Y} j}\left[\mathrm{Y}_{j}\right]_{\mathrm{bs}}
\end{aligned}
$$


In Eq. (59) $\phi_{\mathrm{Y} q}$ stands for the mole fraction of $\mathrm{Y}_{q}$ in the near-surface particle bulk. If mass or volume fraction are used instead, the number concentrations $\left[\mathrm{Y}_{p}\right]_{\mathrm{bs}}$ have to be scaled by molar mass or partial molar volume, respectively. $k_{\mathrm{b}, \mathrm{ss}, \mathrm{rx}, \mathrm{Y} j}$ and $k_{\mathrm{ss}, \mathrm{b}, \mathrm{rx}, \mathrm{Y} j}$ are the pseudo-first-order rate coefficients for reactive bulk-to-surface and surface-to-bulk transfer of $\mathrm{Y}_{j}$, respectively.

\section{b) Mutual exchange}

In analogy to the surface-bulk mass transport of volatile species, we assume that the mass transport fluxes of non-volatile particle components $\mathrm{Y}_{j}$ exhibit a first-order dependence on their surface and near-surface bulk concentrations, respectively:

$\begin{aligned} J_{\mathrm{ss}, \mathrm{b}, \mathrm{ex}, \mathrm{Y} j} & =k_{\mathrm{ss}, \mathrm{b}, \mathrm{ex}, \mathrm{Y} j}\left[\mathrm{Y}_{j}\right]_{\mathrm{ss}} \\ J_{\mathrm{b}, \mathrm{ss}, \mathrm{ex}, \mathrm{Y} j} & =k_{\mathrm{b}, \mathrm{ss}, \mathrm{ex}, \mathrm{Y} j}\left[\mathrm{Y}_{j}\right]_{\mathrm{bs}}\end{aligned}$

Again, the transfer rate coefficients can be expected to increase with increasing dynamic variability of the quasi-static surface and with decreasing viscosity of the near-surface particle bulk. Linear dependences on surface and near-surface bulk composition could be accounted for by linear combination of the inverse rate coefficients for pure substrates.

In contrast to the mass transport of volatile species between bulk and sorption layer, however, the mutual exchange of non-volatile species between quasi-static surface layer and near-surface particle bulk has to be balanced at all times because $\sum_{q} \theta_{\mathrm{ss}, \mathrm{Y} q}=1$ by definition, i.e. the quasi-static surface has to be a monomolecular layer (Sect. 3.1, Eq. 36).

Since precise values for the transfer rate coefficients of all species present in real aerosol particles will hardly ever be available, practical application of Eqs. (60) and (61) for a comprehensive description of surface-bulk exchange will require a self-consistent normalisation formalism. The normalisation could be achieved in analogy to Eqs. (58) and (59) using an overall exchange rate coefficient instead of the transformation rate coefficient. The magnitude of such an overall exchange rate coefficient or of individual exchange rate coefficients for different species and different types of particles could be estimated based on diffusion coefficients and kinetic theory of condensed phases. A detailed discussion of this issue, however, is beyond the scope of this framework paper.

\section{c) Overall transfer fluxes}

Combining the above equations describing the two different transfer mechanisms, the overall transfer fluxes of non-volatile species $\mathrm{Y}_{j}$ between the quasi-static surface layer and the near-surface particle bulk, $J_{\mathrm{ss}, \mathrm{b}, \mathrm{Y} j}$ and $J_{\mathrm{b}, \mathrm{ss}, \mathrm{Y}} j$ can be expressed as

$J_{\mathrm{ss}, \mathrm{b}, \mathrm{Y} j}=J_{\mathrm{ss}, \mathrm{b}, \mathrm{rx}, \mathrm{Y} j}+J_{\mathrm{ss}, \mathrm{b}, \mathrm{ex}, \mathrm{Y} j}=k_{\mathrm{ss}, \mathrm{b}, \mathrm{Y} j}\left[\mathrm{Y}_{j}\right]_{\mathrm{ss}}$
$J_{\mathrm{b}, \mathrm{ss}, \mathrm{Y}}{ }_{j}=J_{\mathrm{b}, \mathrm{ss}, \mathrm{rx}, \mathrm{Y} j}+J_{\mathrm{b}, \mathrm{ss}, \mathrm{ex}, \mathrm{Y} j}=k_{\mathrm{b}, \mathrm{ss}, \mathrm{Y} j}\left[\mathrm{Y}_{j}\right]_{\mathrm{bs}}$

With pseudo-first-order transfer rate coefficients

$k_{\mathrm{ss}, \mathrm{b}, \mathrm{Y} j}=k_{\mathrm{ss}, \mathrm{b}, \mathrm{rx}, \mathrm{Y} j}+k_{\mathrm{ss}, \mathrm{b}, \mathrm{ex}, \mathrm{Y} j}$

and

$k_{\mathrm{b}, \mathrm{ss}, \mathrm{Y} j}=k_{\mathrm{b}, \mathrm{ss}, \mathrm{rx}, \mathrm{Y} j}+k_{\mathrm{b}, \mathrm{ss}, \mathrm{ex}, \mathrm{Y} j}$

\subsection{Bulk reactivity and solubility}

As outlined in Sects. 3.1-3.4 the concentrations of $X_{i}$ and $\mathrm{Y}_{j}$ in the near-surface particle bulk, $\left[\mathrm{X}_{i}\right]_{\mathrm{bs}}$ and $\left[\mathrm{Y}_{j}\right]_{\mathrm{bs}}$, can influence the interaction between gas and surface molecules and can be changed by surface-bulk mass transport and reactions. On the other hand, the composition of the near-surface particle bulk is influenced by transport, solubility, and chemical reaction in the particle bulk, which will generally change over time (solubility saturation, depletion of reaction partners and change of diffusion coefficients due to chemical aging).

A detailed discussion of physicochemical processes within the particle bulk is beyond the scope of this paper, which is focused on aerosol surface chemistry. Here we just include a couple of special cases which are also considered in traditional resistor model formulations.

\subsubsection{Chemical reaction}

Under steady-state conditions and if surface-bulk reactions are negligible, the net mass transport flux of $\mathrm{X}_{i}$ from the surface to the near-surface particle bulk, $J_{\mathrm{s}, \mathrm{b}, \text { net, } \mathrm{X} i}$, can be matched with the so-called reacto-diffusive flux of $\mathrm{X}_{i}$ in the particle bulk, $J_{\mathrm{b}, \mathrm{rd}, \mathrm{X} i}$ :

$J_{\mathrm{s}, \mathrm{b}, \mathrm{net}, \mathrm{X} i}=J_{\mathrm{s}, \mathrm{b}, \mathrm{X} i}-J_{\mathrm{b}, \mathrm{s}, \mathrm{X} i}=J_{\mathrm{b}, \mathrm{rd}, \mathrm{X} i}$

$J_{\mathrm{b}, \mathrm{rd}, \mathrm{X} i}$ is the flux of $\mathrm{X}_{i}$ from the near-surface particle bulk towards the particle core which is driven by the consumption of $\mathrm{X}_{i}$ through chemical reaction. Assuming spherical geometry, a uniform pseudo-first-order loss rate coefficient $k_{\mathrm{b}, \mathrm{X} i}$, and a uniform diffusion coefficient $D_{\mathrm{b}, \mathrm{X} i}$ of $\mathrm{X}_{i}$ in the particle bulk, the reacto-diffusive flux can be expressed as (Hanson, 1997):

$J_{\mathrm{b}, \mathrm{rd}, \mathrm{X} i}=C_{\mathrm{b}, \mathrm{rd}, \mathrm{X} i} \sqrt{k_{\mathrm{b}, \mathrm{X} i} D_{\mathrm{b}, \mathrm{X} i}}\left[\mathrm{X}_{i}\right]_{\mathrm{bs}}$

$C_{\mathrm{b}, \mathrm{rd}, \mathrm{X} i}$ is the reacto-diffusive geometry correction factor (conversion from planar to spherical geometry) which is determined by the particle radius, $r_{p}$, and the so called reactodiffusive length for species $\mathrm{X}_{i}, l_{\mathrm{rd}, \mathrm{X} i}=\left(D_{\mathrm{b}, \mathrm{X} i} / k_{\mathrm{b}, \mathrm{X} i}\right)^{1 / 2}$ :

$C_{\mathrm{b}, \mathrm{rd}, \mathrm{X} i}=\operatorname{coth}\left(\frac{r_{\mathrm{p}}}{l_{\mathrm{rd}, \mathrm{X} i}}\right)-\frac{l_{\mathrm{rd}, \mathrm{X} i}}{r_{\mathrm{p}}}$

According to Eqs. (66), (67), (55), and (56) the concentration ratio $\left[\mathrm{X}_{i}\right]_{\mathrm{bs}} /\left[\mathrm{X}_{i}\right]_{\mathrm{S}}$ under steady-state conditions is given by

$\frac{\left[\mathrm{X}_{i}\right]_{\mathrm{bs}}}{\left[\mathrm{X}_{i}\right]_{\mathrm{s}}}=\frac{k_{\mathrm{s}, \mathrm{b}, \mathrm{X} i}}{k_{\mathrm{b}, \mathrm{s}, \mathrm{X} i}+C_{\mathrm{b}, \mathrm{rd}, \mathrm{X} i} \sqrt{k_{\mathrm{b}, \mathrm{X} i} D_{\mathrm{b}, \mathrm{X} i}}}$ 
and the net flux of surface-to-bulk mass transport can be expressed as a function of $\left[\mathrm{X}_{i}\right]_{\mathrm{S}}$ and a pseudo-first-order transfer rate coefficient $k_{\mathrm{s}, \mathrm{b}, \text { net }, \mathrm{X} i}$ :

$$
J_{\mathrm{s}, \mathrm{b}, \mathrm{net}, \mathrm{X} i}=k_{\mathrm{s}, \mathrm{b}, \mathrm{net}, \mathrm{X} i}\left[\mathrm{X}_{i}\right]_{\mathrm{s}}
$$

$$
\begin{aligned}
k_{\mathrm{s}, \mathrm{b}, \mathrm{net}, \mathrm{X} i} & =\frac{k_{\mathrm{s}, \mathrm{b}, \mathrm{X} i} C_{\mathrm{b}, \mathrm{rd}, \mathrm{X} i} \sqrt{k_{\mathrm{b}, \mathrm{X} i} D_{\mathrm{b}, \mathrm{X} i}}}{k_{\mathrm{b}, \mathrm{s}, \mathrm{X} i}+C_{\mathrm{b}, \mathrm{rd}, \mathrm{X} i} \sqrt{k_{\mathrm{b}, \mathrm{X} i} D_{\mathrm{b}, \mathrm{X} i}}} \\
& =k_{\mathrm{s}, \mathrm{b}, \mathrm{X} i}\left(1+\frac{k_{\mathrm{b}, \mathrm{SX} i}}{C_{\mathrm{b}, \mathrm{rd}, \mathrm{X} i} \sqrt{k_{\mathrm{b}, \mathrm{X} i} D_{\mathrm{b}, \mathrm{X} i}}}\right)^{-1}
\end{aligned}
$$

Formalisms for the description of reactive transformation of the particle bulk composition by diffusion and chemical reaction as a function of gas-particle interaction time have been presented and applied in recent studies (Worsnop et al., 2002; Smith et al., 2002, 2003). Again, a detailed discussion of such processes is beyond the scope of this paper, but it should be possible to flexibly include such formalisms in the model framework presented here. In fact, it is certainly more straightforward to include additional processes in the flux-based kinetic model framework presented here than in the traditional resistor model.

\subsubsection{Dissolution}

Under mass transport equilibrium conditions (negligible chemical loss and production) the rate coefficients of gassurface and surface-bulk transport can be combined to obtain the solubility or gas-particle partitioning coefficient, $K_{\mathrm{sol}, \mathrm{cp}, \mathrm{X} i}$, which describes the partitioning of a volatile species between gas phase and condensed phase (particle bulk). At infinite dilution, i.e. for ideal or at least highly dilute solutions, $K_{\mathrm{sol}, \mathrm{cp}, \mathrm{X} i}$ equals the Henry's law coefficient for $\mathrm{X}_{i}$ in the investigated condensed phase, $H_{\mathrm{cp}, \mathrm{X} i}$. Solubilities or Henry's law coefficients are mostly reported as amount-of-substance concentrations in the condensed phase per unit partial pressure in the gas phase (index "cp"; Sander, 1999). By multiplication with the gas constant and temperature, they can be converted into dimensionless ratios of condensed phase and gas phase concentrations (index "cc"; Sander, 1999):

$K_{\mathrm{sol}, \mathrm{cc}, \mathrm{X} i}=K_{\mathrm{sol}, \mathrm{cp}, \mathrm{X} i} R T=\left[\mathrm{X}_{i}\right]_{\mathrm{b}, \mathrm{sat}} /\left[\mathrm{X}_{i}\right]_{\mathrm{g}, \mathrm{sat}}$

$\left[\mathrm{X}_{i}\right]_{\mathrm{b} \text {,sat }}$ and $\left[\mathrm{X}_{i}\right]_{\mathrm{g}, \text { sat }}$ are the equilibrium or solubility saturation number concentrations of $\mathrm{X}_{i}$ in the condensed phase (particle bulk) and in the gas phase, respectively. Mass balance implies that $k_{\mathrm{s}, \mathrm{b}, \mathrm{X} i}\left[\mathrm{X}_{i}\right]_{\mathrm{s}, \mathrm{sat}}=k_{\mathrm{b}, \mathrm{s}, \mathrm{X} i}\left[\mathrm{X}_{i}\right]_{\mathrm{b} \text {, sat }}$ and $k_{\mathrm{d}, \mathrm{X} i}\left[\mathrm{X}_{i}\right]_{\mathrm{s}, \mathrm{sat}}=k_{\mathrm{a}, \mathrm{X} i}\left[\mathrm{X}_{i}\right]_{\mathrm{g}, \mathrm{sat}}$, which leads to

$$
K_{\mathrm{sol}, \mathrm{cc}, \mathrm{X} i}=\frac{k_{\mathrm{s}, \mathrm{b}, \mathrm{X} i}}{k_{\mathrm{b}, \mathrm{s}, \mathrm{X} i}} \frac{k_{\mathrm{a}, \mathrm{X} i}}{k_{\mathrm{d}, \mathrm{X} i}}=\frac{k_{\mathrm{s}, \mathrm{b}, \mathrm{X} i}}{k_{\mathrm{b}, \mathrm{s}, \mathrm{X} i}} \frac{\alpha_{\mathrm{s}, \mathrm{X} i} \omega_{\mathrm{X} i}}{4 k_{\mathrm{d}, \mathrm{X} i}}
$$

Equation (73) is equivalent to an expression previously derived by Hanson (1997), who also pointed out that the fractional surface coverage has to be taken into account in case of
Langmuir-type adsorption with significant surface coverage but did not explicitly follow up on the implications. The direct proportionality between $K_{\mathrm{sol}, \mathrm{cc}, \mathrm{X} i}$ and $\alpha_{\mathrm{s}, \mathrm{X} i}$, however, implies a gas phase composition dependence of the solubility, because $\alpha_{\mathrm{s}, \mathrm{X} i}$ decreases with increasing surface and gas phase concentration of all competitively co-adsorbing species. A comparable treatment of the equilibrium between gas, interface and bulk has also been presented by Donaldson (1999). This effect limits the applicability of solubilities or Henry's law coefficients determined for highly dilute solutions $\left(\left[\mathrm{X}_{i}\right]_{\mathrm{b}} \approx 0, \theta_{\mathrm{S}} \approx 0, \alpha_{\mathrm{s}, \mathrm{X} i} \approx \alpha_{\mathrm{s}, 0, \mathrm{X} i}, K_{\mathrm{sol}, \mathrm{cc}, \mathrm{X} i} \approx H_{\mathrm{cc}, \mathrm{X} i}\right)$. Surface saturation effects are expected to be important at elevated concentration levels and for viscous liquids with slow surface-bulk mass transport (e.g. liquid organic droplets or particle coatings; Marcolli et al., 2004). They may also affect aqueous droplets contaminated with organic surfactants (Djikaev and Tabazadeh, 2003; Shunthirasingham et al., 2007). For such systems $K_{\mathrm{sol}, \mathrm{cc}, \mathrm{X} i}$ and $K_{\mathrm{sol}, \mathrm{cp}, \mathrm{X} i}$, respectively, have to be deconvoluted into the underlying gassurface and surface-bulk exchange rate coefficients in order to allow reliable application and extrapolation of solubilities or Henry's law coefficients to varying conditions in the atmosphere or in laboratory experiments. Exemplary calculations of $K_{\mathrm{sol}, \mathrm{cc}, \mathrm{X} i}$ as a function of $\left[\mathrm{X}_{i}\right]_{\mathrm{g}}, \alpha_{\mathrm{s}, 0, \mathrm{X} i}, k_{\mathrm{d}, \mathrm{X} i}, k_{\mathrm{s}, \mathrm{b}, \mathrm{X} i}$, and $k_{\mathrm{b}, \mathrm{s}, \mathrm{X} i}$ as well as the time dependence of solubility-driven, non-reactive gas uptake into liquids are illustrated in a companion paper (Ammann and Pöschl, 2007). Note that the concentration dependence following from the kinetic model of gas-particle partitioning is consistent with the thermodynamic approach of correcting Henry's law (limiting case for dilute solutions) by activity coefficients for concentrated solutions.

\subsection{Overall gas uptake}

Based on Eqs. (15) and (29) the overall flux of net uptake of a volatile species $\mathrm{X}_{i}$ by the condensed phase can be described by

$$
J_{\mathrm{net}, \mathrm{X} i}=J_{\mathrm{ads}, \mathrm{X} i}-J_{\mathrm{des}, \mathrm{X} i}+L_{\mathrm{g}, \mathrm{gsr}, \mathrm{X} i}-P_{\mathrm{g}, \mathrm{gsr}, \mathrm{X} i}
$$

with

$$
\begin{gathered}
J_{\mathrm{ads}, \mathrm{X} i}-J_{\mathrm{des}, \mathrm{X} i}=d\left[\mathrm{X}_{i}\right]_{\mathrm{s}} / \mathrm{d} t-\left(P_{\mathrm{s}, \mathrm{X} i}-L_{\mathrm{s}, \mathrm{X} i}\right) \\
-\left(J_{\mathrm{b}, \mathrm{s}, \mathrm{X} i}-J_{\mathrm{s}, \mathrm{b}, \mathrm{X} i}\right)
\end{gathered}
$$

Accordingly, the uptake coefficient can be expressed as

$\gamma_{\mathrm{X} i}=\gamma_{\mathrm{sor}, \mathrm{X} i}+\gamma_{\mathrm{gsr}, \mathrm{X} i}$

with

$$
\begin{aligned}
& \gamma_{\mathrm{sor}, \mathrm{X} i}=\frac{J_{\mathrm{ads}, \mathrm{X} i}-J_{\mathrm{des}, \mathrm{X} i}}{J_{\mathrm{coll}, \mathrm{X} i}} \\
& \gamma_{\mathrm{gsr}, \mathrm{Xi}}=\frac{L_{\mathrm{g}, \mathrm{gsr}, \mathrm{Xi}}-P_{\mathrm{g}, \mathrm{gsr}, \mathrm{X} i}}{J_{\mathrm{coll}, \mathrm{Xi}}}
\end{aligned}
$$




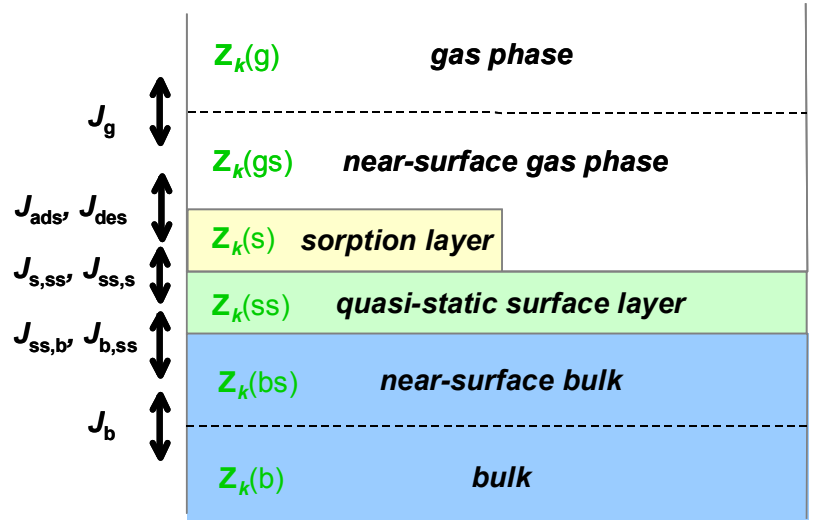

Fig. 4. Double-layer surface model compartments and transport fluxes for semivolatile species $Z_{k}$.

The "sorption uptake coefficient", $\gamma_{\mathrm{sor}, \mathrm{X} i}$, and the "gassurface reaction uptake coefficient", $\gamma_{\mathrm{gsr}, \mathrm{X} i}$, are limited to $\gamma_{\mathrm{sor}, \mathrm{X} i} \leq \alpha_{\mathrm{s}, \mathrm{X} i} \leq 1, \gamma_{\mathrm{gsr}, \mathrm{X} i} \leq 1$, and $\gamma_{\mathrm{sor}, \mathrm{X} i}+\gamma_{\mathrm{gsr}, \mathrm{X} i} \leq 1$, respectively. For values $\geq 0$, these uptake coefficients can be regarded as the probabilities that a collision of $\mathrm{X}_{i}$ with the surface leads to net uptake of $\mathrm{X}_{i}$ by adsorption (surface accommodation) and subsequent accumulation or reactive consumption at the surface or in the bulk of the particle $\left(\gamma_{\mathrm{sor}, \mathrm{X} i}\right)$, or by elementary gas-surface reactions $\left(\gamma_{\mathrm{gsr}, \mathrm{X} i}\right)$, respectively. Neither $\gamma_{\mathrm{sor}, \mathrm{X} i}$ nor $\gamma_{\mathrm{gsr}, \mathrm{X} i}$, however, describe the probability for individual gas molecules $\mathrm{X}_{i}$ colliding with the surface to be taken up by or react with the condensed phase. In fact, $\gamma_{\mathrm{sor}, \mathrm{X} i}$ and $\gamma_{\mathrm{gsr}, \mathrm{X} i}$ can assume negative values if the particle acts as a source of $\mathrm{X}_{i}$ $\left(J_{\mathrm{des}, \mathrm{X} i}+P_{\mathrm{g}, \mathrm{gsr}, \mathrm{X} i}>J_{\mathrm{ads}, \mathrm{X} i}+L_{\mathrm{g}, \mathrm{gsr}, \mathrm{X} i}\right)$, while at the same time the probability for an individual molecule colliding with the surface to be lost from the gas phase may still be larger than zero.

The probabilities for individual gas molecules colliding with the surface to be adsorbed or react at the surface are given by the following terms: $\alpha_{\mathrm{s}, \mathrm{X} i}$ for adsorption (surface accommodation), $L_{\mathrm{g}, \mathrm{gsr}, \mathrm{X} i} / J_{\text {coll, } \mathrm{X} i}$ for elementary gas surface reactions, and $\left(\alpha_{\mathrm{s}, \mathrm{X} i} L_{\mathrm{s}, \mathrm{X} i}\right) /\left(L_{\mathrm{s}, \mathrm{X} i}+J_{\mathrm{des}, \mathrm{X} i}+J_{\mathrm{s}, \mathrm{b}, \mathrm{X} i}\right)$ for adsorption and subsequent surface layer reaction. The probability for a gas molecule colliding with the surface to enter the bulk of the particle is given by:

$\alpha_{\mathrm{b}, \mathrm{X} i}=\alpha_{\mathrm{s}, \mathrm{X} i} \frac{J_{\mathrm{s}, \mathrm{b}, \mathrm{X} i}}{J_{\mathrm{s}, \mathrm{b}, \mathrm{X} i}+J_{\mathrm{des}, \mathrm{X} i}+L_{\mathrm{s}, \mathrm{X} i}}$

In the atmospheric chemistry literature, the probability for a gas molecule colliding with the surface to enter the bulk of the particle has usually been designated as the "mass accommodation coefficient" with the symbol $\alpha_{\mathrm{X} i}$, but we propose to use the term "bulk accommodation coefficient" and symbol $\alpha_{\mathrm{b}, \mathrm{X} i}$ instead. The proposed terminology shall help to avoid confusing the overall process of mass transport across the gas-particle interface, i.e. from the (near-surface) gas

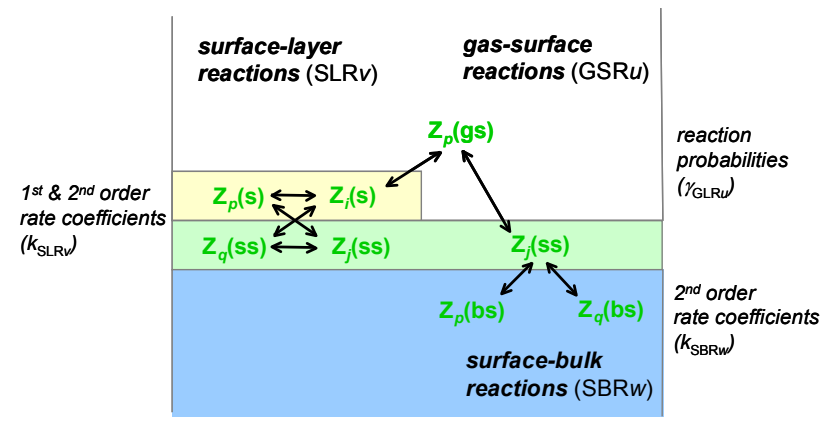

Fig. 5. Classification of chemical reactions between semivolatile species at the surface.

phase onto the particle surface and further into the (nearsurface) particle bulk ("bulk accommodation" characterised by $\alpha_{\mathrm{b}, \mathrm{X} i}$ ), with its first (quasi-)elementary step ("surface accommodation" characterised by $\alpha_{\mathrm{s}, \mathrm{X} i}$ ). This distinction is particularly important for the understanding of heterogeneous chemical reactions and surface saturation effects as detailed below. Especially for the treatment of processes at ice surfaces, these definitions have not been used in a consistent way (e.g., Huthwelker et al., 2006; and references therein). Note that $\alpha_{\mathrm{s}, \mathrm{X} i}$ is the maximum value for $\alpha_{\mathrm{b}, \mathrm{X} i}$ as well as for $\gamma_{\mathrm{sor}, \mathrm{X} i}$ but not for $\gamma_{\mathrm{X} i}$ and $\gamma_{\mathrm{gsr}, \mathrm{X} i}$, which can exceed $\alpha_{\mathrm{s}, \mathrm{X} i}$ in case of significant gas-surface reactions.

In the final version of this paper we have chosen the symbols $\alpha_{\mathrm{s}, \mathrm{X} i}$ and $\alpha_{\mathrm{b}, \mathrm{X} i}$ for surface and bulk accommodation coefficients, respectively, in order to maximize the selfconsistency of terminology (greek letters for all quantities normalized by the gas kinetic flux) and to minimize the potential for confusion with related but differently defined quantities in surface science (sticking vs. trapping probabilities; Sect. 3.2).

Note, however, that we had used the alternative symbols $S_{\mathrm{X} i}$ and $\alpha_{\mathrm{X} i}$ in the preceding discussion paper (Pöschl et al., 2005a) to emphasize the compatibility with earlier surface reaction studies in atmospheric science (e.g. Hanson, 1997; Worsnop, 2002; Ammann et al., 2003; Reid and Sayer, 2003; Rudich, 2003; Huthwelker et al., 2006; and references therein). For convenience and ease of comparison, both variants are included in the list of symbols (Appendix A).

The development of the model framework presented here has been targeted primarily at the description of aerosol surface chemistry. Nevertheless Eqs. (74) to (79) are equally applicable to systems where the rate of gas uptake is dominated by particle bulk processes (e.g. liquid droplets with reactive bulk components and highly dynamic surfaces). In such cases, the above relations simplify to $\gamma_{\mathrm{X} i} \approx \gamma_{\mathrm{sor}, \mathrm{X} i} \approx\left(J_{\mathrm{s}, \mathrm{b}, \mathrm{X} i}-J_{\mathrm{b}, \mathrm{s}, \mathrm{X} i}\right) / J_{\mathrm{coll}, \mathrm{X} i}$ and $\alpha_{\mathrm{b}, \mathrm{X} i} \approx \alpha_{\mathrm{s}, \mathrm{X} i}$ as discussed below and illustrated with exemplary model calculations in a companion paper (Ammann and Pöschl, 2007). 


\subsection{Semivolatile species and condensation/evaporation}

Semivolatile chemical species, $Z_{k}$, could be described and flexibly included in the double-layer model framework outlined above with the following relations:

$$
\mathrm{Z}_{k}(\mathrm{gs}) \underset{J_{\mathrm{des}, \mathrm{Z} k}}{\stackrel{J_{\mathrm{ads}, \mathrm{Z} k}}{\longrightarrow}} \mathrm{Z}_{k}(\mathrm{~s}) \underset{J_{\mathrm{ss}, \mathrm{s}, \mathrm{Z} k}}{\stackrel{J_{\mathrm{s}, \mathrm{ss}, \mathrm{Z} k}}{\longrightarrow}} \mathrm{Z}_{k}(\mathrm{ss}) \underset{J_{\mathrm{b}, \mathrm{ss}, \mathrm{Z} k}}{\stackrel{J_{\mathrm{ss}, \mathrm{b}, \mathrm{Z} k}}{\longrightarrow}} \mathrm{Z}_{k}(\mathrm{bs})
$$

$$
\begin{aligned}
\mathrm{d}\left[Z_{k}\right]_{\mathrm{s}} / \mathrm{d} t & =J_{\mathrm{ads}, \mathrm{Z} k}-J_{\mathrm{des}, \mathrm{Z} k}+P_{\mathrm{s}, \mathrm{Z} k}-L_{\mathrm{s}, \mathrm{Z} k} \\
& +J_{\mathrm{ss}, \mathrm{s}, \mathrm{Z} k}-J_{\mathrm{s}, \mathrm{ss}, \mathrm{Z} k}
\end{aligned}
$$

$$
\begin{aligned}
\mathrm{d}\left[Z_{k}\right]_{\mathrm{ss}} / \mathrm{d} t & =J_{\mathrm{s}, \mathrm{ss}, \mathrm{Z} k}-J_{\mathrm{ss}, \mathrm{s}, \mathrm{Z} k}+P_{\mathrm{ss}, \mathrm{Z} k}-L_{\mathrm{ss}, \mathrm{Z} k} \\
& +J_{\mathrm{b}, \mathrm{ss}, \mathrm{Z} k}-J_{\mathrm{ss}, \mathrm{b}, \mathrm{Z} k}
\end{aligned}
$$

$\left[\mathrm{Z}_{k}\right]_{\mathrm{s}}$ and $\left[\mathrm{Z}_{k}\right]_{\mathrm{ss}}$ are the concentrations of $\mathrm{Z}_{k}$ in the sorption layer and quasi-static surface layer, respectively (number per unit area). $J_{\mathrm{ss}, \mathrm{s}, \mathrm{Z} k}$ and $J_{\mathrm{s}, \mathrm{ss}, \mathrm{Z} k}$ are the flux densities of mass transport from the quasi-static surface layer to the sorption layer and vice versa (number per unit area and unit time). All other flux densities on the right hand side of Eqs. (81) and (82) are analogous to those described above for volatile and non-volatile species. The relevant processes are illustrated in Figs. 4 (transport) and 5 (chemical reaction).

Equations (80)-(82) should allow to describe also multilayer adsorption (Vinokurov and Kankare, 2002) and bulk condensation or evaporation within the presented kinetic model framework. In the sorption layer, $\mathrm{Z}_{k}$ would competitively inhibit the adsorption of other semivolatile or volatile species as described for $X_{i}$ in Sect. 3.2. In the quasi-static surface layer, on the other hand, $\mathrm{Z}_{k}$ would provide sorption sites (area) for gas molecules. The extent to which a semivolatile species at the particle surface acts as an adsorbate species or as a quasi-static surface component, i.e. its effective volatility and gas-particle partitioning, could be described by the ratio of the rate parameters governing the reversible transfer of $Z_{k}$ between the two surface layers. Transfer from the quasi-static surface layer to the sorption layer is a (formal) kinetic step which can be pictured as a thermal activation process transforming a quasi-static surface component (with relatively low potential energy) into an adsorbate species (with relatively high potential energy) which can either desorb into the gas phase or return to the quasi-static surface (thermal deactivation).

In principle, all species of aerosol and cloud systems could be treated as semivolatile species $\mathrm{Z}_{k}$, the distinction between volatile species $\mathrm{X}_{i}$ and non-volatile species $\mathrm{Y}_{j}$ could be abandoned, and formalisms for the calculation of the flux terms on the right hand side of Eqs. (81) and (82) could be developed in analogy to the formalisms for volatile and non-volatile species presented above. $J_{\mathrm{ss}, \mathrm{s}, \mathrm{Z} k}$ and $J_{\mathrm{s}, \mathrm{ss}, \mathrm{Z} k}$ could be described in a similar way as $J_{\mathrm{b}, \mathrm{ss}, \mathrm{Y} j}$ and $J_{\mathrm{ss}, \mathrm{b}, \mathrm{Y} j}$ (Sect. 3.4.2). A detailed description of semivolatile species, multilayer adsorption, and bulk condensation or evaporation is, however, beyond the scope of this manuscript.

For particles consisting of a semivolatile main component at steady-state (e.g. $\mathrm{H}_{2} \mathrm{O}$ in liquid or solid cloud particles), the effects of continuous surface regeneration by condensation and evaporation of the semivolatile main component can be convoluted into the effective rate parameters describing the mass transport of volatile trace species across the gasparticle interface, and the semivolatile main particle component can be regarded as quasi-non-volatile. In fact, this is an implicit assumption of the traditional resistor model for the interaction of reactive trace gases with cloud droplets.

\section{Model application and special cases}

\subsection{Composition and time dependence}

The flux formalism and rate equations presented above allow to describe mass transport, chemical reaction and changing chemical composition in aerosol and cloud systems with multiple chemical species and competitive processes under transient conditions. For such systems the surface mass balance equations given in Sect. 3.1 lead to a set of coupled differential equations. These can be solved numerically by inserting the rate equations given in Sects. 3.2-3.5 or alternative/complementary mathematical descriptions of the involved physicochemical processes, provided that the initial concentrations and relevant mass transport and reaction rate coefficients are known or can be reasonably estimated. Exemplary practical applications and model calculations will be presented in a companion paper (Ammann and Pöschl, 2007).

In the rate equations of Sect. 3 gas phase diffusion effects are implicitly taken into account by considering gas phase concentrations close to the surface, $\left[\mathrm{X}_{i}\right]_{\mathrm{gs}}$, rather than average gas phase concentrations, $\left[\mathrm{X}_{i}\right]_{\mathrm{g}}$. As outlined in Sect. 2, $\left[\mathrm{X}_{i}\right]_{\mathrm{gs}}$ can be calculated by multiplication of $\left[\mathrm{X}_{i}\right]_{\mathrm{g}}$ with the gas phase diffusion correction factor $C_{\mathrm{g}, \mathrm{X} i}$ which is determined by the uptake coefficient $\gamma_{\mathrm{X} i}$ and the Knudsen number $K n_{\mathrm{X} i}$.

For consistent analysis and interpretation of kinetic measurement data of aerosol and cloud surface chemistry and gas-particle interactions, and for their application and extrapolation in atmospheric models, it is important to recognize the (potential) dependence of rate parameters on the composition of the investigated system. In this respect, the rate parameters introduced in the presented model framework (above and in the following sections) can be classified as follows:

1. Rate parameters which can be influenced by the gas phase, double-layer surface, and particle bulk composition of the investigated aerosol (alphabetical order): $\alpha_{\mathrm{b}, \mathrm{X} i}, \alpha_{\mathrm{s}, \mathrm{X} i}, \quad \gamma_{\mathrm{X} i}, \quad \gamma_{\mathrm{eff}, \mathrm{X} i}, \gamma_{\mathrm{gsr}, \mathrm{X} i}$, $\gamma_{\mathrm{sor}, \mathrm{X} i}, \quad \Gamma_{\mathrm{b}, \mathrm{X} i}, \quad \Gamma_{\mathrm{g}, \mathrm{X} i}, \quad \Gamma_{\mathrm{s}, \mathrm{X} i}, \quad \Gamma_{\mathrm{s}, \mathrm{b}, \mathrm{X} i}, \quad C_{\mathrm{g}, \mathrm{X} i}, \quad k_{\mathrm{a}, \mathrm{X} i}$, 
$k_{\mathrm{b}, \mathrm{ss}, \mathrm{rx}, \mathrm{Y}} j, k_{\mathrm{b}, \mathrm{ss}, \mathrm{Y} j}, k_{\mathrm{g}, \mathrm{p}, \mathrm{X} i}, k_{\mathrm{ss}, \mathrm{rx}}, k_{\mathrm{ss}, \mathrm{b}, \mathrm{rx}, \mathrm{Y} j}, k_{\mathrm{ss}, \mathrm{b}, \mathrm{Y} j}$, $k_{\mathrm{s}, \mathrm{X} i}, k_{\mathrm{s}, \mathrm{g}, \mathrm{X} i}, k_{\mathrm{s}, \mathrm{s}, \mathrm{X} i}, k_{\mathrm{ss}, \mathrm{Y} j}, k_{\mathrm{ss}, \mathrm{g}, \mathrm{Y} j}, k_{\mathrm{ss}, \mathrm{s}, \mathrm{Y} j}, K_{\mathrm{ads}, \mathrm{X} i}^{\prime}$, $K_{\mathrm{sol}, \mathrm{cc}, \mathrm{X} i}, K_{\mathrm{sol}, \mathrm{cp}, \mathrm{X} i}$

2. Rate parameters which are assumed to be independent of gas phase and sorption layer composition but can be influenced by the quasi-static surface layer and nearsurface particle bulk composition: $\alpha_{\mathrm{s}, 0, \mathrm{X} i}, \gamma_{\mathrm{GSR} u, \mathrm{X} i, \mathrm{X} p}$, $\gamma_{\mathrm{GSR} u, \mathrm{X} i, \mathrm{Y} q}, \quad \tau_{\mathrm{d}, \mathrm{X} i}, \quad \tau_{\mathrm{s}, \mathrm{b}, \mathrm{X} i}, \quad H_{\mathrm{cc}, \mathrm{X} i}, \quad H_{\mathrm{cp}, \mathrm{X} i}, k_{\mathrm{a}, 0, \mathrm{X} i}$, $k_{\mathrm{d}, \mathrm{X} i}, k_{\mathrm{b}, \mathrm{s}, \mathrm{X} i}, k_{\mathrm{b}, \mathrm{ss}, \mathrm{ex}, \mathrm{Y} j}, k_{\mathrm{s}, \mathrm{b}, \mathrm{X} i}, k_{\mathrm{s}, \mathrm{b}, \mathrm{net}, \mathrm{X} i}, k_{\mathrm{ss}, \mathrm{b}, \mathrm{ex}, \mathrm{Y} j}$, $k_{\mathrm{s}, \mathrm{ss}, \mathrm{X} i}, k_{\mathrm{Ss}, \mathrm{ss}, \mathrm{Y} j}, k_{\mathrm{SLR} v, \mathrm{X} p}, \quad k_{\mathrm{SLR} v, \mathrm{Y} p}, \quad k_{\mathrm{SLR} v, \mathrm{X} p, \mathrm{X} q}$, $k_{\mathrm{SLR} v, \mathrm{X} p, \mathrm{Y} q}, k_{\mathrm{SLR} v, \mathrm{Y} p, \mathrm{Y} q}, k_{\mathrm{SBR} w, \mathrm{Y} p, \mathrm{X} r}, k_{\mathrm{SBR} w, \mathrm{Y} p, \mathrm{Y} q}$, $K_{\text {ads, }, i}$.

3. Rate parameters which are assumed to be independent of double-layer surface composition but depend on gas phase or particle bulk composition, respectively: $C_{\mathrm{b}, \mathrm{rd}, \mathrm{X} i}, D_{\mathrm{b}, \mathrm{X} i}, D_{\mathrm{g}, \mathrm{X} i}, k_{\mathrm{b}, \mathrm{X} i}, l_{\mathrm{rd}, \mathrm{X} i}$.

Characteristic composition dependences, in particular the effects of varying gas phase concentrations, are illustrated in a companion paper (Ammann and Pöschl, 2007).

In transient systems, composition-dependent rate parameters are likely to exhibit pronounced time dependences, which may vary with the chemical nature and physical state of the aerosol and its components. Exemplary temporal evolutions of aerosol surface composition and rate parameters are illustrated in a companion paper (Ammann and Pöschl, 2007).

\subsection{Temperature dependence and heat transfer}

Of course the rate parameters of mass transport and chemical reaction introduced above will exhibit more or less pronounced temperature dependences, which can be described by appropriate mathematical formalisms like Arrhenius equations. This approach has already been introduced and applied for the description of selected adsorption and reaction processes in stratospheric aerosols at different temperatures (Elliott et al., 1991; Tabazadeh and Turco, 1993; Mozurkevich, 1993; Carslaw and Peter, unpublished manuscript, 1997), and for specific systems the required thermochemical data are available in the scientific literature of physical chemistry and chemical engineering (e.g. Masel, 1996; and references therein). For detailed and reliable models of atmospheric aerosol chemistry the temperature dependences of rate parameters will have to be further explored and characterized in analogy to atmospheric gas phase reaction rate coefficients (Sander et al., 2002; Atkinson et al., 2004). Appropriate formalisms and parameters (Arrhenius equations and activation energies, etc.) can be flexibly included in the presented model framework, but a detailed treatment of this aspect would go beyond the scope of this paper.

As pointed out in the interactive public discussion of our manuscript (Pöschl et al., 2005a, b, c), the development and presentation of the proposed model framework have been focussed on consistent description of aerosol and cloud surface chemistry and gas-particle interactions of reactive trace substances, rather than on phase transitions of major gas phase and particle components with substantial uptake/release of latent heat (bulk condensation or evaporation, melting or freezing). Nevertheless, the uptake/release of latent heat upon adsorption/desorption, condensation/evaporation, mixing/dissolution, solvatation/segregation, etc. as well as the transport of sensible heat in the gas phase, across the interface, and in the particle bulk can be flexibly added by complementing the presented mass balance, mass transport, and reaction rate equations with analogous energy balance and heat flux equations. Based on the heat capacities and conductivities of the particles and gas phase in the investigated aerosol or cloud system, the uptake or release of heat can be translated into a temperature change, which in turn can be taken into account in the determination of temperaturedependent kinetic parameters (Arrhenius equations, etc.).

For example, the release and transport of heat during gasliquid condensation of water could be captured with the formalism outlined by Winkler et al. (2004), using a "thermal accommodation coefficient" $\left(\alpha_{\mathrm{t}}\right)$ to describe the efficiency of energy equilibration between impinging gas molecules and particle surface. In agreement with Winkler et al. (2004), but going beyond their treatment of a simple non-reactive system, we emphasize the need for a clear distinction of the processes and coefficients of thermal accommodation (heat transfer), surface accommodation (adsorption), and bulk accommodation (absorption) of gas molecules by an aerosol or cloud particle. Even if the values of these coefficients are likely to be (near-)identical and close to unity for many atmospherically relevant conditions, species, and systems such as warm water clouds $\left(\alpha_{\mathrm{t}, \mathrm{X} i} \approx \alpha_{\mathrm{s}, \mathrm{X} i} \approx \alpha_{\mathrm{b}, \mathrm{X} i} \approx 1\right.$; Laaksonen et al., 2005; Garrett et al., 2006; Winkler et al., 2006), the underlying processes should not be confused (see Sect. 4.6).

In any case, heat transfer and related temperature changes can be included in the proposed kinetic model framework without necessitating a modification of the terminology and formalisms presented in this paper. A detailed treatment of these aspects would, however, go beyond the scope of this paper.

\subsection{Special mechanisms and conditions}

When only reversible adsorption and surface layer reactions of volatile species but no gas-surface and surface bulk reactions or surface-bulk transfer are considered $\left(P_{\mathrm{g}, \mathrm{gsr}, \mathrm{X} i}=\right.$ $\left.L_{\mathrm{g}, \mathrm{gsr}, \mathrm{X} i}=P_{\mathrm{s}, \mathrm{g}, \mathrm{X} i}=L_{\mathrm{s}, \mathrm{g}, \mathrm{X} i}=J_{\mathrm{b}, \mathrm{s}, \mathrm{X} i}=J_{\mathrm{s}, \mathrm{b}, \mathrm{X} i}=0\right)$, the formalisms outlined above are equivalent to classical Langmuir-Hinshelwood reaction mechanisms. If, on the other hand, only elementary gas-surface reactions of volatile species but no surface-layer reactions and surfacebulk reactions or surface-bulk transfer are considered $\left(P_{\mathrm{s}, \mathrm{s}, \mathrm{X} i}=L_{\mathrm{s}, \mathrm{s}, \mathrm{X} i}=P_{\mathrm{s}, \mathrm{ss}, \mathrm{X} i}=L_{\mathrm{s}, \mathrm{ss}, \mathrm{X} i}=J_{\mathrm{b}, \mathrm{s}, \mathrm{X} i}=J_{\mathrm{s}, \mathrm{b}, \mathrm{X} i}=0\right)$, 
they are equivalent to classical Eley-Rideal reaction mechanisms. For these two types of reaction mechanisms a wide range of special cases with different rate limiting steps (adsorption, desorption, or chemical reaction) and different types of interacting species have been described in the scientific literature of chemical engineering and catalysis (Masel, 1996). The rate equations for chemical surface reactions following these mechanistic schemes can be readily inserted into the presented model framework.

Characteristic effects of reversible adsorption and particle aging on the concentration- and time-dependence of uptake coefficients in simple Langmuir-Hinshelwood reaction systems have already been presented by Ammann et al. (2003). Further exemplary model systems and calculations involving multiple chemical species, reactions, and mass transport processes under transient and steady-state conditions are presented and discussed in a companion paper (Ammann and Pöschl, 2007).

In the following sections we present rate equations and equivalent resistor model formulations derived from the general formalisms presented above for several special cases involving reversible adsorption and reactions at the particle surface as well as surface-bulk transfer processes under (quasi-)steady-state conditions. They are based on the assumption of constant gas phase and particle composition (quasi-steady-state approximation, QSSA), which is generally applicable to describe chemical kinetics on short timescales and can be extended to longer time-scales by iterative calculations as illustrated in a companion paper (Ammann and Pöschl, 2007).

In Sect. 4.4 we consider "adsorption equilibrium" conditions where the surface concentration of volatile species is determined by reversible adsorption which proceeds much faster and can be regarded as fully decoupled from all other involved processes. In Sect. 4.5 we consider "adsorptionreaction steady-state" conditions where the surface concentration of volatile species is determined by reversible adsorption, surface reactions, and surface-bulk exchange which proceed at rates of comparable magnitude and have to be treated as coupled processes. In Sect. 4.6 we consider systems which are dominated by "bulk absorption or condensation", and where it will normally not be necessary to fully resolve the surface processes and effects outlined above.

\subsection{Adsorption equilibrium conditions}

\subsubsection{Surface concentration of $\mathrm{X}_{i}$}

At steady state $\left(\mathrm{d}\left[\mathrm{X}_{i}\right]_{\mathrm{s}} / \mathrm{d} t=0\right)$ and when the rates of adsorption and desorption are of similar magnitude and much higher than the rates of all other processes affecting the surface concentration of a species $X_{i}$ and its particle-related gas phase loss, $\mathrm{X}_{i}$ can be assumed to be in adsorption equilibrium and $\left[\mathrm{X}_{i}\right]_{\mathrm{S}}$ can be approximated by equating the fluxes of adsorption and desorption:

$$
\begin{aligned}
J_{\mathrm{ads}, \mathrm{X} i} & \approx J_{\mathrm{des}, \mathrm{X} i} \gg P_{\mathrm{g}, \mathrm{gsr}, \mathrm{X} i}+L_{\mathrm{g}, \mathrm{gsr}, \mathrm{X} i}+P_{\mathrm{s}, \mathrm{X} i}+L_{\mathrm{s}, \mathrm{X} i} \\
& +J_{\mathrm{b}, \mathrm{s}, \mathrm{X} i}+J_{\mathrm{s}, \mathrm{b}, \mathrm{X} i}
\end{aligned}
$$

Combining relations (33)-(34) and (38)-(40), and introducing a (Langmuir) adsorption equilibrium constant $K_{\mathrm{ads}, \mathrm{X} i}$ leads to

$$
K_{\mathrm{ads}, \mathrm{X} i}\left[\mathrm{X}_{i}\right]_{\mathrm{gs}}=\frac{\theta_{\mathrm{s}, \mathrm{X} i}}{1-\theta_{\mathrm{s}}}=\frac{\theta_{\mathrm{s}, \mathrm{X} i}}{1-\sum_{p} \theta_{\mathrm{s}, \mathrm{X} p}}
$$

with

$$
K_{\mathrm{ads}, \mathrm{X} i}=\frac{\sigma_{\mathrm{X} i} k_{\mathrm{a}, 0, \mathrm{X} i}}{k_{\mathrm{d}, \mathrm{X} i}}=\alpha_{\mathrm{s}, 0, \mathrm{X} i} \frac{\sigma_{\mathrm{X} i} \omega_{\mathrm{X} i}}{4 k_{\mathrm{d}, \mathrm{X} i}}
$$

If all other competitively adsorbing species $\mathrm{X}_{p}$ are assumed to be in adsorption equilibrium as well, their fractional surface coverages can be substituted by $\theta_{\mathrm{s}, \mathrm{X} p}=\left(\theta_{\mathrm{s}, \mathrm{X} i} K_{\mathrm{ads}, \mathrm{X} p}\left[\mathrm{X}_{p}\right]_{\mathrm{gs}}\right) /\left(K_{\mathrm{ads}, \mathrm{X} i}\left[\mathrm{X}_{i}\right]_{\mathrm{gs}}\right), \quad$ and the surface concentration of $\mathrm{X}_{i}$ as well as the overall fractional surface coverage $\theta_{\mathrm{s}}$ can be expressed as a function of gas phase concentrations and adsorption equilibrium constants:

$$
\begin{aligned}
& {\left[\mathrm{X}_{i}\right]_{\mathrm{s}}=\sigma_{\mathrm{X} i}^{-1} \frac{K_{\mathrm{ads}, \mathrm{X} i}\left[\mathrm{X}_{i}\right]_{\mathrm{gs}}}{1+\sum_{p} K_{\mathrm{ads}, \mathrm{X} p}\left[\mathrm{X}_{p}\right]_{\mathrm{gs}}}} \\
& \theta_{s}=\frac{\sum_{p} K_{\mathrm{ads}, \mathrm{X} p}\left[\mathrm{X}_{p}\right]_{\mathrm{gs}}}{1+\sum_{p} K_{\mathrm{ads}, \mathrm{X} p}\left[\mathrm{X}_{p}\right]_{\mathrm{gs}}}
\end{aligned}
$$

4.4.2 Surface and bulk accommodation and net uptake of $\mathrm{X}_{i}$

The surface and bulk accommodation coefficients under adsorption equilibrium conditions follow from relations (32)(33), (79), (83), (85) and (87):

$\alpha_{\mathrm{s}, \mathrm{X} i}=\frac{\alpha_{\mathrm{s}, 0, \mathrm{X} i}}{1+\sum_{p} K_{\mathrm{ads}, \mathrm{X} p}\left[\mathrm{X}_{p}\right]_{\mathrm{gs}}}$

$\alpha_{\mathrm{b}, \mathrm{X} i}=\alpha_{\mathrm{s}, \mathrm{X} i} \frac{k_{\mathrm{s}, \mathrm{b}, \mathrm{X} i}}{k_{\mathrm{s}, \mathrm{b}, \mathrm{X} i}+k_{\mathrm{d}, \mathrm{X} i}}$

Jayne et al. (1990) derived similar expressions to describe the dependence of $\mathrm{SO}_{2}$ uptake into aqueous solution droplets on gas phase concentration and surface coverage. Relations equivalent to (89) have also been derived by Davidovits et al. (1995) and Hanson (1997), but they did not explicitly account for competitive adsorption and assumed $\alpha_{\mathrm{s}, \mathrm{X} i}$ to be the maximum value not only for $\alpha_{\mathrm{b}, \mathrm{X} i}$ but also for $\gamma_{\mathrm{X} i}$, neglecting the possibility of gas-surface reactions (Eqs. 74-79).

The net flux of $\mathrm{X}_{i}$ from the gas phase to the condensed phase under adsorption equilibrium conditions can be calculated from

$$
\begin{aligned}
J_{\text {net }, \mathrm{X} i} & =L_{\mathrm{g}, \mathrm{gsr}, \mathrm{X} i}-P_{\mathrm{g}, \mathrm{gsr}, \mathrm{X} i}+L_{\mathrm{s}, \mathrm{X} i}-P_{\mathrm{s}, \mathrm{X} i} \\
& +J_{\mathrm{s}, \mathrm{b}, \mathrm{X} i}-J_{\mathrm{b}, \mathrm{s}, \mathrm{X} i} .
\end{aligned}
$$


By inserting Eq. (86) into the formulae presented in Sects. 3.3 and 3.4, all terms on the right hand side of Eq. (90) and $J_{\text {net, } \mathrm{X} i}$ can be expressed as explicit functions of the nearsurface gas phase concentrations of all competitively adsorbing volatile species and of the surface and near-surface bulk concentrations of non-volatile particle components. In the same way $\gamma_{\mathrm{sor}, \mathrm{X} i}, \gamma_{\mathrm{gsr}, \mathrm{X} i}$, and $\gamma_{\mathrm{X} i}$ can be expressed and calculated according to Eqs. (74)-(78).

From relations (74)-(78) and (83) follows $\gamma_{\text {sor, } \mathrm{X} i} \ll 1$, $\gamma_{\mathrm{gsr}, \mathrm{X} i} \ll 1$, and $\gamma_{\mathrm{X} i} \ll 1$. Provided that the particle diameter is not much larger than the mean free path of $\mathrm{X}_{i}$ and according to Eqs. (4), (14), (19), and (20), $\gamma_{\mathrm{X} i} \ll 1$ implies $C_{\mathrm{g}, \mathrm{X} i} \approx 1,\left[\mathrm{X}_{i}\right]_{\mathrm{g}, \mathrm{s}} \approx\left[\mathrm{X}_{i}\right]_{\mathrm{g}}$, and $\gamma_{\mathrm{X} i} \approx \gamma_{\mathrm{eff}, \mathrm{X} i}$. Thus the average gas phase concentration $\left[\mathrm{X}_{i}\right]_{\mathrm{g}}$ can be used instead of $\left[\mathrm{X}_{i}\right]_{\mathrm{gs}}$ under these conditions.

\subsubsection{Surface concentration of $\mathrm{Y}_{j}$}

For non-volatile particle components $\mathrm{Y}_{j}$ the rate of surface concentration change, $\mathrm{d}\left[\mathrm{Y}_{j}\right]_{\mathrm{ss}} / \mathrm{d} t$, is given by Eq. (29). Under adsorption equilibrium conditions all terms on the right hand side of Eq. (94) can be expressed as explicit functions of the near-surface gas phase concentrations of the competitively adsorbing and reacting volatile species and of the surface and near-surface bulk concentrations of non-volatile particle components by inserting Eq. (86) into the formulae presented in Sects. 3.3 and 3.4. In case of significant transformation of particle components by chemical reaction (chemical aging of the particle), the change of surface and near-surface bulk concentrations can feed back into the calculation of surface reaction rates and adsorption equilibrium constants via Eq. (85), Eq. (35) for $\alpha_{\mathrm{s}, 0, \mathrm{X} i}$, and analogous equations for other rate parameters. Under these conditions, the calculation of surface and near-surface bulk concentrations has to be iterated for both volatile and non-volatile species in order to maintain the quasi-steady-state approximation (assumption of constant chemical composition) on which Eqs. (86)-(90) are based.

4.4.4 Special Case A: "adsorption equilibrium and negligible chemical production at the surface"

\section{Net uptake of $\mathrm{X}_{i}$}

For a species $\mathrm{X}_{i}$ with negligible chemical production at the particle surface $\left(P_{\mathrm{g}, \mathrm{gsrX} i}+P_{\mathrm{s}, \mathrm{X} i} \ll L_{\mathrm{s}, \mathrm{X} i}+J_{\mathrm{s}, \mathrm{b}, \mathrm{X} i}+J_{\mathrm{b}, \mathrm{s}, \mathrm{X} i}\right)$, Eq. (90) can be reduced to

$J_{\mathrm{net}, \mathrm{X} i}=L_{\mathrm{g}, \mathrm{gsr}, \mathrm{X} i}+L_{\mathrm{s}, \mathrm{X} i}+J_{\mathrm{s}, \mathrm{b}, \mathrm{X} i}-J_{\mathrm{b}, \mathrm{s}, \mathrm{X} i}$

Based on the formulae of Sect. 3.3, the chemical loss terms $L_{\mathrm{g}, \mathrm{gsr}, \mathrm{X} i}$ and $L_{\mathrm{S}, \mathrm{X} i}$ can be described as pseudo-first order processes with the following rate equations and parameters:

$L_{\mathrm{g}, \mathrm{gsr}, \mathrm{X} i}=\gamma_{\mathrm{gsr}, \mathrm{X} i} \frac{\omega_{\mathrm{X} i}}{4}\left[\mathrm{X}_{i}\right]_{\mathrm{gs}}$

$L_{\mathrm{s}, \mathrm{X} i}=k_{\mathrm{s}, \mathrm{X} i}\left[\mathrm{X}_{i}\right]_{\mathrm{s}}$ $\gamma_{\mathrm{gsr}, \mathrm{X} i}=-\sum_{u} c_{\mathrm{GSR} u, \mathrm{~g}, \mathrm{X} i}\left(\sum_{p} \gamma_{\mathrm{GSR} u, \mathrm{~g}, \mathrm{X} i, \mathrm{X} p} \frac{K_{\mathrm{ads}, \mathrm{X} p}\left[\mathrm{X}_{p}\right]_{\mathrm{gs}}}{1+\sum_{q} K_{\mathrm{ads}, \mathrm{X} q}\left[\mathrm{X}_{q}\right]_{\mathrm{gs}}}+\right.$

$\left.\sum_{r} \gamma_{\mathrm{GSR} u, \mathrm{~g}, \mathrm{X} i, \mathrm{Yr} r} \sigma_{\mathrm{Yr} r}\left[\mathrm{Y}_{r}\right]_{\mathrm{ss}} \frac{1}{1+\sum_{q} K_{\mathrm{ads}, \mathrm{X} q}\left[\mathrm{X}_{q}\right]_{\mathrm{gs}}}\right)$

$k_{\mathrm{s}, \mathrm{X} i}=k_{\mathrm{s}, \mathrm{g}, \mathrm{X} i}+k_{\mathrm{s}, \mathrm{s}, \mathrm{X} i}+k_{\mathrm{s}, \mathrm{ss}, \mathrm{X} i}$

$k_{\mathrm{s}, \mathrm{g}, \mathrm{X} i}=-\sigma_{\mathrm{X} i} \sum_{u} \sum_{p} c_{\mathrm{GSR} u, s, \mathrm{X} i} \gamma_{\mathrm{GSR} u, \mathrm{X} i, \mathrm{X} p} \frac{\omega_{\mathrm{X} p}}{4}\left[\mathrm{X}_{p}\right]_{\mathrm{gs}}$

$k_{\mathrm{S}, \mathrm{s}, \mathrm{X} i}=-\sum_{v} c_{\mathrm{SLR} v, s, \mathrm{X} i}$

$\left(k_{\mathrm{SLR} v, \mathrm{X} i}+\sum_{p} k_{\mathrm{SLR} v, \mathrm{X} i, \mathrm{X}_{p}} \sigma_{\mathrm{X} p}^{-1} \frac{K_{\mathrm{ads}, \mathrm{X} p}\left[\mathrm{X}_{p}\right]_{\mathrm{gs}}}{1+\sum_{q} K_{\mathrm{ads}, \mathrm{X} q}\left[\mathrm{X}_{q}\right]_{\mathrm{gs}}}\right)$

$k_{\mathrm{S}, \mathrm{ss}, \mathrm{X} i}=-\sum_{v} \sum_{q} c_{\mathrm{SLR} v, s, \mathrm{X} i} k_{\mathrm{SLR} v, \mathrm{X} i, \mathrm{Y} q}\left[\mathrm{Y}_{q}\right]_{\mathrm{ss}}$

$k_{\mathrm{S}, \mathrm{X} i}$ is the overall pseudo-first-order rate coefficient for the chemical loss of $\mathrm{X}_{i}$ in the sorption layer. $k_{\mathrm{s}, \mathrm{g}, \mathrm{X} i}, k_{\mathrm{s}, \mathrm{s}, \mathrm{X} i}$, and $k_{\mathrm{s}, \mathrm{ss}, \mathrm{X} i}$ are individual pseudo-first-order loss rate coefficients for gas-surface reactions and surface layer reactions within the sorption layer or between sorption layer and quasi-static surface layer, respectively.

According to Sect. 3.5.1, the net surface-bulk transfer of $\mathrm{X}_{i}$ under steady-state conditions can also be described as a pseudo-first-order process with a rate coefficient $k_{\mathrm{s}, \mathrm{b}, \text { net, } \mathrm{X} i}$. Combining Eqs. (70), (77), (86), and (93) leads to

$\gamma_{\mathrm{sor}, \mathrm{X} i}=\alpha_{\mathrm{s}, \mathrm{X} i} \frac{k_{\mathrm{s}, \mathrm{X} i}+k_{\mathrm{s}, \mathrm{b}, \mathrm{net}, \mathrm{X} i}}{k_{\mathrm{d}, \mathrm{X} i}}$

The overall uptake coefficient for $\mathrm{X}_{i}$ is given by the sum of $\gamma_{\mathrm{gsr}, \mathrm{X} i}$ and $\gamma_{\mathrm{sor}, \mathrm{X} i}$ (Eq. 76).

\section{Surface concentration of $\mathrm{Y}_{j}$}

Assuming that there is no or negligible chemical production, surface-bulk reaction, and surface-bulk transport of a non-volatile particle component $Y_{j}$, its surface concentration change over time can be described by

$$
\begin{aligned}
d\left[\mathrm{Y}_{j}\right]_{\mathrm{ss}} / \mathrm{d} t & =-\left(L_{\mathrm{ss}, \mathrm{g}, \mathrm{Y} j}+L_{\mathrm{ss}, \mathrm{s}, \mathrm{Y} j}+L_{\mathrm{ss}, \mathrm{ss}, \mathrm{Y} j}\right) \\
& =-k_{\mathrm{ss}, \mathrm{Y} j}\left[\mathrm{Y}_{j}\right]_{\mathrm{ss}}
\end{aligned}
$$

with an overall pseudo-first-order loss rate coefficient $k_{\mathrm{ss}, \mathrm{Y} j}=k_{\mathrm{ss}, \mathrm{g}, \mathrm{Y} j}+k_{\mathrm{ss}, \mathrm{s}, \mathrm{Y} j}+k_{\mathrm{ss}, \mathrm{ss}, \mathrm{Y} j}$ that comprises individual pseudo-first-order rate coefficients for gas-surface reactions and surface layer reactions within the quasi-static layer or between sorption layer and quasi-static layer, respectively:

$$
k_{\mathrm{ss}, \mathrm{g}, \mathrm{Y} j}=-\sigma_{Y j} \sum_{u} \sum_{p} c_{\mathrm{GSR} u, s s, \mathrm{Y} j} \gamma_{\mathrm{GSR} u, \mathrm{X} i, \mathrm{Y} j} \frac{\mathrm{XX}_{p}}{4}\left[\mathrm{X}_{p}\right]_{\mathrm{gs}}
$$




$$
\begin{gathered}
k_{\mathrm{ss}, \mathrm{s}, \mathrm{Y} j}=-\sum_{v} \sum_{p} c_{\mathrm{SLR} v, s s, \mathrm{Y} j} k_{\mathrm{SLR} v, \mathrm{X} p, \mathrm{Y} j} \sigma_{\mathrm{X} p}^{-1} \\
\frac{K_{\mathrm{ads}, \mathrm{X} p}\left[\mathrm{X}_{p}\right]_{\mathrm{gs}}}{1+\sum_{q} K_{\mathrm{ads}, \mathrm{X} q}\left[\mathrm{X}_{q}\right]_{\mathrm{gs}}}
\end{gathered}
$$

$k_{\mathrm{ss}, \mathrm{ss}, \mathrm{Y} j}=-\sum_{v} c_{\mathrm{SLR} v, s s, \mathrm{Y} j}\left(k_{\mathrm{SLR} v, \mathrm{Y} j}+\sum_{q} k_{\mathrm{SLR} v, \mathrm{Y} q, \mathrm{Y} j}\left[\mathrm{Y}_{q}\right]_{\mathrm{s}}\right)$

\subsection{Adsorption-reaction steady-state}

When the rates of reaction at the surface or surface-bulk exchange of a volatile species $\mathrm{X}_{i}$ are of comparable magnitude as the rate of adsorption, no general explicit analytical expression like Eq. (86) can be derived to describe the surface concentration of volatile species as a function of their gas phase concentration. At steady-state, however, the surface mass balance of all competitively adsorbing and reacting volatile species $\mathrm{X}_{p}\left(p=1, \ldots, i_{\max }\right)$ can be described by a set of $i_{\max }$ algebraic equations in the general form

$$
\begin{gathered}
J_{\mathrm{ads}, \mathrm{X} p}-J_{\mathrm{des}, \mathrm{X} p}+P_{\mathrm{s}, \mathrm{X} p}-L_{\mathrm{s}, \mathrm{X} p}+J_{\mathrm{b}, \mathrm{s}, \mathrm{X} p} \\
-J_{\mathrm{s}, \mathrm{b}, \mathrm{X} p}=0
\end{gathered}
$$

After inserting the rate equations and rate coefficients defined in Sects. 3.2-3.4, the near-surface gas phase concentrations of all competitively adsorbing volatile species, and the surface and near-surface bulk concentrations of non-volatile particle components, Eq. (104) can be solved for the surface concentrations $\left[\mathrm{X}_{p}\right]_{\mathrm{s}}$, and the uptake coefficient $\gamma_{\mathrm{X} i}$ can be calculated according to Eqs. (74)-(78).

In case of significant net consumption of particle components $\mathrm{Y}_{q}$ by chemical reaction (chemical aging of the particle), their surface and near-surface bulk concentration changes feed back into the calculation of mass transport and reaction rates at the surface. Under these conditions, the calculation of surface and near-surface bulk concentrations has to be iterated for both volatile and non-volatile species in order to maintain the quasi-steady-state approximation (assumption of constant chemical composition) on which Eq. (104) is based.

In general, Eq. (104) has to be solved numerically; only under restricted conditions explicit analytical expressions for $\left[\mathrm{X}_{p}\right]_{\mathrm{s}}, \gamma_{\mathrm{X} p}$, and $\mathrm{d}\left[\mathrm{Y}_{j}\right]_{\mathrm{ss}} / \mathrm{d} t$ can be derived as outlined above for general adsorption equilibrium conditions.

4.5.1 Special Case B: "adsorption-reaction steady-state and negligible chemical production at the surface"

\section{Surface concentration of $\mathrm{X}_{i}$}

For a species $\mathrm{X}_{i}$ with negligible chemical production at the particle surface $\left(P_{\mathrm{s}, \mathrm{X} i} \ll J_{\mathrm{des}, \mathrm{X} i}+L_{\mathrm{s}, \mathrm{X} i}+J_{\mathrm{s}, \mathrm{b}, \mathrm{X} i}+J_{\mathrm{b}, \mathrm{s}, \mathrm{X} i}\right)$, the surface mass balance, Eq. (104), can be reduced to

$J_{\mathrm{ads}, \mathrm{X} i}=J_{\mathrm{des}, \mathrm{X} i}+L_{\mathrm{s}, \mathrm{X} i}+J_{\mathrm{s}, \mathrm{b}, \mathrm{X} i}-J_{\mathrm{b}, \mathrm{s}, \mathrm{X} i}$
Inserting Eqs. (38), (40), (70), and (93) into (105) leads to

$$
\begin{gathered}
k_{\mathrm{a}, 0, \mathrm{X} i}\left[\mathrm{X}_{i}\right]_{\mathrm{gs}}\left(1-\sum_{p} \theta_{\mathrm{s}, \mathrm{X} p}\right)=\theta_{\mathrm{s}, \mathrm{X} i} \sigma_{\mathrm{X} i}^{-1} \\
\left(k_{\mathrm{d}, \mathrm{X} i}+k_{\mathrm{s}, \mathrm{X} i}+k_{\mathrm{s}, \mathrm{b}, \mathrm{net}, \mathrm{X} i}\right)
\end{gathered}
$$

By introducing an effective adsorption equilibrium constant, $K_{\mathrm{ads}, \mathrm{X} i}^{\prime}$, Eq. (106) can be further rearranged to

$$
K_{\mathrm{ads}, \mathrm{X} i}^{\prime}\left[\mathrm{X}_{\mathrm{i}}\right]_{\mathrm{gs}}=\frac{\theta_{\mathrm{s}, \mathrm{X} i}}{1-\theta_{s}}=\frac{\theta_{\mathrm{s}, \mathrm{X} i}}{1-\sum_{p} \theta_{\mathrm{s}, \mathrm{X} p}}
$$

with

$$
\begin{aligned}
K_{\mathrm{X} i}^{\prime} & =\frac{\sigma_{\mathrm{Xi}} k_{\mathrm{a}, 0, \mathrm{X} i}}{k_{\mathrm{d}, \mathrm{X} i}+k_{\mathrm{s}, \mathrm{X} i}+k_{\mathrm{s}, \mathrm{b}, \mathrm{net}, \mathrm{X} i}} \\
& =\alpha_{\mathrm{s}, 0, \mathrm{Xi}} \frac{\sigma_{\mathrm{Xi}} \omega_{\mathrm{Xi}}}{4\left(k_{\mathrm{d}, \mathrm{X} i}+k_{\mathrm{s}, \mathrm{X} i}+k_{\mathrm{s}, \mathrm{b}, \mathrm{net}, \mathrm{X} i}\right)}
\end{aligned}
$$

If the assumption of negligible production by surface reaction can be extended to all competitively adsorbing species $\mathrm{X}_{p}$ (or at least to the species dominating the total sorption layer coverage), their fractional surface coverages can be substituted by $\theta_{\mathrm{X} p}=\left(\theta_{\mathrm{X} i} K_{\mathrm{ads}, \mathrm{X} p}^{\prime}\left[\mathrm{X}_{p}\right]_{\mathrm{gs}}\right) /\left(K_{\mathrm{ads}, \mathrm{X} i}^{\prime}\left[\mathrm{X}_{i}\right]_{\mathrm{gs}}\right)$, and $\left[\mathrm{X}_{i}\right]_{\mathrm{S}}$ as well as $\theta_{\mathrm{s}}$ can be expressed as a function of gas phase concentrations and effective adsorption equilibrium constants:

$\left[\mathrm{X}_{i}\right]_{\mathrm{s}}=\sigma_{\mathrm{X} i}^{-1} \frac{K_{\mathrm{ads}, \mathrm{X} i}^{\prime}\left[\mathrm{X}_{i}\right]_{\mathrm{gs}}}{1+\sum_{p} K_{\mathrm{ads}, \mathrm{X} p}^{\prime}\left[\mathrm{X}_{p}\right]_{\mathrm{gs}}}$

$\theta_{s}=\frac{\sum_{p} K_{\mathrm{ads}, \mathrm{X} p}^{\prime}\left[\mathrm{X}_{p}\right]_{\mathrm{gs}}}{1+\sum_{p} K_{\mathrm{ads}, \mathrm{X} p}^{\prime}\left[\mathrm{X}_{p}\right]_{\mathrm{gs}}}$

Surface accommodation, bulk accommodation, and net uptake of $\mathrm{X}_{i}$

For the surface and bulk accommodation coefficients under adsorption-reaction steady-state conditions follows

$$
\begin{aligned}
\alpha_{\mathrm{s}, \mathrm{Xi}} & =\frac{\alpha_{\mathrm{s}, 0, \mathrm{Xi}}}{1+\sum_{p} K_{\mathrm{ads}, \mathrm{X} p}^{\prime}\left[\mathrm{X}_{p}\right]_{\mathrm{gs}}} \\
\alpha_{\mathrm{b}, \mathrm{X} i} & =\alpha_{\mathrm{s}, \mathrm{X} i} \frac{k_{\mathrm{s}, \mathrm{b}, \mathrm{X} i}}{k_{\mathrm{s}, \mathrm{b}, \mathrm{X} i}+k_{\mathrm{s}, \mathrm{X} i}+k_{\mathrm{d}, \mathrm{X} i}}
\end{aligned}
$$

Based on Eq. (109) and in analogy to Special Case A (Sect. 3.2.1, Eqs. 91-99) the following expressions can be derived for the gas-surface reaction uptake coefficient, the pseudo-first-order rate coefficient for reactive loss within the sorption layer, and the sorption uptake coefficient:

$$
\begin{gathered}
\gamma_{\mathrm{gsr}, \mathrm{X} i}=-\sum_{u} c_{\mathrm{GSR} u, g, \mathrm{X} i}\left(\sum_{p} \gamma_{\mathrm{GSR} u, \mathrm{X} i, \mathrm{X} p} \frac{K_{\mathrm{ads}, \mathrm{X} p}^{\prime}\left[\mathrm{X}_{p}\right]_{\mathrm{gs}}}{1+\sum_{q} K_{\mathrm{ads}, \mathrm{X} q}^{\prime}\left[\mathrm{X}_{q}\right]_{\mathrm{gs}}}+\right) \\
\left.\sum_{r} \gamma_{\mathrm{GSR} u, \mathrm{X} i, \mathrm{Y} r} \sigma_{\mathrm{Y} r}\left[\mathrm{Y}_{r}\right]_{\mathrm{ss}} \frac{1}{1+\sum_{q} K_{\mathrm{ads}, \mathrm{X} q}^{\prime}\left[\mathrm{X}_{q}\right]_{\mathrm{gs}}}\right)
\end{gathered}
$$


$k_{\mathrm{S}, \mathrm{s}, \mathrm{X} i}=-\sum_{v} c_{\mathrm{SLR} v, \mathrm{~s}, \mathrm{X} i}$

$$
\left(k_{\mathrm{SLR} v, \mathrm{X} i}+\sum_{p} k_{\mathrm{SLR} v, \mathrm{X} i, \mathrm{X} p} \sigma_{\mathrm{X} p}^{-1} \frac{K_{\mathrm{ads}, \mathrm{X}_{p}}^{\prime}\left[\mathrm{X}_{p}\right]_{\mathrm{gs}}}{1+\sum_{q} K_{\mathrm{ads}, \mathrm{X} q}^{\prime}\left[\mathrm{X}_{q}\right]_{\mathrm{gs}}}\right)
$$

$\gamma_{\mathrm{sor}, \mathrm{X} i}=\alpha_{\mathrm{s}, \mathrm{X} i} \frac{k_{\mathrm{s}, \mathrm{X} i}+k_{\mathrm{s}, \mathrm{b}, \mathrm{net}, \mathrm{X} i}}{k_{\mathrm{s}, \mathrm{X} i}+k_{\mathrm{s}, \mathrm{b}, \mathrm{net}, \mathrm{X} i}+k_{\mathrm{d}, \mathrm{X} i}}$

$k_{\mathrm{s}, \mathrm{X} i}, k_{\mathrm{s}, \mathrm{g}, \mathrm{X} i}, k_{\mathrm{s}, \mathrm{ss}, \mathrm{X} i}$, and $k_{\mathrm{s}, \mathrm{b}, \text { net }, \mathrm{X} i}$ are defined in analogy to Special Case A, Eqs. (95), (96), (98), and (71). Again, the overall particle-related gas phase loss is given by the sum of $\gamma_{\mathrm{gsr}, \mathrm{X} i}$ and $\gamma_{\mathrm{sor}, \mathrm{X} i}$.

Note that the possibility of second order reactions within the sorption layer (adsorbate cross and self reactions) leads to a mutual interdependence of the effective adsorption equilibrium constant $K_{\mathrm{ads}, \mathrm{X} i}^{\prime}$ and the pseudo-first-order surface loss rate coefficients $k_{\mathrm{s}, \mathrm{X} i}$ and $k_{\mathrm{s}, \mathrm{s}, \mathrm{X} i}$ as defined in Eqs. (108), (94), and (114): $k_{\mathrm{s}, \mathrm{s}, \mathrm{X} i}$ which is required for the calculation of $k_{\mathrm{s}, \mathrm{X} i}$ and $K_{\mathrm{ads}, \mathrm{X} i}^{\prime}$ depends itself on the surface concentration of all adsorbed species $\left[\mathrm{X}_{p}\right]_{\mathrm{s}}$ and thus on $K_{\mathrm{ads}, \mathrm{X} i}^{\prime}$. As a consequence, no explicit algebraic expression for $K_{\mathrm{ads}, \mathrm{X} i}^{\prime}$ can be derived, and generally the surface concentrations and reaction rates have to be determined numerically. Only when second order sorption layer reactions are negligible against the overall surface reactivity $\left(\sum_{p} c_{\mathrm{SLR} v, \mathrm{~s}, \mathrm{X} i} k_{\mathrm{SLR} v, \mathrm{X} i, \mathrm{X} p}\left[\mathrm{X}_{p}\right]_{\mathrm{s}} \ll k_{\mathrm{s}, \mathrm{X} i}\right)$, or when surface reactivity is negligible against mass transport $\left(k_{\mathrm{s}, \mathrm{X} p} \ll k_{\mathrm{d}, \mathrm{X} p}+\right.$ $\left.k_{\mathrm{s}, \mathrm{b}, \mathrm{net}, \mathrm{X} p}\right)$, the effective adsorption equilibrium constant $K_{\mathrm{ads}, \mathrm{X} i}^{\prime}$ can be expressed explicitly as a function of volatile species gas phase concentrations $\left[\mathrm{X}_{p}\right]_{\mathrm{gs}}$, non-volatile particle component surface concentrations $\left[\mathrm{Y}_{q}\right]_{\mathrm{ss}}$, and basic rate coefficients.

\section{Surface concentration of $\mathrm{Y}_{j}$}

The surface concentration change of a particle component $\mathrm{Y}_{j}$ with negligible chemical production, surface-bulk reaction, and surface-bulk mass transport can be calculated according to Eq. (100) with the same rate coefficients $k_{\mathrm{ss}, \mathrm{g}, \mathrm{Y} j}$ and $k_{\mathrm{ss}, \mathrm{ss}, \mathrm{Y} j}$ as in Special Case A, but with a modified pseudofirst-order surface reaction rate coefficient $k_{\mathrm{ss}, \mathrm{s}, \mathrm{Y} j}$ and replacement of $K_{\text {ads, X } p}$ by $K_{\text {ads, }}^{\prime} p$ :

$$
\begin{gathered}
k_{\mathrm{ss}, \mathrm{s}, \mathrm{Y} j}=-\sum_{v} \sum_{p} c_{\mathrm{SLR} v, \mathrm{ss}, \mathrm{Y} j} k_{\mathrm{SLR} v, \mathrm{X} p, \mathrm{Y} j} \sigma_{\mathrm{X} p}^{-1} \\
\frac{K_{\mathrm{ads}, \mathrm{X} p}^{\prime}\left[\mathrm{X}_{p}\right]_{\mathrm{gs}}}{1+\sum_{q} K_{\mathrm{ads}, \mathrm{X} q}^{\prime}\left[\mathrm{X}_{q}\right]_{\mathrm{gs}}}
\end{gathered}
$$

Effects of reversible and competitive adsorption and surface saturation

Reversible and competitive adsorption on a quasi-static surface implies that the surface accommodation coefficient of every species $\mathrm{X}_{i}$ decreases with increasing surface concentration and thus with increasing gas phase concentration of all competitively adsorbing species (surface saturation effects). Consequently, all rate parameters proportional to $\alpha_{\mathrm{s}, \mathrm{X} i}$, including bulk accommodation, sorption uptake, and gas-particle partitioning coefficients (solubilities), will also exhibit a dependence on gas phase composition which can only be neglected when the total sorption layer surface coverage is much less than unity $\left(\theta_{\mathrm{S}} \ll 1\right)$. For systems in Langmuir adsorption equilibrium or in adsorption-reaction steady-state with negligible surface production of volatile species, the condition $\theta_{\mathrm{S}} \ll 1$ is fulfilled when the sum of the products of (near-surface) gas phase concentration and effective adsorption equilibrium constant of all volatile species $\mathrm{X}_{p}$ (including $\mathrm{X}_{i}$ ) is much less than unity:

$\sum_{p} K_{\mathrm{ads}, \mathrm{X} p}^{\prime}\left[\mathrm{X}_{p}\right]_{\mathrm{gs}} \ll 1$

Under these conditions $\alpha_{\mathrm{s}, \mathrm{X} i}$ can be replaced by $\alpha_{\mathrm{s}, 0, \mathrm{X} i}$, and the relation between gas phase and surface concentration of $\mathrm{X}_{i}$ becomes quasi-linear, as assumed by Hanson (1997):

$\left[\mathrm{X}_{i}\right]_{\mathrm{s}} \approx \sigma_{\mathrm{X} i}^{-1} K_{\mathrm{ads}, \mathrm{X} i}^{\prime}\left[\mathrm{X}_{i}\right]_{\mathrm{gs}}$

Relations (117) and (118) may often be valid under atmospheric background conditions. For the modeling of highly polluted air masses (e.g. fossil fuel combustion or biomass burning plumes; Pöschl, 2002b; von Glasow et al., 2003; Hobbs et al., 2003; Jost et al., 2003; Meilinger et al., 2005) and for the analysis and extrapolation of laboratory experiments with relatively high trace gas concentrations, however, non-linear gas phase concentration dependences of rate parameters caused by reversible and competitive adsorption can play an important role (e.g. Pöschl et al., 2001; Ammann et al., 2003; and references therein). Exemplary model calculations and parameter variations are illustrated in a companion paper (Ammann and Pöschl, 2005).

\subsubsection{Resistor model formulation of Special Case B}

To re-formulate the flux equations describing net gas uptake in Special Case B (adsorption-reaction steady-state and negligible chemical production at the surface) in terms of the traditional resistance model, Eq. (115) can be inverted to

$$
\frac{1}{\gamma_{\mathrm{sor}, \mathrm{X} i}}=\frac{1}{\alpha_{\mathrm{s}, \mathrm{X} i}}\left(1+\frac{k_{\mathrm{d}, \mathrm{X} i}}{k_{\mathrm{s}, \mathrm{X} i}+k_{\mathrm{s}, \mathrm{b}, \mathrm{net}, \mathrm{X} i}}\right)
$$

All parameters in Eq. (119) are defined in the same way as in Sect. 3.2.1, and by inserting Eq. (71) for $k_{\mathrm{s}, \mathrm{b}, \mathrm{net}, \mathrm{X} i}$ it can be further rearranged to

$$
\begin{aligned}
& \frac{1}{\gamma_{\mathrm{sor}, \mathrm{X} i}}=\frac{1}{\alpha_{\mathrm{s}, \mathrm{X} i}}
\end{aligned}
$$

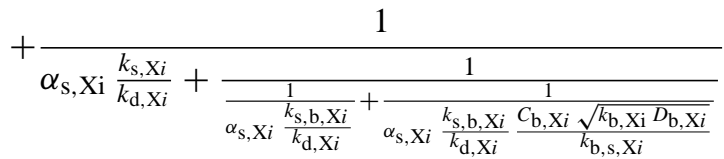


and

$\frac{1}{\gamma_{\mathrm{sor}, \mathrm{X} i}}=\frac{1}{\alpha_{\mathrm{s}, \mathrm{X} i}}+\frac{1}{\Gamma_{\mathrm{s}, \mathrm{X} i}+\frac{1}{\frac{1}{\Gamma_{\mathrm{s}, \mathrm{b}, \mathrm{X} i}}+\frac{1}{\Gamma_{\mathrm{b}, \mathrm{X} i}}}}$

with

$$
\begin{aligned}
& \Gamma_{\mathrm{s}, \mathrm{X} i}=\alpha_{\mathrm{s}, \mathrm{X} i} \frac{k_{\mathrm{s}, \mathrm{X} i}}{k_{\mathrm{d}, \mathrm{X} i}}=\frac{4 k_{\mathrm{a}, \mathrm{X} i}}{\omega_{\mathrm{X} i}} \frac{k_{\mathrm{s}, \mathrm{X} i}}{k_{\mathrm{d}, \mathrm{X} i}} \\
& \Gamma_{\mathrm{s}, \mathrm{b}, \mathrm{X} i}=\alpha_{\mathrm{s}, \mathrm{X} i} \frac{k_{\mathrm{s}, \mathrm{b}, \mathrm{X} i}}{k_{\mathrm{d}, \mathrm{X} i}}
\end{aligned}
$$$$
\Gamma_{\mathrm{b}, \mathrm{X} i}=\alpha_{\mathrm{s}, \mathrm{X} i} \frac{k_{\mathrm{s}, \mathrm{b}, \mathrm{X} i}}{k_{\mathrm{d}, \mathrm{X} i}} \frac{C_{\mathrm{b}, \mathrm{X} i} \sqrt{k_{\mathrm{b}, \mathrm{X} i} D_{\mathrm{b}, \mathrm{X} i}}}{k_{\mathrm{b}, \mathrm{s}, \mathrm{X} i}}
$$$$
=\frac{4}{\omega_{\mathrm{X} i}} K_{\mathrm{sol}, \mathrm{cp}, \mathrm{X} i} N_{\mathrm{A}} R T C_{\mathrm{b}, \mathrm{X} i} \sqrt{k_{\mathrm{b}, \mathrm{X} i} D_{\mathrm{b}, \mathrm{X} i}}
$$

Equation (121) is equivalent to earlier resistor model formulations (Hanson, 1997; Davidovits et al., 1995; Worsnop et al., 2002; Smith et al., 2003; Reid and Sayer, 2003; and references therein), in which the processes of surface reaction, surface-bulk transfer, and bulk diffusion and reaction are represented by the "conductance terms" (inverse resistances) $\Gamma_{\mathrm{s}, \mathrm{X} i}, \Gamma_{\mathrm{s}, \mathrm{b}, \mathrm{X} i}$, and $\Gamma_{\mathrm{b}, \mathrm{X} i}$.

In Eq. (121) and in most previous resistor model formulations, however, the possibility of elementary gas-surface reactions has not been taken into account. To account for such processes and to obtain a comprehensive expression for the uptake coefficient $\gamma_{\mathrm{X} i}, \gamma_{\mathrm{gsr}, \mathrm{X} i}$ as defined in Eq. (113) has to be added and Eq. (121) has to be extended to

$$
\gamma_{\mathrm{X} i}=\gamma_{\mathrm{gsrX} i}+\frac{1}{\frac{1}{\alpha_{\mathrm{s}, \mathrm{X} i}}+\frac{1}{\Gamma_{\mathrm{s}, \mathrm{X} i}+\frac{1}{\Gamma_{\mathrm{b}, \mathrm{X} i}+\frac{1}{\Gamma_{\mathrm{s}, \mathrm{b}, \mathrm{X} i}}}}}
$$

Even though this aspect tends to be obscured by resistance model formulations such as Eqs. (121) and (125), the gassurface reaction probability $\gamma_{\mathrm{gss}, \mathrm{X} i}$ is the only parameter in Eq. (125) which is independent of the surface accommodation coefficient $\alpha_{\mathrm{s}, \mathrm{X} i}$. Surface layer and bulk reactions are coupled to the surface accommodation process, and the conductance terms $\Gamma_{\mathrm{s}, \mathrm{X} i}, \Gamma_{\mathrm{s}, \mathrm{b}, \mathrm{X} i}$, and $\Gamma_{\mathrm{b}, \mathrm{X} i}$ are directly proportional to $\alpha_{\mathrm{s}, \mathrm{X} i}$ as shown by Eqs. (122)-(124).

\subsection{Bulk absorption or condensation}

If the rates of elementary gas-surface reactions and surfacelayer reactions are negligible against uptake into the particle bulk $\left(\gamma_{\mathrm{gsr}, \mathrm{X} i} \ll \gamma_{\mathrm{sor}, \mathrm{X} i}\right.$ and $\left.k_{\mathrm{s}, \mathrm{X} i} \ll k_{\mathrm{s}, \mathrm{b}, \text { net }, \mathrm{X} i}\right)$, then the terms $\gamma_{\mathrm{gsr}, \mathrm{X} i}$ and $\Gamma_{\mathrm{s}, \mathrm{X} i}$ can be omitted from Eq. (125). In this case the resistances $1 / \alpha_{\mathrm{s}, \mathrm{X} i}$ and $1 / \Gamma_{\mathrm{s}, \mathrm{b}, \mathrm{X} i}$ can be convoluted into a "bulk accommodation resistance" $1 / \alpha_{\mathrm{b}, \mathrm{X} i}$ to obtain the traditional resistance model formulation for gas uptake (absorption) by liquid droplets, Eq. (7), and the bulk accommodation coefficient $\alpha_{\mathrm{b}, \mathrm{X} i}$ is given by Eq. (89).
When surface saturation effects are negligible (Eq. 117, Sect. 4.5.1) and the rates of surface reaction and desorption are much lower than the rate of surface-bulk transfer $\left(k_{\mathrm{s}, \mathrm{X} i}+k_{\mathrm{d}, \mathrm{X} i} \ll k_{\mathrm{s}, \mathrm{b}, \mathrm{X} i}\right)$, then bulk and surface accommodation coefficients are near-identical and independent of gasphase composition $\left(\alpha_{\mathrm{b}, \mathrm{X} i} \approx \alpha_{\mathrm{s}, \mathrm{X} i} \approx \alpha_{\mathrm{s}, 0, \mathrm{X} i}\right)$.

Under such conditions, it will normally not be necessary to apply the double-layer surface model and to resolve the surface processes and effects outlined above. Accordingly, traditional definitions of mass accommodation and basic equations of cloud microphysics are sufficient to calculate condensation rates for the growth of water droplets in supersaturated water vapour (e.g., Kulmala and Wagner, 2001; Winkler et al., 2004; Laaksonen et al., 2005; Winkler et al., 2006).

Nevertheless, a lack of consistent and explicit distinction between surface and bulk accommodation seems to be a likely explanation for some of the apparent discrepancies between different studies and values reported for the "mass accommodation" coefficient of water vapour on liquid water: $\sim 1.0$ and not $<0.4$ (Winkler et al., 2004; Laaksonen et al., 2005; Winkler et al., 2006) vs. $\sim 0.2$ but not $>0.3$ (Davidovits et al., 2004, 2005). In fact, surface accommodation followed by rapid isotope exchange reactions at the surface and partial desorption of the reaction products might explain why some of the apparent "mass accommodation" coefficients observed for isotopically labelled water are smaller than others. Detailed investigations and discussions of this subject would go beyond the scope of the present manuscript and will be pursued in follow-up studies.

\section{Summary and conclusions}

Among the major obstacles on the way to full mechanistic understanding and reliable prediction of aerosol and cloud properties and effects on the atmosphere, climate and public health are not only the limited availability of measurement data, but also the limited applicability and compatibility of model formalisms used for the analysis, interpretation, and description of aerosol and cloud interactions and transformation. In particular, the kinetics of heterogenous reactions and multiphase processes (concentration, time, and temperature dependences) are usually not well characterized, and most experimental and modeling studies involve system- and method-specific rate equations and parameters, which are hard to compare and extrapolate.

Comprehensive investigations of atmospheric aerosol and cloud effects, however, need to include a consistent description of a wide range of components and processes: systems with multiple condensed phases, interfaces and mixing states (solid/liquid, surface/bulk, homogeneous/heterogeneous, internal/external mixing); multiple chemical species (volatile/semivolatile/non-volatile, 
reactive/non-reactive); multiple competing physical and chemical processes (particle formation/transformation, gas uptake/release, mass transport, phase transition, chemical reaction, reversible/irreversible).

For this purpose we have developed and presented a kinetic model framework with consistent and unambiguous terminology and universally applicable rate equations and parameters, which allow to describe mass transport and chemical reactions at the gas-particle interface and to link aerosol and cloud surface processes with gas phase and particle bulk processes. The key elements and essential aspects of the kinetic model framework can be summarized as follows:

(a) simple and descriptive double-layer surface model (sorption layer and quasi-static layer);

(b) straightforward flux-based mass balance and rate equations;

(c) clear separation of mass transport and chemical reaction;

(d) well-defined and consistent rate parameters (uptake and accommodation coefficients, reaction probabilities, reaction rate coefficients and mass transport rate coefficients);

(e) clear distinction between gas phase, gas-surface, and surface-bulk transport (gas phase diffusion, surface and bulk accommodation);

(f) clear distinction between gas-surface, surface layer, and surface-bulk reactions (Langmuir-Hinshelwood and Eley-Rideal mechanisms);

(g) mechanistic description of concentration and time dependences for all processes and conditions (transient and steady-state);

(h) flexible addition of unlimited numbers of chemical species and physicochemical processes depending on the complexity of the investigated systems;

(i) optional aggregation or resolution of intermediate species, sequential processes, and surface layers depending on the power and requirements of the applied experimental and modelling techniques;

(j) full compatibility with traditional resistor model formulations (steady-state approximations).

Following up on the interactive public discussion of our manuscript (Pöschl et al., 2005a, b, c), we would like to reconfirm that the proposed double-layer surface model and unambiguous definition of elementary steps of mass transport and chemical reactions represent a minimum of detail and complexity required for the description of aerosol and cloud surface chemistry, and thus for consistent description of atmospheric gas-particle interactions including both surface and bulk processes.

Numerous experimental studies referenced above and in our companion paper Part 2 (Ammann and Pöschl, 2007) have demonstrated that the kinetics of heterogeneous reactions at the surface of aerosol particles or surrogate surfaces exhibit non-linear concentration and timedependences, which can hardly be described in a physically meaningful way without invoking competitive co-adsorption of gas molecules in a sorption layer (Langmuir-Hinshelwood mechanisms, etc.). Competitive co-adsorption, however, can hardly be described without assuming a quasi-static surface layer which determines the quality and quantity of sorption sites (surface area).

The near-surface gas phase and near-surface particle bulk as defined in our model framework are essentially the same as in earlier model formalisms linking interfacial mass transport to diffusion in the gas phase and particle bulk. These had mostly referred to "concentrations at/near the surface" without providing a descriptive definition and illustration of the model domain (compartment) which is effectively characterized by these "concentrations at/near the surface".

As illustrated by the examples given in our companion paper Part 2 (Ammann and Pöschl, 2007), many of the kinetic parameters required for consistent description of chemical reactions and mass transport within and across sorption layers and quasi-static surface layers can be derived from existing literature data - not only for solid particles (e.g. soot interacting with $\mathrm{O}_{3}, \mathrm{NO}_{2}$, and $\mathrm{H}_{2} \mathrm{O}$ ) but also for liquid droplets (e.g., aqueous droplets interacting with $\mathrm{SO}_{2}$ ).

On the other hand, we do not want to suggest that it would be necessary to resolve the multiple surface layers and the kinetics of all (quasi-)elementary molecular processes outlined above for all types of gas-particle interactions in the atmosphere. For bulk condensation or evaporation and absorption of gases by liquid aerosol and cloud particles, it should normally be sufficient to determine and use a bulk accommodation coefficient (traditional "mass accommodation coefficient") to characterize the molecular kinetics of gas-toparticle mass transfer, and a simple evaporation rate coefficient for the reverse process. In many cases, it may even be sufficient to consider only diffusion in the gas phase and/or condensed phase as the rate limiting process, and to neglect the molecular kinetics of mass transfer at the surface (gasparticle interface).

When, however, there is a demand or need to resolve molecular kinetics at the gas-particle interface (e.g., to account for effects of surface reaction or surface saturation), the proposed model framework enables the description and linkage of elementary steps of molecular motion and interaction as well as macroscopic observables within a consistent set of terms and formalisms. 
The framework formalism and terminology are sufficiently general and consistent to allow both: detailed investigations of complex systems by resolving individual elementary processes whenever it is necessary, and efficient description of simple systems by aggregation of multiple elementary processes whenever it is possible and convenient.

With regard to chemical species, the presented formalisms allow to resolve the formation, interaction, and decomposition of unlimited numbers of highly reactive and short-lived intermediates at the particle surface via consecutive or competitive gas-surface, surface layer, and surface bulk reactions. This can be important for the atmospheric abundance of hazardous air pollutants in densely populated areas and for the influence of meteorological conditions, local emissions, and long range transport on aerosol health effects.

On the other hand, a master mechanism of aerosol chemistry based on the proposed kinetic model framework would also support systematic lumping (grouping) of the hundreds and thousands of organic species and reactions in air particulate matter into surrogate species (substance classes with fairly uniform physicochemical properties) and surrogate reactions (reaction types with fairly uniform pathways and kinetics), which appear to be appropriate for efficient description of atmospheric aerosol aging and climate effects on global scales.
Exemplary practical applications and model calculations illustrating the relevance of the above aspects are presented in a companion paper (Ammann and Pöschl, 2007). We hope that the presented model framework will serve as a useful tool and common basis for experimental and theoretical studies investigating and describing atmospheric aerosol and cloud surface chemistry and gas-particle interactions. In particular, it is meant to support

(a) the planning and design of laboratory experiments for the elucidation and determination of rate parameters (mapping of most insightful experimental conditions; identification and characterization of relevant concentration and time dependences);

(b) the establishment, evaluation, and quality assurance of comprehensive and self-consistent collections of rate parameters (in analogy to existing evaluated data bases of gas phase reaction rate coefficients);

(c) the development of detailed master mechanisms for process models and the derivation of simplified but yet realistic parameterizations for atmospheric and climate models (in analogy to existing master mechanisms and condensed mechanisms of atmospheric gas phase chemistry). 


\section{Appendix A}

\section{List of symbols}

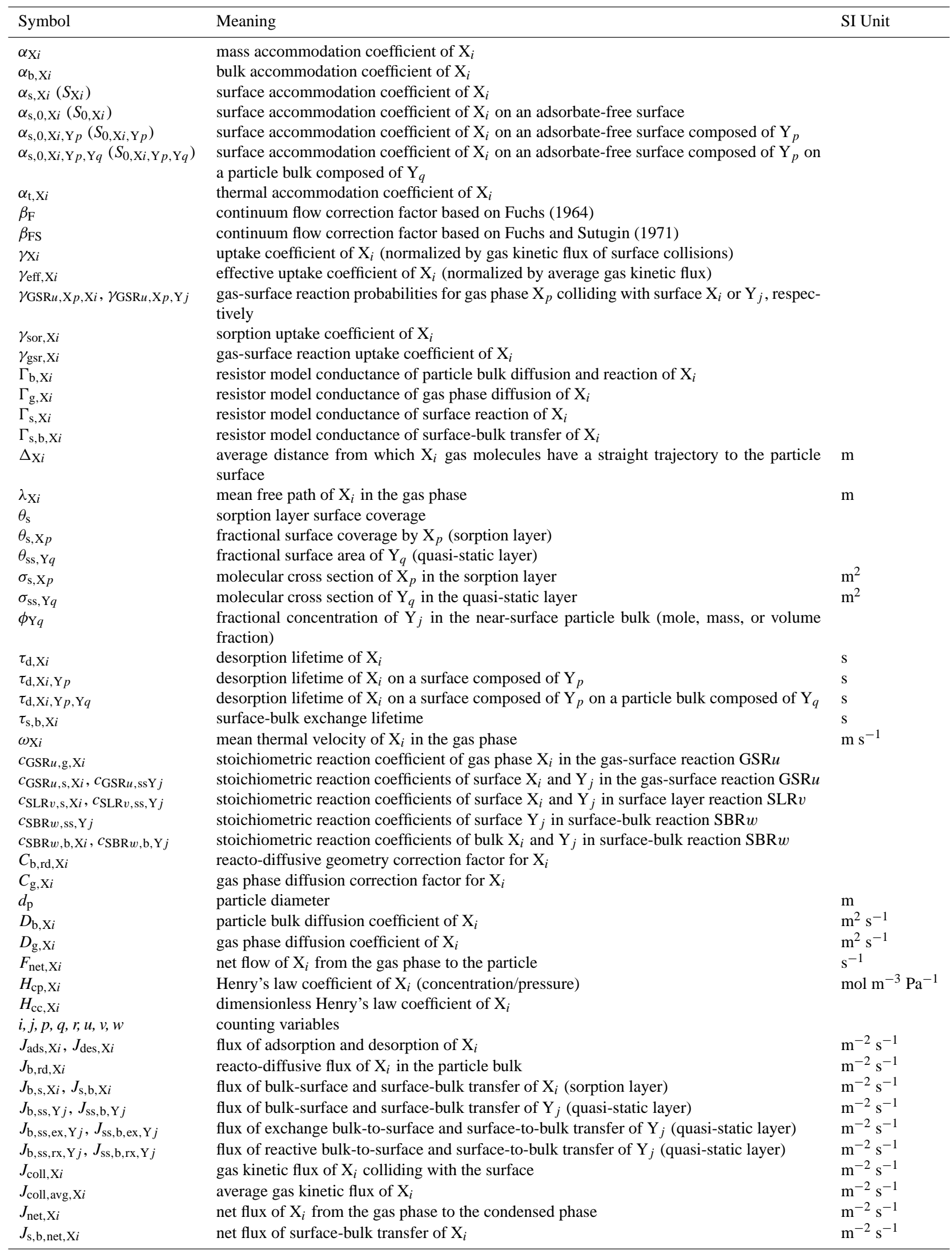




\begin{tabular}{|c|c|c|}
\hline Symbol & Meaning & SI Unit \\
\hline$k_{\mathrm{a}, \mathrm{X} i}$ & first-order adsorption rate coefficient of $\mathrm{X}_{i}$ & $\mathrm{~m} \mathrm{~s}^{-1}$ \\
\hline$k_{\mathrm{a}, 0, \mathrm{X} i}$ & first-order adsorption rate coefficient of $\mathrm{X}_{i}$ on an adsorbate-free surface & $\mathrm{m} \mathrm{s}^{-1}$ \\
\hline$k_{\mathrm{b}, \mathrm{X} i}$ & pseudo-first-order rate coefficient for chemical loss of $\mathrm{X}_{i}$ in the particle bulk & $\mathrm{s}^{-1}$ \\
\hline$k_{\mathrm{b}, \mathrm{s}, \mathrm{X} i}$ & first-order rate coefficient for bulk-to-surface transfer of $X_{i}$ & $\mathrm{~m} \mathrm{~s}^{-1}$ \\
\hline$k_{\mathrm{b}, \mathrm{ss}, \mathrm{Y} j}$ & first-order rate coefficient for bulk-to-surface transfer of $\mathrm{Y}_{j}$ & $\mathrm{~m} \mathrm{~s}^{-1}$ \\
\hline$k_{\mathrm{b}, \mathrm{ss}, \mathrm{ex}, \mathrm{Y} j}$ & first-order rate coefficient for bulk-to-surface transfer of $\mathrm{Y}_{j}$ by mutual exchange & $\mathrm{m} \mathrm{s}^{-1}$ \\
\hline$k_{\mathrm{b}, \mathrm{ss}, \mathrm{rx}, \mathrm{Y} j}$ & $\begin{array}{l}\text { pseudo-first-order rate coefficient for bulk-to-surface transfer of } \mathrm{Y}_{j} \text { by reactive trans- } \\
\text { formation }\end{array}$ & $\mathrm{m} \mathrm{s}^{-1}$ \\
\hline$k_{\mathrm{d}, \mathrm{X} i}$ & first-order desorption rate coefficient of $\mathrm{X}_{i}$ & $\mathrm{~s}^{-1}$ \\
\hline$k_{\mathrm{g}, \mathrm{p}, \mathrm{X} i}$ & $\begin{array}{l}\text { pseudo-first-order rate coefficient for gas phase loss of } X_{i} \text { due to gas-particle interac- } \\
\text { tions }\end{array}$ & $\mathrm{s}^{-1}$ \\
\hline$k_{\mathrm{s}, \mathrm{X} i}$ & pseudo-first-order rate coefficient for chemical loss of $\mathrm{X}_{i}$ in the sorption layer & $\mathrm{s}^{-1}$ \\
\hline$k_{\mathrm{s}, \mathrm{b}, \mathrm{X} i}$ & first-order rate coefficient for surface-to-bulk transfer of $X_{i}$ & $\mathrm{~s}^{-1}$ \\
\hline$k_{\mathrm{s}, \mathrm{b}, \mathrm{net}, \mathrm{X} i}$ & pseudo-first-order rate coefficient for net surface-to-bulk transfer of $\mathrm{X}_{i}$ & $\mathrm{~s}^{-1}$ \\
\hline$k_{\mathrm{s}, \mathrm{g}, \mathrm{X} i}, k_{\mathrm{s}, \mathrm{s}, \mathrm{X} i}, k_{\mathrm{s}, \mathrm{ss}, \mathrm{X} i}$ & $\begin{array}{l}\text { pseudo-first-order rate coefficients for chemial loss of } \mathrm{X}_{i} \text { in the sorption layer } \\
\text { by gas-surface reactions and surface layer reactions within the sorption layer or be- } \\
\text { tween sorption and quasi-static layer, respectively }\end{array}$ & $\mathrm{s}^{-1}$ \\
\hline$k_{\mathrm{ss}, \mathrm{Y} j}$ & $\begin{array}{l}\text { pseudo-first-order rate coefficient for chemical loss of } \mathrm{Y}_{j} \text { in the quasi-static surface } \\
\text { layer }\end{array}$ & $\mathrm{s}^{-1}$ \\
\hline$k_{\mathrm{ss}, \mathrm{b}, \mathrm{Y} j}$ & first-order rate coefficient for surface-bulk transfer of $Y_{j}$ & $\mathrm{~s}^{-1}$ \\
\hline$k_{\mathrm{ss}, \mathrm{b}, \mathrm{ex}, \mathrm{Y} j}$ & first-order rate coefficient for surface-bulk transfer of $\mathrm{Y}_{j}$ by mutual exchange & $\mathrm{s}^{-1}$ \\
\hline$k_{\mathrm{ss}, \mathrm{b}, \mathrm{rx}, \mathrm{Y} j}$ & $\begin{array}{l}\text { pseudo-first-order rate coefficient for surface-bulk transfer of } \mathrm{Y}_{j} \\
\text { by reactive transformation }\end{array}$ & $\mathrm{s}^{-1}$ \\
\hline$k_{\mathrm{ss}, \mathrm{g}, \mathrm{Y}}{ }_{j}, k_{\mathrm{ss}, \mathrm{s}, \mathrm{Y} j}, k_{\mathrm{ss}, \mathrm{ss}, \mathrm{Y} j}$ & $\begin{array}{l}\text { pseudo-first-order rate coefficients for chemial loss of } Y_{j} \text { in } \\
\text { the quasi-static layer by gas-surface reactions and surface } \\
\text { layer reactions within the quasi-static layer or between } \\
\text { sorption and quasi-static layer, respectively }\end{array}$ & $\mathrm{s}^{-1}$ \\
\hline$k_{\mathrm{ss}, \mathrm{r} x}$ & $\begin{array}{l}\text { pseudo-first-order rate coefficient for reactive transformation } \\
\text { of the quasi-static surface }\end{array}$ & $\mathrm{s}^{-1}$ \\
\hline$k_{\mathrm{SBR} w, \mathrm{Y} p, \mathrm{Y} q}, k_{\mathrm{SBR} w, \mathrm{Y} p, \mathrm{X} r}$ & $\begin{array}{l}\text { second-order rate coefficients for surface-bulk reactions of } \mathrm{Y}_{p} \\
\text { with } \mathrm{Y}_{q} \text {, and } \mathrm{Y}_{p} \text { with } \mathrm{X}_{r} \text {, respectively }\end{array}$ & $\mathrm{m}^{3} \mathrm{~s}^{-1}$ \\
\hline$k_{\mathrm{SLR} v, \mathrm{X} p}, k_{\mathrm{SLR} v, \mathrm{Y} q}$ & $\begin{array}{l}\text { first-order rate coefficients for surface layer reactions of } \\
\mathrm{X}_{p} \text { and } \mathrm{Y}_{q} \text {, respectively }\end{array}$ & $\mathrm{s}^{-1}$ \\
\hline$k_{\mathrm{SLR} v, \mathrm{X} p, \mathrm{X} q}, k_{\mathrm{SLR} v, \mathrm{X} p, \mathrm{Y} q}, k_{\mathrm{SLR} v, \mathrm{Y} p, \mathrm{Y} q}$ & $\begin{array}{l}\text { second-order rate coefficients for surface layer reactions of } \\
\mathrm{X}_{p} \text { with } \mathrm{X}_{q}, \mathrm{X}_{p} \text { with } \mathrm{Y}_{q} \text {, and } \mathrm{Y}_{p} \text { with } \mathrm{Y}_{q} \text {, respectively }\end{array}$ & $\mathrm{m}^{2} \mathrm{~s}^{-1}$ \\
\hline$K_{\text {ads, } \mathrm{X} i}$ & adsorption equilibrium constant of $\mathrm{X}_{i}$ & $\mathrm{~m}^{3}$ \\
\hline$K_{\mathrm{ads}, \mathrm{X} i}^{\prime}$ & effective adsorption equilibrium constant of $\mathrm{X}_{i}$ & $\mathrm{~m}^{3}$ \\
\hline$K_{\mathrm{sol}, \mathrm{cp}, \mathrm{X} i}$ & $\begin{array}{l}\text { solubility or gas-particle partitioning coefficient of } \mathrm{X}_{i} \\
\text { (concentration/pressure) }\end{array}$ & mol m${ }^{-3} \mathrm{~Pa}^{-1}$ \\
\hline$K_{\mathrm{sol}, \mathrm{cc}, \mathrm{X} i}$ & dimensionless solubility or gas-particle partitioning coefficient of $\mathrm{X}_{i}$ & \\
\hline$K n_{\mathrm{X} i}$ & Knudsen number for $\mathrm{X}_{i}$ & \\
\hline$l_{\mathrm{rd}, \mathrm{X} i}$ & reacto-diffusive length for $\mathrm{X}_{i}$ in the particle bulk & $\mathrm{m}$ \\
\hline$M_{\mathrm{X} i}$ & molar mass of $\mathrm{X}_{i}$ & $\mathrm{~kg} \mathrm{~mol}^{-1}$ \\
\hline & Avogadro constant & $\mathrm{mol}^{-1}$ \\
\hline$P_{\mathrm{b}, \mathrm{ss}, \mathrm{X} i}, L_{\mathrm{b}, \mathrm{ss}, \mathrm{X} i}$ & $\begin{array}{l}\text { chemical production and loss of } X_{i} \text { in the near surface bulk } \\
\text { by surface-bulk reactions }\end{array}$ & $\mathrm{m}^{-2} \mathrm{~s}^{-1}$ \\
\hline$P_{\mathrm{b}, \mathrm{ss}, \mathrm{Y}}, L_{\mathrm{b}, \mathrm{ss}, \mathrm{Y} j}$ & $\begin{array}{l}\text { chemical production and loss of } Y_{j} \text { in the near surface bulk } \\
\text { by surface-bulk reactions }\end{array}$ & $\mathrm{m}^{-2} \mathrm{~s}^{-1}$ \\
\hline$P_{\mathrm{g}, \mathrm{gsr}, \mathrm{X} i}, L_{\mathrm{g}, \mathrm{gsr}, \mathrm{X} i}$ & chemical production and loss of gas phase $X_{i}$ by gas-surface reactions & $\mathrm{m}^{-2} \mathrm{~s}^{-1}$ \\
\hline$P_{\mathrm{g}, \mathrm{p}, \mathrm{X} i}, L_{\mathrm{g}, \mathrm{p}, \mathrm{X} i}$ & gas phase production and loss of $X_{i}$ due to gas-particle interactions & $\mathrm{m}^{-3} \mathrm{~s}^{-1}$ \\
\hline$P_{\mathrm{s}, \mathrm{X} i}, L_{\mathrm{s}, \mathrm{X} i}$ & chemical production and loss of $X_{i}$ in the sorption layer & $\mathrm{m}^{-2} \mathrm{~s}^{-1}$ \\
\hline$P_{\mathrm{s}, \mathrm{g}, \mathrm{X} i}, L_{\mathrm{s}, \mathrm{g}, \mathrm{X} i}$ & chemical production and loss of $X_{i}$ in the sorption layer by gas-surface reactions & $\mathrm{m}^{-2} \mathrm{~s}^{-1}$ \\
\hline$P_{\mathrm{s}, \mathrm{s}, \mathrm{X} i}, L_{\mathrm{s}, \mathrm{s}, \mathrm{X} i}, P_{\mathrm{s}, \mathrm{ss}, \mathrm{X} i}, L_{\mathrm{s}, \mathrm{ss}, \mathrm{X} i}$ & $\begin{array}{l}\text { chemical production and loss of } X_{i} \text { in the sorption layer } \\
\text { by surface layer reactions (reaction partner in sorption } \\
\text { or quasi-static layer, respectively) }\end{array}$ & $\mathrm{m}^{-2} \mathrm{~s}^{-1}$ \\
\hline$P_{\mathrm{ss}, \mathrm{Y} j}, L_{\mathrm{ss}, \mathrm{Y} j}$ & chemical production and loss of $Y_{j}$ in the quasi-static surface layer & $\mathrm{m}^{-2} \mathrm{~s}^{-1}$ \\
\hline$P_{\mathrm{ss}, \mathrm{b}, \mathrm{Y} j}, L_{\mathrm{ss}, \mathrm{b}, \mathrm{Y} j}$ & $\begin{array}{l}\text { chemical production and loss of } \mathrm{Y}_{j} \text { in the quasi-static surface layer } \\
\text { by surface-bulk reactions }\end{array}$ & $\mathrm{m}^{-2} \mathrm{~s}^{-1}$ \\
\hline$P_{\mathrm{ss}, \mathrm{g}, \mathrm{Y} j}, L_{\mathrm{ss}, \mathrm{g}, \mathrm{Y} j}$ & $\begin{array}{l}\text { chemical production and loss of } \mathrm{Y}_{j} \text { in the quasi-static surface layer } \\
\text { by gas-surface reactions }\end{array}$ & $\mathrm{m}^{-2} \mathrm{~s}^{-1}$ \\
\hline$P_{\mathrm{ss}, \mathrm{s}, \mathrm{Y} j}, L_{\mathrm{ss}, \mathrm{s}, \mathrm{Y} j}, P_{\mathrm{ss}, \mathrm{ss}, \mathrm{Y} j}, L_{\mathrm{ss}, \mathrm{ss}, \mathrm{Y} j}$ & $\begin{array}{l}\text { chemical production and loss of } \mathrm{Y}_{j} \text { in the quasi-static layer by surface layer reactions } \\
\text { (reaction partner in sorption or quasi-static layer, respectively) }\end{array}$ & $\mathrm{m}^{-2} \mathrm{~s}^{-1}$ \\
\hline$[\mathrm{PS}]_{g}$ & particle surface concentration & $\mathrm{m}^{2} \mathrm{~m}^{-3}$ \\
\hline
\end{tabular}




\begin{tabular}{lll}
\hline Symbol & Meaning & $\mathrm{SI} \mathrm{Unit}$ \\
\hline$R$ & gas constant & $\mathrm{J} \mathrm{K}^{-1} \mathrm{~mol}^{-1}$ \\
$r_{\mathrm{p}}$ & particle radius & $\mathrm{m}^{-2}$ \\
{$[\mathrm{SS}]_{\mathrm{ss}}$} & sorption site surface concentration & $\mathrm{m}^{-2}$ \\
$T$ & absolute temperature & $\mathrm{K}$ \\
$u_{\max }, v_{\max }, w_{\max }$ & total number of gas-surface, surface-layer, and surface-bulk reactions, respectively & \\
$\mathrm{X}_{i}$ & volatile molecular species & $\mathrm{m}^{-3}$ \\
{$\left[\mathrm{X}_{i}\right]_{\mathrm{b}}$} & particle bulk number concentration of $\mathrm{X}_{i}$ & $\mathrm{~m}^{-3}$ \\
{$\left[\mathrm{X}_{i}\right]_{\mathrm{bs}}$} & near-surface particle bulk number concentration of $\mathrm{X}_{i}$ & $\mathrm{~m}^{-3}$ \\
{$\left[\mathrm{X}_{i}\right]_{\mathrm{b}, \text { sat }}$} & saturation particle bulk number concentration of $\mathrm{X}_{i}$ & $\mathrm{~m}^{-3}$ \\
{$\left[\mathrm{X}_{i}\right]_{\mathrm{g}}$} & gas phase number concentration of $\mathrm{X}_{i}$ & $\mathrm{~m}^{-3}$ \\
{$\left[\mathrm{X}_{i}\right]_{\mathrm{gs}}$} & near-surface gas phase number concentration of $\mathrm{X}_{i}$ & $\mathrm{~m}^{-3}$ \\
{$\left[\mathrm{X}_{i}\right]_{\mathrm{g}, \mathrm{sat}}$} & saturation gas phase number concentration of $\mathrm{X}_{i}$ & $\mathrm{~m}^{-2}$ \\
{$\left[\mathrm{X}_{i}\right]_{\mathrm{s}}$} & surface number concentration of $\mathrm{X}_{i}$ (sorption layer) & $\mathrm{m}^{-2}$ \\
{$\left[\mathrm{X}_{i}\right]_{\mathrm{s}, \mathrm{max}}$} & maximum surface number concentration of $\mathrm{X}_{i}($ sorption layer) & \\
$\mathrm{Y}_{j}$ & non-volatile molecular species & $\mathrm{m}^{-2}$ \\
{$\left[\mathrm{Y}_{j}\right]_{\mathrm{ss}}$} & surface number concentration of $\mathrm{Y}_{j}$ (quasi-static layer) & $\mathrm{m}^{-3}$ \\
{$\left[\mathrm{Y}_{j}\right]_{\mathrm{b}}$} & particle bulk number concentration of $\mathrm{Y}_{j}$ & $\mathrm{~m}^{-3}$ \\
{$\left[\mathrm{Y}_{j}\right]_{\mathrm{bs}}$} & near-surface particle bulk number concentration of $\mathrm{Y}_{j}$ & \\
$\mathrm{Z}_{k}$ & semivolatile molecular species & $\mathrm{m}^{-2}$ \\
{$\left[\mathrm{Z}_{k}\right]_{\mathrm{s}}$} & surface number concentration of $\mathrm{Z}_{k}$ (sorption layer) & $\mathrm{m}^{-2}$ \\
{$\left[\mathrm{Z}_{k}\right]_{\mathrm{ss}}$} & surface number concentration of $\mathrm{Z}_{k}$ (quasi-static layer) & \\
\hline
\end{tabular}

Acknowledgements. The authors would like to thank T. BartelsRausch, K. Carslaw, S. Clegg, T. Cox, N. Deisel, W. Elbert, R. Garland, G. Held, M. Kerbrat, M. Kulmala, T. Mentel, N. Otto, T. Peter, R. Remorov, D. Rose, R. Sander, J. Scheintaub, U. Schurath, D. Worsnop, an anonymous referee, and many other members of the atmospheric science community for stimulating discussions and support. This work was supported by the European Integrated Project on Aerosol Cloud Climate and Air Quality Interactions (EUCAARI). U. Pöschl acknowledges support by the German Federal Ministry of Education and Research (BMBF, AFO2000 07ATC05, CARBAERO). Y. Rudich acknowledges support from the Israel Science Foundation and from the Minerva Foundation with funding from the German Federal Ministry of Education and Research. M. Ammann acknowledges support by the Swiss National Science Foundation (grant no. 200020-100275).

Edited by: M. Kulmala 


\section{References}

Abo Riziq, A., Dinar, E., Erlick, C., and Rudich, Y.: Optical properties of absorbing and non-absorbing aerosols retrieved by cavity ring down (CRD) spectroscopy, Atmos. Chem. Phys., 7, 15231536, 2007, http://www.atmos-chem-phys.net/7/1523/2007/.

Adams, J. W., Holmes, N. S., and Crowley, J. N.: Uptake and reaction of $\mathrm{HOBr}$ on frozen and dry $\mathrm{NaCl} / \mathrm{NaBr}$ surfaces between 253 and 233 K, Atmos. Chem. Phys., 2, 79-91, 2002,

http://www.atmos-chem-phys.net/2/79/2002/.

Adams, J. W., Rodriguez, D., and Cox, R. A.: The uptake of SO2 on Saharan dust: a flow tube study, Atmos. Chem. Phys., 5, 26792689, 2005,

http://www.atmos-chem-phys.net/5/2679/2005/.

Al-Hosney, H. A. and Grassian, V. H.: Water, sulfur dioxide and nitric acid adsorption on calcium carbonate: A transmission and ATR-FTIR study, Phys. Chem. Chem. Phys., 7, 1266-1276, 2005.

Ammann, M., Pöschl, U., and Rudich, Y.: Effects of reversible adsorption and Langmuir-Hinshelwood surface reactions on gas uptake by atmospheric particles, Phys. Chem. Chem. Phys., 5, 351-356, 2003.

Ammann, M. and Pöschl, U.: Kinetic model framework for aerosol and cloud surface chemistry and gas-particle interactions - Part 2: exemplary practical applications and numerical simulations, Atmos. Chem. Phys., 7, 6025-6045, 2007,

http://www.atmos-chem-phys.net/7/6025/2007/.

Andreae, M. O. and Crutzen, P. J.: Atmospheric aerosols: biogeochemical sources and role in atmospheric chemistry, Science, 276, 1052-1058, 1997.

Arens, F., Gutzwiller, L., Baltensperger, U., Gäggeler, H. W., and Ammann, M.: Heterogeneous reaction of NO2 on diesel soot particles, Environ. Sci. Technol., 35, 2191-2199, 2001.

Asad, A., Mmereki, B. T., and Donaldson, D. J.: Enhanced uptake of water by oxidatively processed oleic acid, Atmos. Chem. Phys., 4, 2083-2089, 2004,

http://www.atmos-chem-phys.net/4/2083/2004/.

Atkinson, R., Baulch, D. L., Cox, R. A., Hampson, R. F., Kerr, J. A., Rossi, M. J., and Troe, J.: Evaluated kinetic, photochemical and heterogeneous data for atmospheric chemistry: Supplement V, IUPAC submcommittee on gas kinetic data evaluation for atmospheric chemistry, J. Phys. Chem. Ref. Data, 26, 521-1011, 1997.

Atkinson, R., Baulch, D. L., Cox, R. A., Crowley, J. N., Hampson, R. F., Hynes, R. G., Jenkin, M. E., Rossi, M. J., and Troe, J.: Evaluated kinetic and photochemical data for atmospheric chemistry: Volume $\mathrm{I}$ - gas phase reactions of $\mathrm{O}_{\mathrm{x}}, \mathrm{HO}_{\mathrm{x}}, \mathrm{NO}_{\mathrm{x}}$ and $\mathrm{SO}_{\mathrm{x}}$ species, Atmos. Chem. Phys., 4, 1461-1738, 2004, http://www.atmos-chem-phys.net/4/1461/2004/.

Atkinson, R., Baulch, D. L., Cox, R. A., Crowley, J. N., Hampson, R. F., Hynes, R. G., Jenkin, M. E., Rossi, M. J., Troe, J., and IUPAC Subcommittee: Evaluated kinetic and photochemical data for atmospheric chemistry: Volume II - gas phase reactions of organic species, Atmos. Chem. Phys., 6, 3625-4055, 2006, http://www.atmos-chem-phys.net/6/3625/2006/.

Atkinson, R., Baulch, D. L., Cox, R. A., Crowley, J. N., Hampson, R. F., Hynes, R. G., Jenkin, M. E., Rossi, M. J., and Troe, J.: Evaluated kinetic and photochemical data for atmospheric chemistry: Volume III - gas phase reactions of inorganic halogens,
Atmos. Chem. Phys., 7, 981-1191, 2007, http://www.atmos-chem-phys.net/7/981/2007/.

Aumont, B., Szopa, S., and Madronich, S.: Modelling the evolution of organic carbon during its gas-phase tropospheric oxidation: development of an explicit model based on a self generating approach, Atmos. Chem. Phys., 5, 2497-2517, 2005, http://www.atmos-chem-phys.net/5/2497/2005/.

Austin, J., Shindell, D., Beagley, S. R., Bruhl, C., Dameris, M., Manzini, E., Nagashima, T., Newman, P., Pawson, S., Pitari, G., Rozanov, E., Schnadt, C., and Shepherd, T. G.: Uncertainties and assessments of chemistry-climate models of the stratosphere, Atmos. Chem. Phys., 3, 1-27, 2003, http://www.atmos-chem-phys.net/3/1/2003/.

Baetzold, R. C. and Somorjai, G. A.: Preexponential factors in surface reactions, J. Catal., 45, 94-105, 1976.

Bartels-Rausch, T., Eichler, B., Zimmermann, P., Gaggeler, H. W., and Ammann, M.: The adsorption enthalpy of nitrogen oxides on crystalline ice, Atmos. Chem. Phys., 2, 235-247, 2002, http://www.atmos-chem-phys.net/2/235/2002/.

Bartels-Rausch, T., Huthwelker, T., Gaeggeler, H. W., and Ammann, M.: An atmospheric pressure coated wall flow tube study of acetone adsorption on ice, J. Phys. Chem. A, 109, 4531-4539, 2005.

Berry, R. S., Rice, S. A., and Ross, J.: Physical Chemistry, Oxford University Press, New York, 2000.

Bertram, A. K., Ivanov, A. V., Hunter, M., Molina, L. T., and Molina, M. J.: The reaction probability of $\mathrm{OH}$ on organic surfaces of tropospheric interest, J. Phys. Chem. A, 105, 9415-9421, 2001.

Bloss, C., Wagner, V., Bonzanini, A., Jenkin, M. E., Wirtz, K., Martin-Reviejo, M., and Pilling, M. J.: Evaluation of detailed aromatic mechanisms (MCMv3 and MCMv3.1) against environmental chamber data, Atmos. Chem. Phys., 5, 623-639, 2005a.

Bloss, C., Wagner, V., Jenkin, M. E., Volkamer, R., Bloss, W. J., Lee, J. D., Heard, D. E., Wirtz, K., Martin-Reviejo, M., Rea, G., Wenger, J. C., and Pilling, M. J.: Development of a detailed chemical mechanism (MCMv3.1) for the atmospheric oxidation of aromatic hydrocarbons, Atmos. Chem. Phys., 5, 641-664, $2005 b$.

Bömmel, H., Haake, M., Luft, P., Horejs-Hoeck, J., Hein, H., Bartels, J., Schauer, C., Pöschl, U., Kracht, M., and Duschl, A.: The diesel exhaust component pyrene induces expression of IL-8 but not of eotaxin, Intern. Immunopharmacol., 3, 1371-1379, 2003.

Broekhuizen, K., Kumar, P. P., and Abbatt, J. P. D.: Partially soluble organics as cloud condensation nuclei: Role of trace soluble and surface active species, Geophys. Res. Lett., 31, 1107, doi:10.1029/2003GL018203, 2004.

Broske, R., Kleffmann, J., and Wiesen, P.: Heterogeneous conversion of NO2 on secondary organic aerosol surfaces: A possible source of nitrous acid (HONO) in the atmosphere?, Atmos. Chem. Phys., 3, 469-474, 2003, http://www.atmos-chem-phys.net/3/469/2003/.

Carslaw, K. S. and Peter, T.: Uncertainties in reactive uptake coefficients for solid stratospheric particles, 1. Surface chemistry, Geophys. Res. Lett., 24, 1743-1746, 1997.

Chan, A. W. H., Kroll, J. H., Ng, N. L., and Seinfeld, J. H.: Kinetic modeling of secondary organic aerosol formation: effects of particle- and gas-phase reactions of semivolatile products, Atmos. Chem. Phys., 7, 4135-4147, 2007, 
http://www.atmos-chem-phys.net/7/4135/2007/.

Clegg, S. M. and Abbatt, J. P. D.: Uptake of gas-phase SO2 and $\mathrm{H} 2 \mathrm{O} 2$ by ice surfaces: Dependence on partial pressure, temperature, and surface acidity, J. Phys. Chem. A, 105, 6630-6636, 2001.

Clement, C. F., Kulmala, M., and Vesala, T.: Theoretical consideration on sticking probabilities, J. Aerosol Sci., 27, 869-882, 1996.

Coe, H., Allan, J. D., Alfarra, M. R., Bower, K. N., Flynn, M. J., McFiggans, G. B., Topping, D. O., Williams, P. I., O’Dowd, C. D., Dall'Osto, M., Beddows, D. C. S., and Harrison, R. M.: Chemical and physical characteristics of aerosol particles at a remote coastal location, Mace Head, Ireland, during NAMBLEX, Atmos. Chem. Phys., 6, 3289-3301, 2006, http://www.atmos-chem-phys.net/6/3289/2006/.

Croft, B., Lohmann, U., and von Salzen, K.: Black carbon ageing in the Canadian Centre for Climate modelling and analysis atmospheric general circulation model, Atmos. Chem. Phys., 5, 1931-1949, 2005,

http://www.atmos-chem-phys.net/5/1931/2005/.

Danckwerts, P. V.: Absorption by Simultaneous Diffusion and Chemical Reaction into Particles of Various Shapes and into Falling Drops, Trans. Faraday Soc., 47, 1014-1023, 1951.

da Rosa, M. B., Behnke, W., and Zetzsch, C.: Study of the heterogeneous reaction of $\mathrm{O}-3$ with $\mathrm{CH} 3 \mathrm{SCH} 3$ using the wetted-wall flowtube technique, Atmos. Chem. Phys., 3, 1665-1673, 2003, http://www.atmos-chem-phys.net/3/1665/2003/.

Davidovits, P., Jayne, J. T., Duan, S. X., Worsnop, D. R., Zahniser, M. S., and Kolb, C. E.: Uptake of Gas Molecules by Liquids: A Model, J. Phys. Chem., 95, 6337-6340, 1991.

Davidovits, P., Hu, J. H., Worsnop, D. R., Zahniser, M. S., and Kolb, C. E.: Entry of gas molecules into liquids, Faraday Discuss., 100, 65-81, 1995.

Davidovits, P., D. R.Worsnop, J. T. Jayne, C. E. Kolb, P. Winkler, A. Vrtala, P. E.Wagner, M. Kulmala, K. E. J. Lehtinen, T. Vesala, and M. Mozurkewich: Mass accommodation coefficient of water vapor on liquid water. Geophys. Res. Lett., 31, L22111, doi:10.1029/2004GL020835, 2004.

Davidovits, P., Worsnop, D. R., Williams, L. R., Kolb, C. E., and Gershenzon, M.: Comment on "Mass accommodation coefficient of water: Molecular dynamics simulation and revised analysis of droplet train/flow reactor experiment", J. Phys. Chem. B, 109, 14 742-14 746, 2005.

Delzeit, L., Devlin, M. S., Rowland, B., Devlin, J. P., and Buch, V.: Adsorbate-induced partial ordering of the irregular surface and subsurface of crystalline ice, J. Phys. Chem., 100, 10076 $10082,1996$.

Dinar, E., Mentel, T. F., and Rudich, Y.: The density of humic and humic like substances (HULIS) from fresh and aged wood burning and pollution aerosol particles, Atmos. Chem. Phys., 6, 5213-5224, 2006a.

Dinar, E., Taraniuk, I., Graber, E. R., Katsman, S., Moise, T., Anttila, T., Mentel, T. F., and Rudich, Y.: Cloud condensation nuclei properties of model and atmospheric HULIS, Atmos. Chem. Phys., 6, 2465-2482, 2006b.

Dinar, E., Taraniuk, I., Graber, E. R., Anttila, T., Mentel, T. F., and Rudich, Y.: Hygroscopic growth of model and atmospheric humic like substances (HULIS), J. Geophys. Res., D112, D05211, doi:05210.01029/02006JD007442, 2007.
Dinar, E., Abo Riziq, A., Spindler, C., Erlick, C., Kiss, G., and Rudich, Y.: The complex refractive index of atmospheric and model humic-like substances (HULIS) retrieved by a cavity ring down aerosol spectrometer (CRD-AS), Faraday Discuss., 137, 279-295, 2008.

Djikaev, Y. S. and Tabazadeh, A.: Effect of adsorption on the uptake of organic trace gas by cloud droplets, J. Geophys. Res., 108(D22), 4689, doi:10.1029/2003JD003741, 2003.

Donaldson, D. J.: Adsorption of atmospheric gases at the air-water interface.I. NH3, J. Phys. Chem. A, 103, 62-70, 1999.

Dubowski, Y., Vieceli, J., Tobias, D. J., Gomez, A., Lin, A., Nizkorodov, S. A., McIntire, T. M., and Finlayson-Pitts, B. J.: Interaction of gas-phase ozone at $296 \mathrm{~K}$ with unsaturated self-assembled monolayers: A new look at an old system, J. Phys. Chem. A, 108, 10473-10 485, 2004.

Elbert, W., Taylor, P. E., Andreae, M. O., and Pschl, U.: Contribution of fungi to primary biogenic aerosols in the atmosphere: wet and dry discharged spores, carbohydrates, and inorganic ions, Atmos. Chem. Phys., 7, 4569-4588, 2007, http://www.atmos-chem-phys.net/7/4569/2007/.

Elliott, S., Turco, R. P., Toon, O. B., and Hamill, P.: Application of Physical adsorption thermodynamics to heterogeneous chemistry on polar stratospheric clouds, J. Atmos. Chem., 13, 211224, 1991.

Ervens, B., George, C., Williams, J. E., Boxton, G. V., Salmon, G. A., Bydder, M., Wilkinsons, F., Dentener, F., Mirabel, P., Wolke, R., and Herrmann, H.: CAPRAM 2.4 (MODAC mechanism): An extended and condensed tropospheric aqueous phase mechanism and its application, J. Geophys. Res., 108, 4426, doi:10.1029/2002JD002202, 2003.

Finlayson-Pitts, B. J. and Pitts Jr., J. N.: Tropospheric air pollution: ozone, airborne toxics, polycyclic aromatic hydrocarbons, and particles, Science, 276, 1045-1052, 1997.

Finlayson-Pitts, B. J. and Pitts Jr., J. N.: Chemistry of the upper and lower atmosphere, Academic Press, San Diego, 2000.

Folkers, M., Mentel, T. F., and Wahner, A.: Influence of an organic coating on the reactivity of aqueous aerosols probed by the heterogeneous hydrolysis of N2O5, Geophys. Res. Lett., 30, 1644, doi:10.1029/2003GL017168, 2003.

Franze, T., Weller, M. G., Niessner, R., and Pöschl, U.: Protein nitration by polluted air, Environ. Sci. Technol., 39, 1673-1678, doi:10.1021/es0488737, 2005.

Frinak, E. K., Wermeille, S. J., Mashburn, C. D., Tolbert, M. A., and Pursell, C. J.: Heterogeneous reaction of gaseous nitric acid on gamma-phase iron(III) oxide, J. Phys. Chem. A, 108, 1560 1566, 2004.

Fuchs, N. A.: The mechanics of aerosols, Pergamon, Oxford, 1964.

Fuchs, N. A. and Sutugin, A. G.: High-dispersed aerosols, in: Topics in current aerosol research, edited by: Hidy, G. M. and Brock, J. R., Pergamon, New York, 1971.

Fuzzi, S., Andreae, M. O., Huebert, B. J., Kulmala, M., Bond, T. C., Boy, M., Doherty, S. J., Guenther, A., Kanakidou, M., Kawamura, K., Kerminen, V. M., Lohmann, U., Russell, L. M., and Pöschl, U.: Critical assessment of the current state of scientific knowledge, terminology, and research needs concerning the role of organic aerosols in the atmosphere, climate, and global change, Atmos. Chem. Phys., 6, 2017-2038, 2006, http://www.atmos-chem-phys.net/6/2017/2006/.

Garrett, B. C., Schenter, G. K., and Morita, A.: Molecular sim- 
ulations of the transport of molecules across the liquid/vapour interface of water, Chem. Rev., 106, 1355-1374, 2006.

Gauderman, W. J., Avol, E., Gilliland, F., Vora, H., Thomas, D., Berhane, K., McConnell, R., Kuenzli, N., Lurmann, F., Rappaport, E., Margolis, H., Bates, D., and Peters, J.: The effect of air pollution on lung development from 10 to 18 years of age, New Eng. J. Med., 351, 1057-1067, 2004.

Gelencser, A., Hoffer, A., Kiss, G., Tombacz, E., Kurdi, R., and Bencze, L.: In-situ formation of light-absorbing organic matter in cloud water, J. Atmos. Chem., 45, 25-33, 2003.

George, I. J., Vlasenko, A., Slowik, J. G., Broekhuizen, K., and Abbatt, J. P. D.: Heterogeneous oxidation of saturated organic aerosols by hydroxyl radicals: uptake kinetics, condensed-phase products, and particle size change, Atmos. Chem. Phys., 7, 4187-4201, 2007,

http://www.atmos-chem-phys.net/7/4187/2007/.

Girardet, C. and Toubin, C.: Molecular atmospheric pollutant adsorption on ice: a theoretical survey, Surf. Sci. Reports, 281, 179, 2001.

Goss, K.-U.: The air-surface adsorption equilibrium of organic compounds under ambient conditions, Crit. Rev. Environ. Sci. Technol., 34, 339-389, 2004.

Grassian, V. H.: Heterogeneous uptake and reaction of nitrogen oxides and volatile organic compounds on the surface of atmospheric particles including oxides, carbonates, soot and mineral dust: implications for the chemical balance of the troposphere, Int. Rev. Phys. Chem., 20, 467-548, 2001.

Gray, P. G. and Do, D. D.: Modeling of the interaction of nitrogendioxide with activated carbon, 1. Adsorption dynamics at the single-particle scale, Chem. Eng. Commun., 117, 219-240, 1992.

Gruijthuijsen, Y. K., Grieshuber, I., Stcklinger, A., Tischler, U., Fehrenbach, T., Weller, M. G., Vogel, L., Vieths, S., Pschl, U., and Duschl, A.: Nitration enhances the allergenic potential of proteins, Int. Arch. Allergy Imm., 141, 265-275, 2006.

Gustafsson, R. J., Orlov, A., Badger, C. L., Griffiths, P. T., Cox, R. A., and Lambert, R. M.: A comprehensive evaluation of water uptake on atmospherically relevant mineral surfaces: DRIFT spectroscopy, thermogravimetric analysis and aerosol growth measurements, Atmos. Chem. Phys., 5, 3415-3421, 2005, http://www.atmos-chem-phys.net/5/3415/2005/.

Hanson, D. R., Ravishankara, A. R., and Solomon, S.: Heterogeneous reactions in sulfuric acid aerosols: - A framework for model calculations, J. Geophys. Res., 99, 3615-3629, 1994.

Hanson, D. R.: Surface specific reactions on liquids, J. Phys. Chem. B, 101, 4998-5001, 1997.

Hatch, C. D., Gough, R. V., and Tolbert, M. A.: Heterogeneous uptake of the $\mathrm{C} 1$ to $\mathrm{C} 4$ organic acids on a swelling clay mineral, Atmos. Chem. Phys., 7, 4445-4458, 2007, http://www.atmos-chem-phys.net/7/4445/2007/.

Hinshelwood, C. N.: The kinetics of chemical change, Clarendon, Oxford, 1940.

Hobbs, P. V., Sinha, P., Yokelson, R. J., Christian, T. J., Blake, D. R., Gao, S., Kirchstetter, T. W., Novakov, T., and Pilewskie, P.: Evolution of gases and particles from a savanna fire in South Africa, J. Geophys. Res., 108, 8485, doi:10.1029/2002JD002352, 2003.

Hynes, R. G., Fernandez, M. A., and Cox, R. A.: Uptake of $\mathrm{HNO} 3$ on water-ice and coadsorption of $\mathrm{HNO} 3$ and $\mathrm{HCl}$ in the temperature range 210-235 K, J. Geophys. Res., 107, 4797,
doi:10.1029/2001JD001557, 2002.

Ivleva, N. P., Messerer, A. K., Yang, X., Niessner, R., and Pöschl, U.: Raman microspectroscopic analysis of changes in the chemical structure and reactivity of soot in a diesel exhaust aftertreatment model system, Environ. Sci. Technol., 41, 3702-3707, 2007.

Jayne, J. T., Davidovits, P., Worsnop, D. R., Zahniser, M. S., and Kolb, C. E.: Uptake of SO2(g) by aqueous surfaces as a function of $\mathrm{pH}$ : The effect of chemical reaction at the interface, J. Phys. Chem., 94, 6041-6048, 1990.

Jayne, J. T., Pöschl, U., Chen, Y.-M., Dai, D., Molina, L. T., Worsnop, D. R., Kolb, C. E., and Molina, M. J.: Pressure and temperature dependence of the gas-phase reaction of $\mathrm{SO} 3$ with $\mathrm{H} 2 \mathrm{O}$ and the heterogeneous reaction of $\mathrm{SO} 3$ with $\mathrm{H} 2 \mathrm{O} / \mathrm{H} 2 \mathrm{SO} 4$ surfaces, J. Phys. Chem. A, 101, 10 000-10 011, 1997.

Jenkin, M. E., Saunders, S. M., Wagner, V., and Pilling, M. J.: Protocol for the development of the Master Chemical Mechanism, MCM v3 (Part B): tropospheric degradation of aromatic volatile organic compounds, Atmos. Chem. Phys., 3, 181-193, 2003, http://www.atmos-chem-phys.net/3/181/2003/.

Jöckel, P., Sander, R., Kerkweg, A., Tost, H., and Lelieveld, J.: Technical Note: The Modular Earth Submodel System (MESSy) - a new approach towards Earth System Modeling, Atmos. Chem. Phys., 5, 433-444, 2005, http://www.atmos-chem-phys.net/5/433/2005/.

Johnson, D., Utembe, S. R., Jenkin, M. E., Derwent, R. G., Hayman, G. D., Alfarra, M. R., Coe, H., and McFiggans, G.: Simulating regional scale secondary organic aerosol formation during the TORCH 2003 campaign in the southern UK, Atmos. Chem. Phys., 6, 403-418, 2006,

http://www.atmos-chem-phys.net/6/403/2006/.

Jost, C., Trentmann, J., Sprung, D., Andreae, M. O., McQuaid, J. B., and Barjat, H.: Trace gas chemistry in a young biomass burning plume over Namibia: Observations and model simulations, J. Geophys. Res., 108, 8482, doi:10.1029/2002JD002431, 2003.

Kahan, T. F., Kwamena, N.-O. A., and Donaldson, D. J.: Heterogeneous ozonation kinetics of polycyclic aromatic hydrocarbons on organic films, Atmos. Environ., 40, 3448-3459, 2006.

Kwamena, N.-O. A., Thornton, J. A., and Abbatt, J. P. D.: Kinetics of surface-bound benzo[a]pyrene and ozone on solid organic and salt aerosols, J. Phys. Chem. A, 108, 11 626-11 634, 2004.

Kwamena, N.-O. A., Earp, M. E., Young, C. J., Abbatt, J. P. D.: Kinetic and product yield study of the heterogeneous gas-surface reaction of anthracene and ozone, J. Phys. Chem. A, 110, 36383646, 2006.

Kwamena, N.-O. A., Clarke, J. P., Kahan, T. F., Diamond, M. L., and Donaldson, D. J.: Assessing the importance of heterogeneous reactions of polycyclic aromatic hydrocarbons in the urban atmosphere using the multimedia urban model, Atmos. Environ. 41, 37-50, 2007.

Kanakidou, M., Seinfeld, J. H., Pandis, S. N., Barnes, I., Dentener, F. J., Facchini, M. C., van Dingenen, R., Ervens, B., Nenes, A., Nielsen, C. J., Swietlicki, E., Putaud, J. P., Balkanski, Y., Fuzzi, S., Horth, J., Moortgat, G. K., Winterhalter, R., Myhre, C. E. L., Tsigaridis, K., Vignati, E., Stephanou, E. G., and Wilson, J.: Organic aerosol and global climate modelling: a review, Atmos. Chem. Phys., 5, 1053-1123, 2005,

http://www.atmos-chem-phys.net/5/1053/2005/.

Karagulian, F., Santschi, C., and Rossi, M. J.: The heterogeneous 
chemical kinetics of $\mathrm{N} 2 \mathrm{O} 5$ on $\mathrm{CaCO} 3$ and other atmospheric mineral dust surrogates, Atmos. Chem. Phys., 6, 1373-1388, 2006 , http://www.atmos-chem-phys.net/6/1373/2006/.

Katrib, Y., Deiber, G., Schweitzer, F., Mirabel, P., and George, C.: Chemical transformation of bromine chloride at the air/water interface, J. Aerosol Sci., 32, 893-911, 2001.

Katrib, Y., Martin, S. T., Rudich, Y., Davidovits, P., Jayne, J. T., and Worsnop, D. R.: Density changes of aerosol particles as a result of chemical reaction, Atmos. Chem. Phys., 5, 275-291, 2005, http://www.atmos-chem-phys.net/5/275/2005/.

Katsouyanni, K., Touloumi, G., Samoli, E., Gryparis, A., Le Tertre, A., Monopolis, Y., Rossi, G., Zmirou, D., Ballester, F., Boumghar, A., Anderson, H. R., Wojtyniak, B., Paldy, A., Braunstein, R., Pekkanen, J., Schindler, C., and Schwartz, J.: Confounding and effect modification in the short-term effects of ambient particles on total mortality: results from 29 European cities within the APHEA2 project, Epidemiology 12, 521-531, 2001.

Kleffmann, J. and Wiesen, P.: Heterogeneous conversion of NO2 and $\mathrm{NO}$ on $\mathrm{HNO} 3$ treated soot surfaces: atmospheric implications, Atmos. Chem. Phys., 5, 77-83, 2005, http://www.atmos-chem-phys.net/5/77/2005/.

Kolb, C. E., Worsnop, D. R., Zahniser, M. S., Davidovits, P., Keyser, L. F., Leu, M.-T., Molina, M. J., Hanson, D. R., Ravishankara, A. R., Williams, L. R., and Tolbert, M. A.: Laboratory studies of atmospheric heterogeneous chemistry, in: Progress and Problems of Atmospheric Chemistry, edited by: J. R. Barker, Chap. 18, Advanced Series in Physical Chemistry, edited by: C.-Y. Ng, World Scientific, Singapore, Vol. 3, 1995.

Kulmala, M. and Vesala T.: Condensation in the Continuum Regime, J. Aerosol Sci., 22, 337-346, 1991.

Kulmala, M. and Wagner, P. E.: Mass accommodation and uptake coeffcients - a quantitative comparison, J. Aerosol Sci., 32, 833$841,2001$.

Kulmala, M., Suni, T., Lehtinen, K. E. J., Dal Maso, M., Boy, M., Reissell, A., Rannik, Ü., Aalto, P., Keronen, P., Hakola, H., Bäck, J., Hoffmann, T., Vesala, T., and Hari, P.: A new feedback mechanism linking forests, aerosols, and climate, Atmos. Chem. Phys., 4, 557-562, 2004,

http://www.atmos-chem-phys.net/4/557/2004/.

Kumar, P. P., Broekhuizen, K., and Abbatt, J. P. D.: Organic acids as cloud condensation nuclei: Laboratory studies of highly soluble and insoluble species, Atmos. Chem. Phys., 3, 949-982, 2003, http://www.atmos-chem-phys.net/3/949/2003/.

Laaksonen, A., Vesala, T., Kulmala, M., Winkler, P. M., and Wagner, P. E.: Commentary on cloud modelling and the mass accommodation coefficient of water, Atmos. Chem. Phys., 5, 461-464, 2005 ,

http://www.atmos-chem-phys.net/5/461/2005/.

Laidler, K. J., Glasstone, S., and Eyring, H.: Application of the theory of absolute reaction rates to heterogeneous processes: II. Chemical reactions on surfaces, J. Chem. Phys., 8, 659-667, 1940.

Langmuir, I.: The constitution and fundamental properties of solids and liquids, Part I. Solids, J. Am. Chem. Soc. 38, 2221-2295, 1916.

Letzel, T., Pöschl, U., Wissiack, R., Rosenberg, E., Grasserbauer, M., and Niessner, R.: Phenyl-modified reversed-phase liquid chromatography coupled to atmospheric pressure chemical ion- ization mass spectrometry: A universal method for the analysis of partially oxidized aromatic hydrocarbons, Anal. Chem., 73, 1634-1645, 2001.

Li, W. G. and Davis, E. J.: Aerosol evaporation in the transition regime, Aerosol Sci. Technol., 25, 11-21, 1996.

Li, Y. Q., Davidovits, P., Shi, Q., Jayne, J. T., Kolb, C. E., and Worsnop, D. R.: Mass and thermal accommodation coefficients of $\mathrm{H} 2 \mathrm{O}(\mathrm{g})$ on liquid water as a function of temperature, J. Phys. Chem. A, 105, 10627-10 634, 2001.

Li, L., Chen, Z. M., Zhang, Y. H., Zhu, T., Li, J. L., and Ding, J.: Kinetics and mechanism of heterogeneous oxidation of sulfur dioxide by ozone on surface of calcium carbonate, Atmos. Chem. Phys., 6, 2453-2464, 2006, http://www.atmos-chem-phys.net/6/2453/2006/.

Lohmann, U. and Feichter, J.: Global indirect aerosol effects: a review, Atmos. Chem. Phys., 5, 715-737, 2005, http://www.atmos-chem-phys.net/5/715/2005/.

Marcolli, C., Luo, B. P., Peter, T., and Wienhold, F. G.: Internal mixing of the organic aerosol by gas phase diffusion of semivolatile organic compounds, Atmos. Chem. Phys., 4, 25932599, 2004,

http://www.atmos-chem-phys.net/4/2593/2004/.

Masel, R. I.: Principles of adsorption and reaction on solid surfaces, Wiley, New York, 1996.

Maßling, A., Wiedensohler, A., Busch, B., Neusüß, C., Quinn, P., Bates, T., and Covert, D.: Hygroscopic properties of different aerosol types over the Atlantic and Indian Oceans, Atmos. Chem. Phys., 3, 1377-1397, 2003,

http://www.atmos-chem-phys.net/3/1377/2003/.

Matta, E., Facchini, M. C., Decesari, S., Mircea, M., Cavalli, F., Fuzzi, S., Putaud, J.-P., and Dell'Acqua, A.: Mass closure on the chemical species in size-segregated atmospheric aerosol collected in an urban area of the Po Valley, Italy, Atmos. Chem. Phys., 3, 623-637, 2003,

http://www.atmos-chem-phys.net/3/623/2003/.

McFiggans, G., Artaxo, P., Baltensperger, U., Coe, H., Facchini, M. C., Feingold, G., Fuzzi, S., Gysel, M., Laaksonen, A., Lohmann, U., Mentel, T. F., Murphy, D. M., O’Dowd, C. D., Snider, J. R., and Weingartner, E.: The effect of physical and chemical aerosol properties on warm cloud droplet activation, Atmos. Chem. Phys., 6, 2593-2649, 2006,

http://www.atmos-chem-phys.net/6/2593/2006/.

McNeill, V. F., Patterson, J., Wolfe, G. M., and Thornton, J. A.: The effect of varying levels of surfactant on the reactive uptake of N2O5 to aqueous aerosol, Atmos. Chem. Phys., 6, 1635-1644, 2006,

http://www.atmos-chem-phys.net/6/1635/2006/.

Meilinger, S. K., Kärcher, B., and Peter, T.: Suppression of chlorine activation on aviation-produced volatile particles, Atmos. Chem. Phys., 2, 307-312, 2002,

http://www.atmos-chem-phys.net/2/307/2002/.

Meilinger, S. K., Kärcher, B., and Peter, Th.: Microphysics and heterogeneous chemistry in aircraft plumes - high sensitivity on local meteorology and atmospheric composition, Atmos. Chem. Phys., 5, 533-545, 2005, http://www.atmos-chem-phys.net/5/533/2005/.

Messerer, A., Rothe, D., Pöschl, U., and Niessner, R.: Advances in the development of filterless soot deposition systems for the continuous removal or diesel particulate matter, Top. Catal., 30/31, 
247-250, 2004.

Messerer, A., Niessner, R., and Pöschl, U.: Comprehensive kinetic characterization of the oxidation and gasification of model and real diesel soot by nitrogen oxides and oxygen under engine exhaust conditions: Measurement, Langmuir-Hinshelwood, and Arrhenius parameters, Carbon, 44, 307-324 2006.

Mikhailov, E., Vlasenko, S., Niessner, R., and Pöschl, U.: Interaction of aerosol particles composed of protein and salts with water vapor: hygroscopic growth and microstructural rearrangement, Atmos. Chem. Phys., 4, 323-350, 2004,

http://www.atmos-chem-phys.net/4/323/2004/.

Mmereki, B. T., Donaldson, D. J., Gilman, J. B., Eliason, T. L., and Vaida, V.: Kinetics and products of the reaction of gas-phase ozone with anthracene adsorbed at the air-aqueous interface, Atmos. Environ., 38, 6091-6103, 2004.

Moise, T. and Rudich, Y.: Reactive uptake of ozone by proxies for organic aerosols: Surface versus bulk processes, J. Geophys. Res., 105, 14667-14 676, 2000.

Moise, T. and Rudich, Y.: Reactive uptake of $\mathrm{cl}$ and br atoms by organic surfaces - a perspective on the processing of organic aerosols by tropospheric oxidants, Geophys. Res. Lett., 28, 4083-4086, 2001.

Moise, T. and Rudich, Y.: Reactive uptake of ozone by aerosolassociated unsaturated fatty acids: Kinetics, mechanism, and products, J. Phys. Chem. A, 106, 6469-6476, 2002a.

Moise, T., Talukdar, R. K., Frost, G. J., Fox, R. W., and Rudich, Y.: The reactive uptake of NO3 by liquid and frozen organics, J. Geophys. Res., 107, 4014, doi:101629/20015D000334, 2002b.

Moise, T., Rudich, Y., Rousse, D., and George, C.: Multiphase decomposition of novel oxygenated organics in aqueous and organic media, Environ. Sci. Tech., 39, 5203-5208, 2005.

Motz, H. and Wise, H.: Diffusion and heterogeneous reaction. 3. Atom recombination at a catalytic boundary, J. Chem. Phys., 32, 1893-1894, 1960.

Mozurkewich, M.: Effect of competitive adsorption on polar stratospheric cloud reactions, Geophys. Res. Lett., 20, 355-358, 1993.

Nathanson, G. M., Davidovits, P., Worsnop, D. R., and Kolb, C. E.: Dynamics and kinetics at the gas-liquid interface, J. Phys. Chem., 100, 13 007-13 020, 1996.

O'Hanlon, D. and Forster, R. J.: Intermolecular hydrogen bonding: Two component anthraquinone monolayers, Langmuir, 16, 702707, 2000

Pechtl, S., Schmitz, G., and von Glasow, R.: Modelling iodide iodate speciation in atmospheric aerosol: Contributions of inorganic and organic iodine chemistry, Atmos. Chem. Phys., 7, 1381-1393, 2007, http://www.atmos-chem-phys.net/7/1381/2007/.

Pöschl, U., Canagaratna, M., Jayne, J. T., Molina, L. T., Worsnop, D. R., Kolb, C. E., and Molina, M. J.: Mass accommodation coefficient of $\mathrm{H} 2 \mathrm{SO} 4$ vapor on aqueous sulfuric acid surfaces and gaseous diffusion coefficient of $\mathrm{H} 2 \mathrm{SO} 4$ in N2/H2O, J. Phys. Chem. A, 102, 10 082-10 089, 1998.

Pöschl, U., von Kuhlmann, R., Poisson, N., and Crutzen, P. J.: Development and intercomparison of condensed isoprene oxidation mechanisms for global atmospheric modeling, J. Atmos. Chem., 37, 29-52, 2000.

Pöschl, U., Letzel, T., Schauer, C., and Niessner, R.: Interaction of ozone and water vapor with spark discharge soot aerosol particles coated with benzo[a]pyrene: $\mathrm{O}_{3}$ and $\mathrm{H}_{2} \mathrm{O}$ adsorp- tion, benzo[a]pyrene degradation and atmospheric implications, J. Phys. Chem. A, 105, 4029-4041, 2001.

Pöschl, U.: Formation and decomposition of hazardous chemical components contained in atmospheric aerosol particles, J. Aerosol Med., 15, 203-212, 2002a.

Pöschl, U.: Interactive comment on "Modeling the chemical effects of ship exhaust in the cloud-free marine boundary layer" by R. von Glasow et al., Atmos. Chem. Phys. Discuss., 2, S296-S299, 2002b.

Pöschl, U.: Aerosol particle analysis: challenges and progress, Anal. Bioanal. Chem., 375, 30-32, 2003.

Pöschl, U.: Atmospheric aerosols: Composition, transformation, climate and health effects, Angewandte Chemie - International Edition, 44, 7520-7540, 2005.

Pöschl, U., Rudich, Y., and Ammann M.: Kinetic model framework for aerosol and cloud surface chemistry and gas-particle interactions: Part 1 - general equations, parameters, and terminology, Atmos. Chem. Phys. Discuss., 5, 2111-2191, 2005 a.

Pöschl, U., Rudich, Y., and Ammann, M.: Interactive comment on "Kinetic model framework for aerosol and cloud surface chemistry and gas-particle interactions: Part 1 general equations, parameters, and terminology" by U. Pöschl et al., Atmos. Chem. Phys. Discuss., 5, S1916-S1925, 2005b.

Pöschl, U., Rudich, Y., and Ammann, M.: Interactive comment on "Kinetic model framework for aerosol and cloud surface chemistry and gas-particle interactions: Part 1 - general equations, parameters, and terminology" by U. Pöschl et al., Atmos. Chem. Phys. Discuss., 5, S5547-S5555, 2005c.

Pope III, C. A., Burnett, R. T., Thun, M. J., Calle, E. E., Krewski, D., Ito, K., and Thurston, G. D.: Lung cancer, cardiopulmonary mortality, and long-term exposure to fine particulate air pollution, J. Amer. Medical. Assoc., 287, 1132-1141, 2002.

Putaud, J. P., Raes, F., Van Dingenen, R., Bruggemann, E., Facchini, M. C., Decesari, S., Fuzzi, S., Gehrig, R., Huglin, C., Laj, P., Lorbeer, G., Maenhaut, W., Mihalopoulos, N., Müller, K., Querol, X., Rodriguez, S., Schneider, J., Spindler, G., ten Brink, H., Torseth, K., and Wiedensohler, A.: European aerosol phenomenology-2: chemical characteristics of particulate matter at kerbside, urban, rural and background sites in Europe, Atmos. Environ., 38, 2579-2595, 2004a.

Pruppacher, H. R. and Klett, J. D.: Microphysics of clouds and precipitation, 2nd ed., Kluwer Academic Publishers, Dordrecht, 1997.

Putaud, J. P., Van Dingenen, R., Dell'Acqua, A., Raes, F., Matta, E., Decesari, S., Facchini, M. C., and Fuzzi, S.: Size-segregated aerosol mass closure and chemical composition in Monte $\mathrm{Ci}$ mone (I) during MINATROC, Atmos. Chem. Phys., 4, 889-902, 2004b.

Pszenny, A. A. P., Moldanov, J., Keene, W. C., Sander, R., Maben, J. R., Martinez, M., Crutzen, P. J., Perner, D., and Prinn, R. G.: Halogen cycling and aerosol $\mathrm{pH}$ in the Hawaiian marine boundary layer, Atmos. Chem. Phys., 4, 147-168, 2004, http://www.atmos-chem-phys.net/4/147/2004/.

Qu, X. and Davis, E. J.: Droplet evaporation and condensation in the near-continuum regime, J. Aerosol Sci., 32, 861-875, 2001.

Qu, X., Davis, E. J., and Swanson, B. D.: Non-isothermal droplet evaporation and condensation in the near-continuum regime, $\mathrm{J}$. Aerosol Sci., 32, 1315-1339, 2001.

Ramanathan, V., Crutzen, P. J., Kiehl, J. T., and Rosenfeld, D.: 
Aerosols, climate and the hydrological cycle, Science, 294, 2119-2124, 2001.

Ramaswamy, V., Boucher, O., Haigh, J., et al.: Climate Change 2001: The scientific basis (Working group I to the third assessment report of the IPCC), Cambrige Univ. Press, Cambrige, 349416, 2001.

Ravishankara, A. R.: Heterogeneous and multiphase chemistry in the troposphere, Science, 276, 1058-1065, 1997.

Reid, J. P. and Sayer, R. M.: Heterogeneous atmospheric aerosol chemistry: laboratory studies of chemistry on water droplets, Chem. Soc. Rev., 32, 70-79, 2003.

Remorov, R. G., Gershenzon, Y. M., Molina, L. T., and Molina, M. J.: Kinetics and mechanism of $\mathrm{HO} 2$ uptake on solid $\mathrm{NaCl}$, J. Phys. Chem. A, 106, 4558-4565, 2002.

Remorov, R. G. and Bardwell, M. W.: Langmuir approach in the study of interface mass transfer, Surf. Sci., 585, 59-65, 2005.

Remorov, R. G. and George, C.: Analysis of chemical kinetics at the gas-aqueous interface for submicron aerosols, Phys. Chem. Chem. Phys., 8, 4897-4901, 2006.

Rettner, C. T., Auerbach, D. J., Tully, J. C., and Kleyn, A. W.: Chemical dynamics at the gas-surface interface, J. Phys. Chem., 100, 13 021-13 033, 1996.

Rudich, Y.: Laboratory perspectives on the chemical transformations of organic matter in atmospheric particles, Chem. Rev., 103, 5097-5124, 2003.

Rudich, Y., Donahue, N. M., and Mentel, T. F.: Aging of organic aerosol: Bridging the gap between laboratory and field studies, Ann. Rev. Phys. Chem., 58, 321-352, 2007.

Sander, R.: Modelling atmospheric chemistry: interactions between gas-phase species and liquid cloiud/aerosol particles, Survey Geophys., 20, 1-31, 1999.

Sander, S. P., Finlayson-Pitts, B. J., Friedl, R. R., Golden, D. M., Huie, R. E., Kolb, C. E., Kurylo, M. J., Molina, M. J., Moortgat, G. K., Orkin, V. L., and Ravishankara, A. R.: Chemical kinetics and photochemical data for use in atmospheric studies, Evaluation number 14, JPL Publication 02-25, Jet Propulsion Laboratory, Pasadena, 2002.

Sander, R., Keene, W. C., Pszenny, A. A. P., Arimoto, R., Ayers, G. P., Baboukas, E., Cainey, J. M., Crutzen, P. J., Duce, R. A., Honninger, G., Huebert, B. J., Maenhaut, W., Mihalopoulos, N., Turekian, V. C., and Van Dingenen, R.: Inorganic bromine in the marine boundary layer: a critical review, Atmos. Chem. Phys., 3, 1301-1336, 2003,

http://www.atmos-chem-phys.net/3/1301/2003/.

Sander, R., Kerkweg, A., Jöckel, P., and Lelieveld, J.: Technical Note: The new comprehensive atmospheric chemistry module MECCA, Atmos. Chem. Phys., 5, 445-450, 2005, http://www.atmos-chem-phys.net/5/445/2005/.

Sandu, A. and Sander, R.: Technical Note: Simulating chemical systems in Fortran90 and Matlab with the Kinetic PreProcessor KPP-2.1, Atmos. Chem. Phys., 6, 187-195, 2006,

http://www.atmos-chem-phys.net/6/187/2006/.

Saunders, S. M., Jenkin, M. E., Derwent, R. G., and Pilling, M. J.: Protocol for the development of the Master Chemical Mechanism, MCM v3 (Part A): tropospheric degradation of nonaromatic volatile organic compounds, Atmos. Chem. Phys., 3, 161-180, 2003, http://www.atmos-chem-phys.net/3/161/2003/.

Schauer, C., Niessner, R., and Pöschl, U.: Polycyclic aromatic hy- drocarbons in urban air particulate matter: decadal and seasonal trends, chemical degradation, and sampling artifacts, Environ. Sci. Technol., 37, 2861-2868, 2003.

Schauer, C., Niessner, R., and Pöschl, U.: Analysis of nitrated polycyclic aromatic hydrocarbons by liquid chromatography with fluorescence and mass spectrometry detection: air particulate matter, soot, and reaction product studies, Anal. Bioanal. Chem., 378, 725-736, 2004.

Schneider, J., Borrmann, S., Wollny, A. G., Blasner, M., Mihalopoulos, N., Oikonomou, K., Sciare, J., Teller, A., Levin, Z., and Worsnop, D. R.: Online mass spectrometric aerosol measurements during the MINOS campaign (Crete, August 2001), Atmos. Chem. Phys., 4, 65-80, 2004, http://www.atmos-chem-phys.net/4/65/2004/.

Schwartz, S. E. and Freiberg, J. E.: Mass-transport limitation to the rate of reaction of gases in liquid droplets: application to oxidation of SO2 in aqueous solutions., Atmos. Environ., 15, 1129 $1144,1981$.

Schwartz, S. E.: Mass-transport considerations pertinent to aqueous phase reactions of gases in liquid-water clouds, in: NATO ASI Series, Vol. G6, Chemistry of multiphase atmospheric systems, edited by: Jaeschke, W., Springer, New York, 1986.

Sciare, J., Bardouki, H., Moulin, C., and Mihalopoulos, N.: Aerosol sources and their contribution to the chemical composition of aerosols in the Eastern Mediterranean Sea during summertime, Atmos. Chem. Phys., 3, 291-302, 2003, http://www.atmos-chem-phys.net/3/291/2003/.

Seinfeld, J. H. and Pandis, S. N.: Atmospheric chemistry and physics - from air pollution to climate change, John Wiley \& Sons, New York, 1998.

Seisel, S., Börensen, C., Vogt, R., and Zellner, R.: Kinetics and mechanism of the uptake of $\mathrm{N} 2 \mathrm{O} 5$ on mineral dust at $298 \mathrm{~K}$, Atmos. Chem. Phys., 5, 3423-3432, 2005,

http://www.atmos-chem-phys.net/5/3423/2005/.

Shi, Q., Davidovits, P., Jayne, J. T., Worsnop, D. R., and Kolb, C. E.: Uptake of gas-phase ammonia, 1. Uptake by aqueous surfaces as a function of $\mathrm{pH}$, J. Phys. Chem. A, 103, 8812-8823, 1999.

Shunthirasingham, C., Lei, Y. D., and Wania, F.: Evidence of bias in air-water henry's law constants for semivolatile organic compounds measured by inert gas stripping, Environ. Sci. Technol., 41, 3807-3814, 2007.

Smith, G. D., Woods, E., DeForest, C. L., Baer, T., and Miller, R. E.: Reactive uptake of ozone by oleic acid aerosol particles: Application of single-particle mass spectrometry to heterogeneous reaction kinetics, J. Phys. Chem., A, 106, 8085-8095, 2002.

Smith, G. D., Woods, E., Baer, T., and Miller, R. E.: Aerosol uptake described by numerical solution of the diffusion - Reaction equations in the particle, J. Phys. Chem. A, 107 (45), 9582-9587, 2003.

Smolik, J., Zdimal, V., Schwarz, J., Lazaridis, M., Havranek, V., Eleftheriadis, K., Mihalopoulos, N., Bryant, C., and Colbeck, I.: Size resolved mass concentration and elemental composition of atmospheric aerosols over the Eastern Mediterranean area, Atmos. Chem. Phys., 3, 2207-2216, 2003, http://www.atmos-chem-phys.net/3/2207/2003/.

Spracklen, D. V., Pringle, K. J., Carslaw, K. S., Chipperfield, M. P., and Mann, G. W.: A global off-line model of size-resolved aerosol microphysics: I. Model development and prediction of 
aerosol properties, Atmos. Chem. Phys., 5, 2227-2252, 2005, http://www.atmos-chem-phys.net/5/2227/2005/.

Stemmler, K., Ndour, M., Elshorbany, Y., Kleffmann, J., D’Anna, B., George, C., Bohn, B., and Ammann, M.: Light induced conversion of nitrogen dioxide into nitrous acid on submicron humic acid aerosol, Atmos. Chem. Phys., 7, 4237-4248, 2007,

http://www.atmos-chem-phys.net/7/4237/2007/.

Stewart, D. J., Griffiths, P. T., and Cox, R. A.: Reactive uptake coefficients for heterogeneous reaction of N2O5 with submicron aerosols of $\mathrm{NaCl}$ and natural sea salt, Atmos. Chem. Phys., 4, 1381-1388, 2004,

http://www.atmos-chem-phys.net/4/1381/2004/.

Strekowski, R. S., Remorov, R., and George, C.: Direct kinetic study of the reaction of $\mathrm{Cl}-2$ (center dot-) radical anions with ethanol at the air-water interface, J. Phys. Chem. A, 107, 24972504, 2003.

Su, D. S., Jentoft, R., Müller, J.-O., Rothe, D., Jacob, E., Simpson, C. D., Müllen, K., Messerer, A., Pöschl, U., Niessner, R., and Schlögl, R.: Microstructure and oxidation behaviour of Euro IV diesel engine soot: a comparative study with synthetic model soot substances, Catal. Today, 90, 127-132, 2004.

Sullivan, R. C., Thornberry, T., and Abbatt, J. P. D.: Ozone decomposition kinetics on alumina: effects of ozone partial pressure, relative humidity and repeated oxidation cycles, Atmos. Chem. Phys., 4, 1301-1310, 2004,

http://www.atmos-chem-phys.net/4/1301/2004/.

Swartz, E., Shi, Q., Davidovits, P., Jayne, J. T., Worsnop, D. R., and Kolb, C. E.: Uptake of gas-phase ammonia. 2. Uptake by sulfuric acid surfaces, J. Phys. Chem. A, 103, 8824-8833, 1999.

Tabazadeh, A. and Turco, R.: A model for heterogeneous chemical processes on the surfaces of ice and nitric acid trihydrate particles, J. Geophys. Res., 98, 12 727-12 740, 1993.

Tabor, K., Gutzwiller, L., and Rossi, M. J.: Heterogeneous chemical kinetics of NO2 on amorphous carbon at ambient temperature, J. Phys. Chem., 98, 6172-6186, 1994.

Textor, C., Schulz, M., Guibert, S., Kinne, S., Balkanski, Y., Bauer, S., Berntsen, T., Berglen, T., Boucher, O., Chin, M., Dentener, F., Diehl, T., Easter, R., Feichter, H., Fillmore, D., Ghan, S., Ginoux, P., Gong, S., Grini, A., Hendricks, J., Horowitz, L., Huang, P., Isaksen, I., Iversen, I., Kloster, S., Koch, D., Kirkevåg, A., Kristjansson, J. E., Krol, M., Lauer, A., Lamarque, J. F., Liu, X., Montanaro, V., Myhre, G., Penner, J., Pitari, G., Reddy, S., Seland, Ø., Stier, P., Takemura, T., and Tie, X.: Analysis and quantification of the diversities of aerosol life cycles within AeroCom, Atmos. Chem. Phys., 6, 1777-1813, 2006, http://www.atmos-chem-phys.net/6/1777/2006/.

Thornberry, T. and Abbatt, J. P. D.: Heterogeneous reaction of ozone with liquid unsaturated fatty acids: detailed kinetics and gas-phase product studies, Phys. Chem. Chem. Phys., 6, 84-93, 2004.

Tost, H., Jöckel, P., Kerkweg, A., Pozzer, A., Sander, R., and Lelieveld, J.: Global cloud and precipitation chemistry and wet deposition: tropospheric model simulations with ECHAM5/MESSy1, Atmos. Chem. Phys., 7, 2733-2757, 2007, http://www.atmos-chem-phys.net/7/2733/2007/.

Turco, R. P., Toon, O. B., and Hamill, P.: Heterogeneous Physicochemistry of the Polar Ozone Hole, J. Geophys. Res., 94, 16493 16510, 1989.

Van Dingenen, R., Raes, F., Putaud, J. P., Baltensperger, U., Charron, A., Facchini, M. C., Decesari, S., Fuzzi, S., Gehrig, R., Hansson, H. C., Harrison, R. M., Huglin, C., Jones, A. M., Laj,
P., Lorbeer, G., Maenhaut, W., Palmgren, F., Querol, X., Rodriguez, S., Schneider, J., ten Brink, H., Tunved, P., Torseth, K., Wehner, B., Weingartner, E., Wiedensohler, A., and Wahlin, P.: A European aerosol phenomenology - 1: physical characteristics of particulate matter at kerbside, urban, rural and background sites in Europe, Atmos. Environ., 38, 2561-2577, 2004.

Vesala, T., Kulmala, M., Rudolf, R., Vrtala, A., and Wagner, P. E.: Models for condensational growth of binary aerosol particles, J. Aerosol Sci., 28, 565-598, 1997.

Vesala, T., Hannemann, A. U., Luo, B. P., Kulmala, M., and Peter, T.: Rigorous treatment of time-dependent trace gas uptake by droplets including bulk diffusion and surface accommodation, J. Aerosol Sci., 32, 843-860, 2001.

Vinokurov, I. A. and Kankare, J.: Kinetics of multilayer Langmuirian adsorption, Langmuir 18, 6789-6795, 2002.

Vlasenko, A., Sjogren, S., Weingartner, E., Stemmler, K., Gggeler, H. W., and Ammann, M.: Effect of humidity on nitric acid uptake to mineral dust aerosol particles, Atmos. Chem. Phys., 6, 2147-2160, 2006, http://www.atmos-chem-phys.net/6/2147/2006/.

von Glasow, R., Crutzen, P. J., Sander, R., and Lawrence, M. G.: Modeling the chemical effects of ship exhaust in the cloud-free marine boundary layer, Atmos. Chem. Phys., 3, 233-250, 2003, http://www.atmos-chem-phys.net/3/233/2003/.

von Glasow, R.: Importance of the surface reaction $\mathrm{OH}+\mathrm{Cl}^{-}$on sea salt aerosol for the chemistry of the marine boundary layer a model study, Atmos. Chem. Phys., 6, 3571-3581, 2006, http://www.atmos-chem-phys.net/6/3571/2006/.

von Kuhlmann, R., Lawrence, M. G., Pöschl, U., and Crutzen, P. J.: Sensitivities in global scale modeling of isoprene, Atmos. Chem. Phys., 4, 1-17, 2004, http://www.atmos-chem-phys.net/4/1/2004/.

Waibel, A. E., Peter, Th., Carslaw, K. S., Oelhaf, H., Wetzel, G., Crutzen, P. J., Pöschl, U., Tsias, A., Reimer, E., and Fischer, H.: Arctic ozone loss due to denitrification, Science, 283, 2064 2069, 1999.

Widmann, J. F. and Davis, E. J.: Mathematical models of the uptake of $\mathrm{ClONO} 2$ and other gases by atmospheric aerosols, J. Aerosol Sci., 28, 87-106, 1997.

Winkler, P. M., Vrtala, A., Wagner, P. E., Kulmala, M., Lehtinen, K. E., and Vesala, T.: Mass and thermal accommodation during gas-liquid condensation of water, Phys. Rev. Lett., 93, 0750101-07501-04, 2004.

Winkler, P. M., Vrtala, A., Rudolf, R., Wagner, P. E., Riipinen, I., Vesala, T., Lehtinen, K. E. J., Viisanen, Y., and Kulmala, M.: Condensation of water vapor: Experimental determination of mass and thermal accommodation coefficients, J. Geophys. Res., 111, D19202, doi:10.1029/2006JD007194, 2006.

Worsnop, D. R., Shi, Q., Jayne, J. T., Kolb, C. E., Swartz, E., and Davidovits, P.: Gas-phase diffusion in droplet train measurements of uptake coefficients, J. Aerosol Sci., 32, 877-891, 2001.

Worsnop, D. R., Morris, J. W., Shi, Q., Davidovits, P., and Kolb, C. E.: A chemical kinetic model for reactive transformations of aerosol particles, Geophys. Res. Lett., 29(20), 1996, doi:10.1029/2002GL015542, 2002.

Zahardis, J. and Petrucci, G. A.: The oleic acid-ozone heterogeneous reaction system: products, kinetics, secondary chemistry, and atmospheric implications of a model system - a review, Atmos. Chem. Phys., 7, 1237-1274, 2007, http://www.atmos-chem-phys.net/7/1237/2007/. 